\author{
UNIVERSIDADE DE SÃO PAULO \\ ESCOLA DE ENGENHARIA DE SÃO CARLOS
}

Marlon Rodrigues Garcia

Desenvolvimento de um sistema para aplicação e monitoramento online da terapia fotodinâmica de câncer de pele do tipo não melanoma via imagens de fluorescência da protoporfirina-IX no infravermelho próximo

São Carlos 

Marlon Rodrigues Garcia

\section{Desenvolvimento de um sistema para aplicação e monitoramento online da terapia fotodinâmica de câncer de pele do tipo não melanoma via imagens de fluorescência da protoporfirina-IX no infravermelho próximo}

Tese apresentada à Escola de Engenharia de São Carlos da Universidade de São Paulo, para obtenção do título de Doutor em Ciências - Programa de Pós-Graduação em Engenharia Mecânica. Este exemplar trata-se da versão corrigida. A versão original encontra-se disponível junto ao Departamento de Engenharia Mecânica da EESC-USP.

Área de concentração: Dinâmica das Máquinas e Sistemas

Orientador: Prof. Dr. Marcelo Becker

\section{São Carlos}


AUTORIZO A REPRODUÇÃO TOTAL OU PARCIAL DESTE TRABALHO POR QUALQUER MEIO CONVENCIONAL OU ELETRONICO, PARA FINS DE ESTUDO E PESQUISA, DESDE QUE CITADA A FONTE.

Ficha catalográfica elaborada pela Biblioteca Prof. Dr. Sérgio Rodrigues Fontes da EESC/USP com os dados inseridos pelo(a) autor(a).

G216

d

Garcia, Marlon Rodrigues

Desenvolvimento de um sistema para aplicação e monitoramento online da terapia fotodinâmica de câncer de pele do tipo não melanoma via imagens de fluorescência da protoporfirina-IX no infravermelho próximo / Marlon Rodrigues Garcia; orientador Marcelo Becker. São Carlos, 2019.

Tese (Doutorado) - Programa de Pós-Graduação em Engenharia Mecânica e Área de Concentração em Dinâmica e Mecatrônica -- Escola de Engenharia de São Carlos da Universidade de São Paulo, 2019.

1. Terapia Fotodinâmica. 2. Monitoramento. 3. Dosimetria. 4. Infravermelho próximo. 5. Teranóstico. 6. Online. I. Título.

Eduardo Graziosi Silva - CRB - 8/8907 


\section{FOLHA DE JULGAMENTO}

Candidato: Engenheiro MARLON RODRIGUES GARCIA.

Título da tese: "Desenvolvimento de um sistema para aplicação e monitoramento online da terapia fotodinâmica de câncer de pele do tipo não melanoma via imagens de fluorescência da protoporfirina-IX no infravermelho próximo".

Data da defesa: 17/10/2019.

Comissão Julgadora:

Resultado:

Prof. Associado Daniel Varela Magalhães

Aproundoo

(Orientador)

(Escola de Engenharia de São Carlos/EESC)

Prof. Associado Adriano Almeida Gonçalves Siqueira

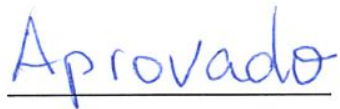

(Escola de Engenharia de São Carlos/EESC)

Profa. Associada Liliane Ventura Schiabel

APROVADO

(Escola de Engenharia de São Carlos/EESC)

Prof. Dr. Emery Cleiton Cabral Correia Lins

Apnouado

(Universidade Federal de Pernambuco/UFPE)

Prof. Associado Luciano Bachmann

(Faculdade de Filosofia, Ciências e Letras de Ribeirão Preto/FFCLRP-USP)

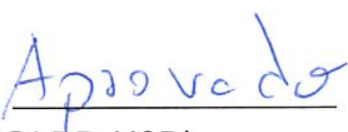

Coordenador do Programa de Pós-Graduação em Engenharia Mecânica:

Prof. Associado Carlos De Marqui Junior

Presidente da Comissão de Pós-Graduação:

Prof. Titular Murilo Araujo Romero 



\section{AGRADECIMENTOS}

Agradeço maiormente à Deus, por me guiar e abençoar em tudo, e por me conceder a vida. Agradeço à Deus por ser o meu alento nos dias de tristeza, e minha alegria nos dias de glória. Agradeço também aos meus pais, Jair Rodrigues Garcia e Marcela Cristiani Rodrigues Garcia, e à minha esposa, Daniele Jeisa Penha Garcia, os quais têm se esforçado ao máximo, e feito tudo o que estava ao alcance, para me ajudar em todos os aspectos.

Agradeço também ao meu orientador, Prof. Dr. Marcelo Becker, aos professores: Prof. Dr. Daniel Varela Magalhães, Prof. Dr. Sebastião Pratavieira, Prof. Dr. Cristina Kurachi, Prof. Dr. Vanderlei Salvador Bagnato, e às técnicas Dra. Lilian Tan Moriyama, e Dra. Natalia Mayumi Inada, por me orientarem e me ajudarem em todo o trabalho, por me apoiarem em todas as boas iniciativas, além de todas os conselhos e ajudas prestadas na vida pessoal e acadêmica.

Gostaria de agradeçer, também, à todos os meus colegas de trabalho e amigos, em especial aos meus amigos: Dr. Ramon Gabriel Rosa, MSc. João Marcelo Nogueira, MSc. Renan Arnon Romano, MSc. Camila de Paula D'Almeida, Dr. Michelle Barreto Requena, MSc. Thereza Cury Fortunato, Dr. Mirian Denise Stringasci, Srt. Erika Toneth Ponce Ayala, MSc. Victor Sanchez, Sr. Johan Sebastián Díaz Tovar, Dr. Hilde Harb Buzzá, Sr. Guilherme Thiago Chaves, Sr. Richard Mascarin, Sr. Luiz Paulo Damaceno. Todos eles me ajudaram imensamente.

O presente trabalho foi realizado com apoio da Coordenação de Aperfeiçoamento de Pessoal de Nível Superior - Brasil (CAPES) - Código de Financiamento 001. 



\section{RESUMO}

GARCIA, M. R. Desenvolvimento de um sistema para aplicação e monitoramento online da terapia fotodinâmica de câncer de pele do tipo não melanoma via imagens de fluorescência da protoporfirina-IX no infravermelho próximo. 2019. 100p. Tese (Doutorado) - Escola de Engenharia de São Carlos, Universidade de São Paulo, São Carlos, 2019.

O presente trabalho é dedicado ao desenvolvimento, caracterização e experimentação de um sistema capaz de realizar e monitorar a terapia fotodinâmica (TFD) de câncer de pele do tipo não melanoma, via imagens de fluorescência da protoporfirina-IX (PpIX). O monitoramento é realizado com a aquisição da fluorescência em torno de $700 \mathrm{~nm}$, excitada pela própria iluminação de tratamento $(633 \mathrm{~nm})$, o que aumenta a penetração da luz no tecido, e simplifica a tecnologia. Utilizou-se um filtro óptico passa baixa para filtrar a excitação, e um passa banda para coletar a fluorescência. Quatro circuitos principais controlaram o sistema: de alimentação geral, de alimentação do laser, controle de temperatura, e circuito de fotodeteç̧ão. Juntamente com os circuitos, um computador portátil contendo um algoritmo escrito em LabVIEW (National Instruments, EUA) foi utilizado para se controlar o sistema: câmera digital, placa de aquisição, e espectrômetro (quando em uso). O sistema foi montado em uma caixa com $30 \mathrm{~cm} \times 34 \mathrm{~cm} \times 8 \mathrm{~cm}$, contendo, também, uma ponta de prova que pode ser levada até ao paciente. Montado o sistema, o mesmo foi caracterizado para a medição da fluorescência da PpIX em um phantom feito para se mimetizar as propriedades ópticas da pele. Neste experimento foi possível se obter uma alta linearidade, e uma considerável sensibilidade, sendo seu limite de detecção de aproximadamente $500 \mathrm{nM}$. Também realizou-se um estudo em modelo animal, com seis camundongos, nos quais foram induzidos tumores de células da linhagem carcinoma espinocelular. Para esse estudo, tratou-se os tumores com o presente equipamento, à uma irradiância de $50 \mathrm{~mW} / \mathrm{cm}^{2}$, durante 40 minutos. Durante o tratamento, imagens de fluorescência foram adquiridas utilizando-se o protótipo desenvolvido, e utilizando-se um equipamento comercial (Lince, MMOptics, Brasil) com excitação violeta (407 nm), para comparação. Obtendo-se as curvas de fotobranqueamento, foi possível se observar maiores valores de tempo de decaimento médio para a fluorescência excitada no vermelho (medida pelo protótipo), do que para a excitada pelo violeta (equipamento comercial). Esse resultado indica que a excitação vermelha pode penetrar regiões mais profundas, adquirindo informação de camadas mais internas do tumor. Para as imagens excitadas pelo violeta, foi possível se notar um rápido decaimento do sinal de fluorescência, de modo que, já na metade do tratamento, a fluorescência da lesão era menor do que no tecido saudável em redor. Para as imagens excitadas pelo vermelho, entretanto, até o final do tratamento a intensidade de fluorescência foi maior no interior da lesão, podendo-se, inclusive, delimitar a borda da lesão até na última imagem de fluorescência adquirida. 
Portanto, faz-se interessante a utilização desse sistema para o tratamento e monitoramento da TFD de lesões de pele, com potencial de quantificar o dano fotodinâmico, prever o resultado terapêutico, melhorar o entendimento da terapia, e permitir a aplicação de um protocolo customizado, que altera seus parâmetros para melhor atender as necessidades de cada lesão. Isso aumentaria as taxas de cura da TFD, possibilitando sua maior adesão entre os clínicos, como ferramenta padrão de tratamento de câncer de pele do tipo não melanoma.

Palavras-chave: Monitoramento. Dosimetria. Terapia Fotodinâmica (TFD). Infravermelho próximo (NIR). Teranóstico. 


\section{ABSTRACT}

GARCIA, M. R. Development of a system to apply and online monitor photodynamic therapy of non-melanoma skin cancer using the near-infrared protoporphyrin-IX fluorescence. 2019. 100p. Tese (Doutorado) - Escola de Engenharia de São Carlos, Universidade de São Paulo, São Carlos, 2019.

This work is dedicated to the development, characterization, and experimentation of a system capable to perform and monitor the photodynamic therapy (PDT) of nonmelanoma skin cancer, via protoporphyrin-IX (PpIX) fluorescence images. The monitoring is performed with the acquisition of fluorescence around $700 \mathrm{~nm}$, excited by the red treatment light $(633 \mathrm{~nm})$ itself, which increases its penetration into the tissue and simplify the technology. We used a short-pass filter to filter the excitation, and a band-pass filter to collect fluorescence. Four main circuits controlled the system: general power, laser driver, temperature control, and photodetection circuit. Together with the circuits, a laptop with an algorithm written in LabVIEW (National Instruments, USA) was used to control the system, responsible to the control of the digital camera, the acquisition board, and the spectrometer (when in use). The system was assembled into a box with dimensions $30 \mathrm{~cm}$ $\times 34 \mathrm{~cm} \times 8 \mathrm{~cm}$, also containing a probe that can be taken to the patient. With the system assembled, it was characterized for the PpIX fluorescence measurement in a phantom made to mimic the skin optical properties. In this experiment, it was possible to obtain high linearity and a considerable sensitivity between the nominal concentration and the fluorescence detected, with a detection threshold of approximately $500 \mathrm{nM}$. An animal model study was carried out using six mice, in which squamous cell carcinoma cell tumors were induced. For this study, the tumors were treated with the here presented equipment, applying an irradiance of $50 \mathrm{~mW} / \mathrm{cm}^{2}$ for approximately 40 minutes. Throughout the treatment, fluorescence images were acquired using the developed prototype, and with a commercial equipment (Lince, MMOptics, Brazil) with violet excitation (407 nm), for comparison. Obtaining the photobleaching curves, it was possible to observe higher mean decay time values for the red-excited fluorescence (measured by the prototype), than for the violet-excited fluorescence (commercial equipment). This result indicates that the red excitation can penetrate into deeper tissue regions, acquiring information from the innermost layers of the tumor. For the violet-excited images, it was possible to note a fast decay of fluorescence signal, so that in the middle of the treatment, the fluorescence intensity in the lesion was smaller than in the surrounding healthy tissue. For the redexcited images, instead, the fluorescence intensity in the lesion was always higher than in the surrounding tissue, and even the lesion border could be delimited until the last acquired fluorescence image. Therefore, it is interesting to use this system for the PDT treatment and monitoring of skin lesions, with the potential to quantify photodynamic 
damage, predict the therapeutic outcome, improve the understanding of therapy, and allow the application of a customized protocol, which changes its parameters to better meet the needs of each lesion. This would increase the cure rates of PDT, enabling its greater adoption by clinicians as a standard non-melanoma skin cancer treatment.

Keywords: Monitoring. Dosimetry. Photodynamic Therapy (PDT). Near Infra-Red (NIR). Theranostic. 


\section{LISTA DE FIGURAS}

Figura 1 - Diagrama de blocos com os três principais elementos da terapia fotodinâmica: luz, fotossensibilizador e oxigênio molecular. Com estes elementos é possível se formar espécies reativas de oxigênio, e ocasionar morte celular. . . . . . . 33

Figura 2 - Molécula (a) de ácido $\delta$-aminolevulínico (ALA), e molécula (b) de ProtoporfirinaIX $(\mathrm{PpIX}) \ldots \ldots \ldots \ldots \ldots$. . . . . . . . . . . . . . . . . . . . . . .

Figura 3 - Diagrama de Jablonski para a excitação de um fotossensibilizador por um fóton. Neste esquema estão representadas as transições eletrônicas relativas à fluorescência $\left(k_{f}\right)$, ao cruzamento intersistema $\left(k_{I C S}\right)$, e ao quenching $\left(k_{q}\right)$, durante a TFD, até causar morte celular. . . . . . . . . . . . . . . 36

Figura 4 - Malha de realimentação fechada para uma terapia fotodinâmica com protocolo customizado. O algoritmo de decisão para o desligamento da iluminação de tratamento deve se basear no sinal de intensidade de fluorescência do fluoróforo, detectado pelo sistema de medição. . . . . . . . . . . . . . . . . 38

Figura 5 - Absorbância e e emissão de fluorescência normalizadas para uma solução de $5 \mu \mathrm{M}$ de PpIX dissolvida em DMSO (dimetilsulfóxido ou sulfóxido de dimetilo), juntamente com a transmitância simplificada para o filtro de fluorescência utilizado pelo equipamento desenvolvido.

Figura 6 - Diagrama de Jablonski para a absorção de um fóton por uma molécula, com as possíveis transições eletrônicas relacionadas. $S_{0}$ corresponde ao estado eletrônico singleto fundamental, $S_{1}$ e $T_{1}$ correspondem ao estado eletrônico singleto e tripleto excitados, respectivamente. . . . . . . . . . . . . . . . . 42

Figura 7 - Diagrama de Jablonski para a absorção de um fóton por uma molécula, com as possíveis transições eletrônicas relacionadas, considerando também o quenching e o fotobranqueamento. $S_{0}$ é o estado eletrônico singleto fundamental, $S_{1}$ e $T_{1}$ são os estados eletrônicos singleto e tripleto excitados, respectivamente. 43

Figura 8 - Curva de emissão do laser de diodo encapsulado utilizado (WSLD-635-001-2, WaveSpectrum, China). . . . . . . . . . . . . . .

Figura 9 - Transmitância normalizada para os filtros ópticos do tipo passa banda com comprimento de onda central em $700 \mathrm{~nm}$, (a) fabricado pela Proteon, com $20 \mathrm{~nm}$ de FWHM, e (b) fabricado pela Thorlabs, com $40 \mathrm{~nm}$ de FWHM, obtidas com o espectrofotômetro Cary 50 UV-VIS (Varian, EUA). . . . . . 46

Figura 10 - Aparato experimental montado para a caracterização espectral dos componentes ópticos utilizado. . . . . . . . . . . . . . . . . . . . .

Figura 11 - Curvas de transmissão do laser de $633 \mathrm{~nm}$ pelo filtro passa banda de $700 \mathrm{~nm}$ (a) da Proteon, e (b) da Thorlabs, obtidas com 40 ms de tempo de integração, média de 10 amostragens, e filtradas. . . . . . . . . . . . . . 
Figura 12 - Curva de transmitância para o filtro passa baixa com comprimento de onda de corte $\lambda_{c}=650 \mathrm{~nm}$ (FES0650 Thorlabs, EUA), obtida pelo espectrofotômetro Cary 50 UV-VIS (Varian, EUA). . . . . . . . . . . . . . . . . . 48

Figura 13 - Curvas de transmissão do laser de $633 \mathrm{~nm}$ pelo filtro passa baixa de $650 \mathrm{~nm}$ (a) em série com o filtro passa banda de $700 \mathrm{~nm}$ da Proteon, e (b) em série com o filtro passa banda de $700 \mathrm{~nm}$ da Thorlabs, obtidas com $40 \mathrm{~ms}$ de tempo de integração, média de 10 amostragens, e filtradas. . . . . . . . . . 49

Figura 14 - Comparação da transmitância dos dois filtros ópticos passa banda de $700 \mathrm{~nm}$ utilizados, da Proteon (linha azul), com 20 nm de FWHM, e da Thorlabs (linha alaranjada), com $40 \mathrm{~nm}$ de FWHM. . . . . . . . . . . . . . . . . . . 49

Figura 15 - Diagrama esquemático do protótipo desenvolvido, contendo suas três partes fundamentais: de excitação, e de emissão, e elétrica. . . . . . . . . . . . . . 50

Figura 16 - Fotografia (a) do sistema desenvolvido, com a ponta de prova, o laptop, e a caixa preta contendo a parte elétrica, o módulo laser e a placa de aquisição. À direita, também se mostra (b) a ponta de prova com seu porta-filtros removível, contendo o filtro de excitação e o filtro de fluorescência. . . . . . . 51

Figura 17 - Desenho esquemático da parte de excitação, compreendendo o módulo laser, a fibra óptica, e o filtro de excitação. . . . . . . . . . . . . . . . . . . 52

Figura 18 - Módulo laser, composto pela estrutura metálica que contém o laser, a célula Peltier, e um dissipador metálico acoplado à uma ventoinha. . . . . . . . . . 53

Figura 19 - Desenho esquemático da parte óptica de detecção, compreendendo o fotodetector acoplado à fibra óptica, a placa de aquisição USB-6008, o filtro óptico passa banda de $700 \mathrm{~nm}$, a objetiva e a câmera digital. . . . . . . . . . . . 53

Figura 20 - Desenho esquemático da placa de aquisição USB-6008, com seu diagrama de pinos. . . . . . . . . . . . . . . . . 5

Figura 21 - Interface gráfica desenvolvida em Labview (National Instruments, EUA), para a realização de medidas e teste de componentes. . . . . . . . . . . . . 59

Figura 22 - Fluxograma do algoritmo desenvolvido em Labview (National Instruments, EUA) para controle do sistema, contemplando a seus quatro módulos. . . .

Figura 23 - Desenho esquemático do setup óptico para a caracterização da linearidade e da sensibilidade do sistema de medição, para diferentes concentrações de PpIX. 62

Figura 24 - Imagem de fluorescência de uma das lâminas tumorais, superposta à sua imagem de transmissão, obtidas por microscopia confocal (LSM 780, Zeiss, Jena, Alemanha), excitada em $405 \mathrm{~nm}$, e coletada entre $630 \mathrm{~nm}$ e $670 \mathrm{~nm}$. As variáveis: $w_{1}, w_{2}, w_{3}, e_{1}, e_{2}$, e $e_{3}$ são exemplos de como foram extraídas as espessuras do tumor e da epiderme, respectivamente. . . . . . . . . . . . 65 
Figura 25 - Gráfico da intensidade de fluorescência normalizada, por concentração de PpIX, em escala logarítmica, considerando-se concentrações de PpIX de $50 \mathrm{nM}$ à $20 \mu \mathrm{M}$, juntamente com a curva de ajuste, calculada por regressão linear utilizando-se o método dos mínimos quadrados. . . . . . . . . . .

Figura 26 - Imagens de fluorescência do phantom, obtidas para comprimentos de onda em torno de $700 \mathrm{~nm}$, para (a) 0, (b) $350 \mathrm{~J} / \mathrm{cm}^{2}$, (c) $1400 \mathrm{~J} / \mathrm{cm}^{2}$, e (d) $4470 \mathrm{~J} / \mathrm{cm}^{2}$ de dose de luz entregue na superfície do mesmo, à uma irradiância

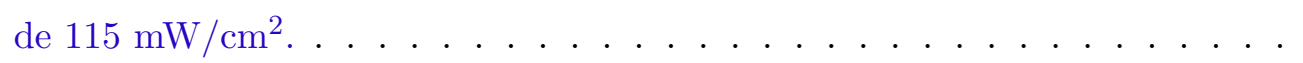

Figura 27 - Intensidade de fluorescência adquirida no experimento em phantom, por dose de luz entregue, obtida através de um ROI na região central das imagens de fluorescência. . . . . . . . . . . . . . . . . . . . . . .

Figura 28 - Imagens de fluorescência excitadas pelo protótipo desenvolvido, no vermelho, para (a) 0, (b) $77,6 \mathrm{~J} / \mathrm{cm}^{2}$, e (c) $152,8 \mathrm{~J} / \mathrm{cm}^{2}$ de dose de luz entregue; e excitadas pelo sistema comercial, no violeta, para (d) 0 , (e) $77,6 \mathrm{~J} / \mathrm{cm}^{2}$, e (f) $152,8 \mathrm{~J} / \mathrm{cm}^{2}$ de dose de luz entregue, para o primeiro camundongo do teste

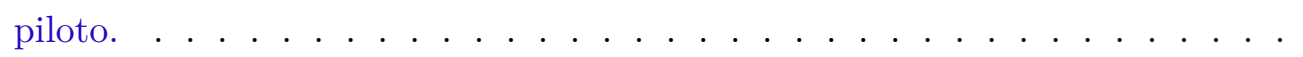

Figura 29 - Imagens de fluorescência excitadas pelo protótipo desenvolvido, no vermelho, para (a) 0, (b) $71,2 \mathrm{~J} / \mathrm{cm}^{2}$, e (c) $145,6 \mathrm{~J} / \mathrm{cm}^{2}$ de dose de luz entregue; e excitadas pelo sistema comercial, no violeta, para (d) 0 , (e) $71,2 \mathrm{~J} / \mathrm{cm}^{2}$, e (f) $145,6 \mathrm{~J} / \mathrm{cm}^{2}$ de dose de luz entregue, para o segundo camundongo do teste

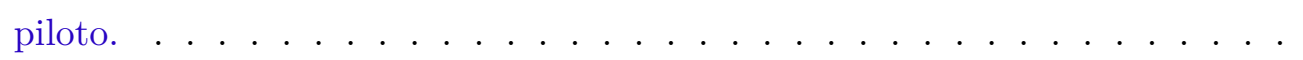

Figura 30 - Imagens de fluorescência adquiridas ao final do tratamento, (a) com o equipamento comercial (excitação violeta) e (b) com o protótipo desenvolvido (excitação vermelha), para o primeiro camundongo; e (c) com o equipamento comercial (excitação violeta) e (d) com o protótipo desenvolvido (excitação vermelha), para o segundo camundongo. . . . . . . . . . . . . .

Figura 31 - Curvas de fotodegradação adquiridas para o primeiro camundongo ((a) e (c)), e para o segundo camundongo ((b) e (d)), juntamente com as curvas de ajuste, para uma ROI em toda a lesão ((a), (b)), e para uma ROI na região central da lesão ((c) e (d)). Também se apresentam as curvas de ajuste, decrescidas de seu termo $I_{b g}$, para o primeiro (e) e para o segundo (f) camundongo, para uma ROI em toda a lesão. . . . . . . . . . . . . .

Figura 32 - Imagens de fluorescência excitadas pelo protótipo desenvolvido, no vermelho, para (a) 0, (b) $63,2 \mathrm{~J} / \mathrm{cm}^{2}$, e (c) $128 \mathrm{~J} / \mathrm{cm}^{2}$ de dose de luz entregue; e excitadas pelo sistema comercial, no violeta, para (d) 0 , (e) $63,2 \mathrm{~J} / \mathrm{cm}^{2}$, e (f) $128 \mathrm{~J} / \mathrm{cm}^{2}$ de dose de luz entregue, para o primeiro camundongo do experimento detalhado. . . . . . . . . . . . . . . . 
Figura 33 - Imagens de fluorescência excitadas pelo protótipo desenvolvido, no vermelho, para (a) 0, (b) $64,8 \mathrm{~J} / \mathrm{cm}^{2}$, e (c) $128,8 \mathrm{~J} / \mathrm{cm}^{2}$ de dose de luz entregue; e excitadas pelo sistema comercial, no violeta, para (d) 0 , (e) $64,8 \mathrm{~J} / \mathrm{cm}^{2}$, e (f) $128,8 \mathrm{~J} / \mathrm{cm}^{2}$ de dose de luz entregue, para o segundo camundongo do experimento detalhado. . . . . . . . . . . . . . . . 72

Figura 34 - Imagens de fluorescência excitadas pelo protótipo desenvolvido, no vermelho, para (a) 0, (b) $63,2 \mathrm{~J} / \mathrm{cm}^{2}$, e (c) $127,2 \mathrm{~J} / \mathrm{cm}^{2}$ de dose de luz entregue; e excitadas pelo sistema comercial, no violeta, para (d) 0 , (e) $63,2 \mathrm{~J} / \mathrm{cm}^{2}$, e (f) $127,2 \mathrm{~J} / \mathrm{cm}^{2}$ de dose de luz entregue, para o terceiro camundongo do experimento detalhado. . . . . . . . . . . . . . . . . . 73

Figura 35 - Imagens de fluorescência excitadas pelo protótipo desenvolvido, no vermelho, para (a) 0, (b) $63,2 \mathrm{~J} / \mathrm{cm}^{2}$, e (c) $128 \mathrm{~J} / \mathrm{cm}^{2}$ de dose de luz entregue; e excitadas pelo sistema comercial, no violeta, para (d) 0 , (e) $63,2 \mathrm{~J} / \mathrm{cm}^{2}$, e (f) $128 \mathrm{~J} / \mathrm{cm}^{2}$ de dose de luz entregue, para o quarto camundongo do experimento detalhado. . . . . . . . . . . . . . . . . . 74

Figura 36 - Imagens de luz branca, da fluorescência excitada no violeta, e da fluorescência excitada pelo vermelho, para os camundongos 1 ((a),(b), e (c), respectivamente), 2 ((d),(e), e (f), respectivamente), 3((g),(h), e (i), respectivamente), e $4((\mathrm{j}),(\mathrm{k})$, e (l), respectivamente), estudados na experimento em modelo animal. . . . . . . . . . . . . . . . . . 75

Figura 37 - Curvas de decaimento da intensidade de fluorescência normalizada, por fluência entregue, para uma ROI englobando toda a lesão, juntamente com as curvas de ajuste, calculadas pelo método dos mínimos quadrados para a Equação 5.1, adquiridas para os camundongos (a) 1, (b) 2, (c) 3, e (d) 4. . . 76

Figura 38 - Curvas de decaimento da intensidade de fluorescência normalizada, por fluência entregue, para uma ROI na região central da lesão, juntamente com as curvas de ajuste, calculadas pelo método dos mínimos quadrados para a Equação 5.1, adquiridas para os camundongos (a) 1, (b) 2, (c) 3, e (d) 4. . . 77

Figura 39 - Curvas de ajuste do decaimento da intensidade de fluorescência, calculadas pelo método dos mínimos quadrados, para os dados do experimento em modelo animal, decrescidas de seu termo $I_{b g}$, que representa a intensidade luminosa de fundo (termo constante da exponencial), para os camundongos (a) 1 , (b) 2 , (c) 3 , e (d) 4

Figura 40 - Sinais de tensão normalizados, obtidos da saída do circuito de fotodetecção, detectados pela placa de aquisição, durante o experimento em modelo animal, para os camundongos (a) 1, (b) 2, (c) 3, e (d). 4. . . . . . . . . . . . 79 


\section{LISTA DE TABELAS}

Tabela 1 - Especificações da câmera DCC1545-M (Thorlabs, EUA). . . . . . . . . 55

Tabela 2 - Tempo médio de decaimento para a fluorescência excitada no vermelho $\left(\tau_{r}\right)$, e no violeta $\left(\tau_{v}\right)$, obtidos das curvas de ajuste, para os dois animais do experimento piloto, considerando-se uma ROI englobando toda a lesão, juntamente com a razão entre os tempos de decaimento do vermelho e do violeta, $\tau_{r} / \tau_{v} \ldots \ldots \ldots \ldots$. . . . . . . . . 69

Tabela 3 - Tempo médio de decaimento para a fluorescência excitada no vermelho $\left(\tau_{r}\right)$, e no violeta $\left(\tau_{v}\right)$, obtidos das curvas de ajuste, para todos os animais, considerando-se uma ROI englobando toda a lesão, juntamente com a razão entre os tempos de decaimento, $\tau_{r} / \tau_{v}$. Também se apresentam os valores médios da espessura do tumor $(w)$ e da epiderme $(e)$ para todos os animais. . . . . . . . . . . . . . . . . 73

Tabela 4 - Tempo médio de decaimento para a fluorescência excitada no vermelho $\left(\tau_{r}\right)$, e no violeta $\left(\tau_{v}\right)$, obtidos das curvas de ajuste, para todos os animais, considerando-se uma ROI na região central da lesão, juntamente com a razão entre os tempos de decaimento, $\tau_{r} / \tau_{v}$. Também se apresentam os valores médios da espessura do tumor $(w)$ e da epiderme $(e)$ para todos os animais. 



\section{LISTA DE ABREVIATURAS E SIGLAS}

$\begin{array}{ll}\text { ALA } & \text { Ácido aminolevulínico; } \\ \text { CEC } & \text { Carcinoma espinocelular; } \\ \text { DMSO } & \text { Dimetilsulfóxid, ou sulfóxido de dimetilo; } \\ \text { ERO } & \text { Espécies reativas de oxigênio; } \\ \text { fps } & \text { Quadros por segundo; } \\ \text { FS } & \text { Fotossensibilizador; } \\ \text { FWHM } & \text { Full width at half maximum; } \\ \text { HpD } & \text { Hematoporphyrin derivative; } \\ \text { LED } & \text { Light emitting diode; } \\ \text { MAL } & \text { Metil-aminolevulinato; } \\ \text { NaCl } & \text { Cloreto de sódio; } \\ \text { PID } & \text { Proporcional, integrador e derivativo; } \\ \text { PpIX } & \text { Protoporfirina IX; } \\ \text { SMA } & \text { SubMiniature version A; } \\ \text { TFD } & \text { Terapia fotodinâmica; }\end{array}$





\section{LISTA DE SÍMBOLOS}

$\alpha$

$\lambda$

$\lambda_{c}$

$\nu$

$\tau$

$\tau_{f}$

$\tau_{r}$

$\tau_{s}$

$\tau_{v}$

c

E

$E_{f}$

$E_{e}$

$F_{0}$

$F_{0 f}$

$F_{0 s}$

$F(t)$

$h$

$H_{e}$

$I_{b g}$

$k_{b s}$

$k_{b t}$

$k_{f}$

$k_{I S C}$

Ângulo entre o tubo de teste e a horizontal;

Comprimento de onda [nm];

Comprimento de onda de corte [nm];

Frequência da radiação propagante;

Tempo médio de decaimento monoexponencial;

Tempo médio de decaimento rápido para biexponencial;

Tempo médio de decaimento total para o vermelho;

Tempo médio de decaimento lento para biexponencial;

Tempo médio de decaimento total para o violeta;

Velocidade de propagação da luz no vácuo $[\mathrm{m} / \mathrm{s}]$;

Energia de um fóton $[\mathrm{J}]$;

Eficiência de medição de um dado equipamento;

Irradiância $\left[\mathrm{W} / \mathrm{m}^{2}\right]$;

Intensidade de fluorescência inicial para o decaimento monoexponencial;

Intensidade de fluorescência inicial para o decaimento rápido;

Intensidade de fluorescência inicial para o decaimento lento;

Intensidade de fluorescência para um tempo $t$ em segundos;

Constante de Planck [J s];

Exposição radiante $\left.\left[\mathrm{J} / \mathrm{m}^{2}\right]\right]$;

Intensidade do sinal de fundo da fluorescência;

Constante de fotobranqueamento do estado singleto;

Constante de fotobranqueamento do estado tripleto;

Constante de fluorescência;

Constante de cruzamento interatômico; 


$\begin{array}{ll}k_{n r} & \text { Constante de decaimento não-radioativo; } \\ k_{p} & \text { Constante de fosforescência; } \\ k_{q s} & \text { Constante de quenching do estado singleto; } \\ k_{q t} & \text { Constante de quenching do estado tripleto; } \\ k_{r} & \text { Constante de relaxamento; } \\ { }^{3} O_{2} & \text { Oxigênio no estado eletrônico fundamental; } \\ { }^{1} O_{2} & \text { Oxigênio no seu estado eletrônico singleto; } \\ p & \text { Coeficiente de determinação; } \\ r^{2} & \text { Estado eletrônico fundamental singleto; } \\ S_{0} & \text { Estado eletrônico excitado singleto; } \\ S_{1} & \text { Tempo em segundos; } \\ t & \text { Transmitância; } \\ T_{1} & \text { Estado eletrônico excitado tripleto; } \\ T_{a j u s t e} & \text { Temperatura de ajuste. }\end{array}$




\section{SUMÁRIO}

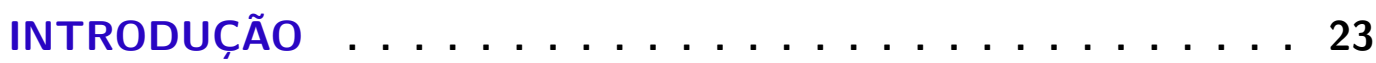

1.1 Revisão Bibliográfica . . . . . . . . . . . . . . . . . . 24

1.1.1 Dose de Luz Entregue . . . . . . . . . . . . . . . . . . 25

1.1.2 Oxigênio Molecular e Oxigênio Singleto . . . . . . . . . . . . . 26

1.1.3 Fluorescência e Fotobranqueamento do Fotossensibilizador . . . . . . . . 27

1.2 Objetivos ................ 30

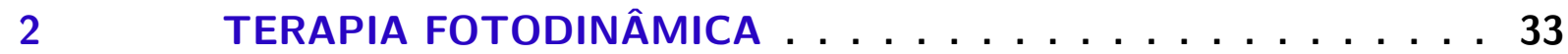

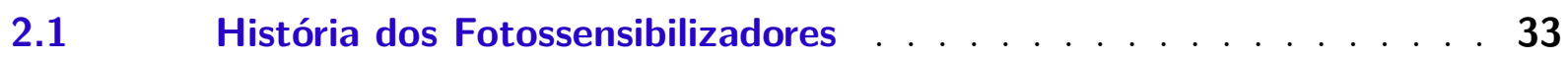

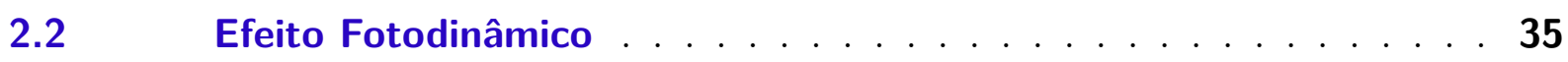

$2.3 \quad$ Monitoramento da TFD . . . . . . . . . . . . . . . . . 36

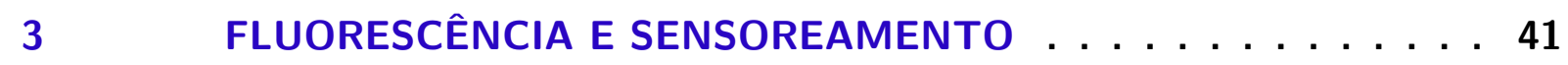

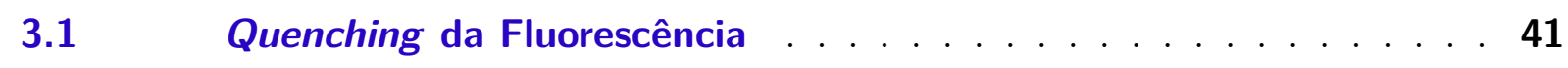

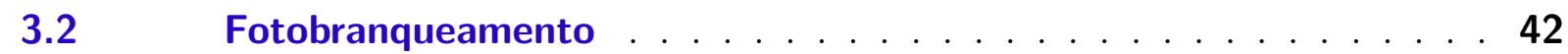

$3.3 \quad$ Fluorescência na Terapia Fotodinâmica . . . . . . . . . 43

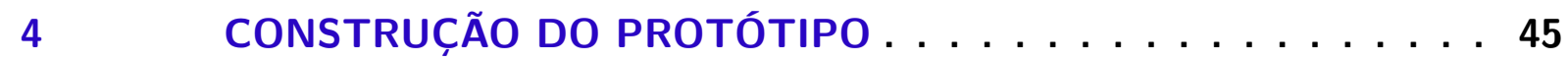

4.1 Caracterização dos Filtros Ópticos e do Laser . . . . . . . . . . . . 45

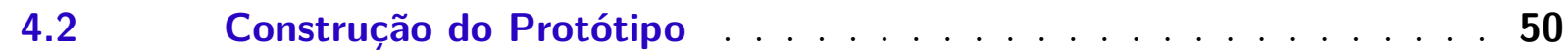

$4.2 .1 \quad$ Parte de Excitação . . . . . . . . . . . . . . . . . . . . . 51

4.2.1.1 Módulo Laser . . . . . . . . . . . . . . . . . . . . . . . . 52

4.2.2 Parte de Detecção . . . . . . . . . . . . . . . . . . . . . 52

$4.2 .3 \quad$ Parte Elétrica . . . . . . . . . . . . . . . . . . . . . . 54

4.2.3.1 Circuito de Alimentação Geral . . . . . . . . . . . . . . . . . . 55

4.2.3.2 Alimentação do Laser . . . . . . . . . . . . . . . . . . . . . . 56

4.2.3.3 Controle de Temperatura . . . . . . . . . . . . . . . . . . 56

4.2.3.4 Circuito de Fotodetecção . . . . . . . . . . . . . . . . . . . 57

$4.2 .4 \quad$ Controle via Software . . . . . . . . . . . . . . . . . . . 57

5 CARACTERIZAÇÃO E EXPERIMENTAÇÃO . . . . . . . . 61

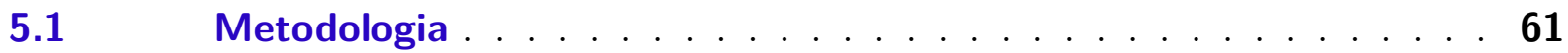

$5.1 .1 \quad$ Caracterização do Sistema . . . . . . . . . . . . . . . 61

5.1 .2 Experimento em Phantom . . . . . . . . . . . . . . 61

$5.1 .3 \quad$ Modelo Animal . . . . . . . . . . . . . . . . . . . 62

$5.2 \quad$ Resultados . . . . . . . . . . . . . . . . . . 64

5.2.1 Caracterização do Sistema . . . . . . . . . . . . . . . . . . . 64 
5.2.2 Experimento em Phantom . . . . . . . . . . . . . . 66

$5.2 .3 \quad$ Modelo Animal . . . . . . . . . . . . . . . . . . . 66

5.2.3.1 Teste Piloto . . . . . . . . . . . . . . . . 66 66

5.2.3.2 Experimento Detalhado . . . . . . . . . . . . . . . . . 69

6 DISCUSSÃO E CONSIDERAÇÕES FINAIS . . . . . . . . . 81

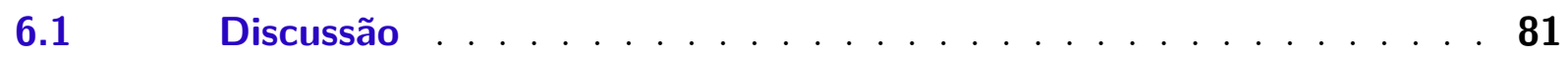

6.1.1 Caracterização da Óptica e Montagem do Sistema . . . . . . . . . . . . 81

6.1.2 Caracterização do Sistema . . . . . . . . . . . . . . . 82

6.1.3 Experimento em Phantom . . . . . . . . . . . . . . . . . . 82

$6.1 .4 \quad$ Modelo Animal . . . . . . . . . . . . . . . . . . . . 82

$6.2 \quad$ Considerações Finais . . . . . . . . . . . . . . . . . 83

$6.3 \quad$ Possíveis Diretrizes Futuras . . . . . . . . . . . . . . . . 85

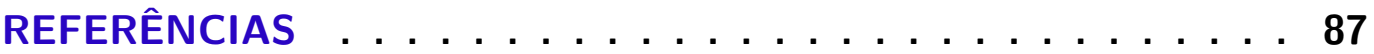

$\begin{array}{ll}\text { APÊNDICES } & 93\end{array}$

APÊNDICE A-CIRCUITOS ELÉTRICOS E DESENHO MECÂNICO .................... 95 


\section{INTRODUÇÃO}

A terapia fotodinâmica (TFD) caracteriza-se na junção de três elementos básicos (luz, fotossensibilizador e oxigênio molecular) para a produção de espécies reativas de oxigênio (ERO), as quais podem causar a morte de tecidos tumorais. Sendo empregada em diferentes tipos de câncer, essa terapia vem se destacando nos últimos anos, principalmente para tratamento de câncer de pele do tipo não melanoma (AGOSTINIS et al., 2011; DOLMANS; FUKUMURA; JAIN, 2003; DOUGHERTY et al., 1998). O protocolo mais amplamente utilizado para o tratamento de câncer de pele não melanoma é baseado na geração de protoporfirina-IX (PpIX) através da administração de ácido $\delta$-aminolevulínico (ALA), ou algum de seus derivados (ACKROYD et al., 2001; BUZZÁ et al., 2019; DOUGHERTY et al., 1998).

Essa modalidade terapêutica tem proporcionado altas taxas de cura, excelentes resultados cosméticos (BUZZÁ et al., 2019; ROOZEBOOM et al., 2013; SZEIMIES et al., 2008), além de um baixo custo de aplicação (AGUILAR et al., 2010), o que a torna extremamente vantajosa. Entretanto, apesar de seus resultados encorajadores, a TFD ainda encontra resistência para ser adotada entre os clínicos. Esse fenômeno pode estar intimamente ligado à atual imprevisibilidade das respostas ao tratamento (POGUE et al., 2016). Essa imprevisibilidade ocorre pois, normalmente, o mesmo protocolo, com parâmetros de tratamento fixos, é utilizado para uma ampla gama de lesões. Dada a alta variabilidade dos parâmetros ópticos e fisiológicos das lesões de pele (DÖGNITZ et al., 2008; KANICK et al., 2015; LERCHE et al., 2015; POGUE et al., 2016), a utilização de um mesmo protocolo para diferentes lesões acarreta uma variação na resposta ao tratamento de cada lesão. Se a terapia é empregada sem monitoramento, essa variação das respostas se torna imprevisível. Esse cenário, somado à administração ineficiente de pelo menos um parâmetro terapeutico, pode ocasionar respostas incompletas, ou até mesmo falhas ao tratamento, culminando, finalmente, no uso não otimizado da TFD, e em sua baixa adoção entre os médicos.

Atualmente, a terapia fotodinâmica está limitada na utilização de todo o seu potencial terapêutico, já que, na maioria dos atuais protocolos, tanto o fotossensibilizador (ou seu precursor), quanto a fluência são administrados com pouco ou nenhum tipo de monitoramento (POGUE et al., 2016). Neste caso, define-se a fluência pela irradiância (normalmente em $\mathrm{mW} / \mathrm{cm}^{2}$ ) vezes o tempo de exposição (normalmente em segundos), ficando em unidades de energia por área $\left(\mathrm{J} / \mathrm{cm}^{2}\right)$. Para uma utilização otimizada dos parâmetros terapêuticos, é de fundamental importância que técnicas dosimétricas sejam empregadas no monitoramento da TFD. Através do uso de técnicas de monitoramento, seria possível prever falhas e resultados incompletos ao tratamento. Tal prática poderia 
aumentar as taxas de cura da TFD, como será visto nos próximos parágrafos, otimizando a utilização da mesma, e abrindo as portas para uma adoção maior dessa modalidade terapêutica como procedimento padrão (POGUE et al., 2016).

As técnicas dosimétricas podem ajudar em duas etapas distintas: no entendimento fundamental da terapia fotodinâmica como um todo, para morte celular do tecido alvo, e em seu monitoramento em tempo real, durante a terapia, já em ambiente clínico. Em termos do entendimento fundamental da terapia, a dosimetria pode ser utilizada para identificar quais são os parâmetros que possivelmente impediriam o sucesso terapêutico, podendo, inclusive, indicar quais seriam os métodos dosimétricos mais adequados para serem aplicados na clínica. O monitoramento em tempo real, por outro lado, munido das constatações fornecidas pela etapa anterior, poderia identificar, em tempo real, a má administração de algum dos parâmetros terapêuticos, ou indicar quais características da lesão estariam impedindo sua remissão completa.

No melhor cenário, essa informação fornecida pelo monitoramento em tempo real poderia ser retroalimentada em um protocolo customizado. Esse protocolo, por sua vez, alteraria seus parâmetros terapêuticos, em tempo real, de modo criar um protocolo específico para atender às necessidades de cada lesão tratada. Essa vantajosa integração, não só permitiria a previsão das respostas das lesões ao tratamento, como também poderia indicar quais parâmetros fotodinâmicos podem ser alterados, ou necessitam de novas técnicas de entrega ao tecido, para prover um melhor resultado terapêutico.

As tecnologias dosimétricas variam desde as técnicas mais simples até técnicas complexas. Em alguns casos, a tecnologia escolhida demanda considerável conhecimento técnico para ser operada, toma grande espaço físico, e tem alto custo de implementação. Embora possa ser empregada na etapa de entendimento fundamental da terapia, esse tipo de tecnologia não é adequada para um monitoramento em tempo real. Para se obter uma alta aceitabilidade dentre seus usuários, e possibilitar uma fácil inserção no mercado médico, é necessário que a técnica de monitoramento em tempo real seja de fácil operação, portátil, de baixo custo, e possua uma interface amigável com o usuário. Adicionalmente, em termos dosimétricos, essa tecnologia deve ser capaz de medir o progresso do tratamento, estimar seu resultado, e possivelmente indicar quais parâmetros estariam impedindo seu sucesso terapêutico.

\subsection{Revisão Bibliográfica}

Como diversas técnicas podem ser empregadas para o monitoramento em tempo real da terapia fotodinâmica, faz-se interessante uma revisão bibliográfica das principais técnicas empregadas, que é o objetivo da presente secção. 


\subsubsection{Dose de Luz Entregue}

Principalmente em seus estudos iniciais, a dosimetria aplicada a terapia fotodinâmica normalmente estava relacionada com a medição da dose de luz (ou fluência) entregue à região de interesse. Em seu estudo, Grossweiner (1986), abordaram um modelo teórico para o cálculo da distribuição do fluxo radiante aplicado na superfície do tecido a ser tratado. Para os cálculos do modelo, Grossweiner utilizou a aproximação de difusão, considerando-se o fotobranqueamento a uma irradiação incidente de $630 \mathrm{~nm}$.

No mesmo ano, Powers e Brown (1986) abordaram a dosimetria da luz aplicada na terapia fotodinâmica em um modelo in vivo de tecido cerebral de ratos. Neste artigo, comparou-se a utilização de dois comprimentos de onda para excitação do fotossensibilizador: $488 \mathrm{~nm}$ e 633 nm. Foi encontrado uma atenuação consideravelmente maior para a luz irradiada em $488 \mathrm{~nm}$, justificada pela intensa vascularização do tecido local, sendo a hemoglobina absorvedora de luz neste comprimento de onda.

Ainda em 1986, Wilson, Muller e Yanch (1986) abordaram a instrumentação e a dosimetria de luz em um estudo clínico de fase I para a TFD de nove tumores cerebrais, após a remoção cirúrgica dos mesmos. Como aparato experimental, utilizou-se uma fibra óptica conectada a uma estrutura metálica contendo um balão esférico (a ser posicionado na cavidade tumoral) preenchido com solução de Nutralipid (solução altamente espalhadora de luz), buscando uma iluminação uniforme de toda a região do colo tumoral.

No ano seguinte Grossweiner, Hill e Lobraico (1987) compararam o modelo teórico desenvolvido em seu último artigo (GROSSWEINER, 1986), com um teste clínico para carcinoma de células escamosas (ou carcinoma espinocelular, CEC) de cabeça e pescoço. Buscou-se estimar os parâmetros ópticos do tecido alvo, visando obter a dose mínima de luz requerida para atingir as bordas do tumor que estiverem mais distantes da fonte luminosa. Neste caso considerou-se, como fonte luminosa, uma fibra óptica com um difusor cilíndrico. Neste estudo, obteve-se uma resposta completa em 83\% dos tumores tratados.

Posteriormente aos pioneiros, diversos artigos abordaram a dosimetria da dose de luz, seja com modelos matemáticos, ou em medidas físicas (BAYS et al., 1997; HEIER et al., 1995; POTTER; MANG; DOUGHERTY, 1987; RADU et al., 2003; VEEN et al., 2002). De maneira mais recente, pode-se citar o trabalho de Swartling et al. (2010), onde se desenvolveu um sistema de dosimetria em tempo real para TFD em câncer de próstata. Nesse trabalho, o software de dosimetria se baseia em imagens de ultrassom para criar modelos tridimensionais para o cálculo da posição da fibra e a dose de luz. A mesma fibra que entrega a luz do tratamento, também é utilizada para se medir as propriedades ópticas em tempo real. Os autores justificaram que as incompletas respostas ao tratamento provavelmente estão relacionadas com a baixa dose de luz empregada $\left(5 \mathrm{~J} / \mathrm{cm}^{2}\right)$.

Apesar de ser uma grandeza física importante para se estimar a eficácia da terapia 
fotodinâmica, somente a medida da dose de luz entregue ao tecido não fornece informações o bastante para atendera às necessidades de um monitoramento em tempo real da TFD. Para tanto, faz-se necessário que a técnica a ser utilizada seja capaz de estimar o dano fotodinâmico gerado no tecido. Normalmente, o dano fotodinâmico está relacionado à concentração de oxigênio singleto (ou de espécies reativas de oxigênio) geradas no tecido alvo. Com o surgimento de novas técnicas capazes de estimar o dano fotodinâmico gerado, prosseguiu-se com a revisão bibliográfica das mesmas, descrita nas próximas seções.

\subsubsection{Oxigênio Molecular e Oxigênio Singleto}

Sendo o oxigênio singleto $\left({ }^{1} \mathrm{O}_{2}\right)$ o principal causador de morte celular no tratamento fotodinâmico, principalmente para a TFD baseada em PpIX (CELLI et al., 2010), sua concentração no tecido alvo está intimamente ligada à eficácia do tratamento. Por conta disso, é de grande interesse se monitorar a concentração de ${ }^{1} O_{2}$ gerada na lesão, durante a TFD, ou até mesmo a concentração de oxigênio a nível molecular $\left({ }^{3} O_{2}\right)$, seu precursor durante o tratamento. Estando essas grandezas diretamente ligadas à dose fotodinâmica gerada no tecido, o monitoramento das mesmas têm alto potencial de prever as respostas ao tratamento, e de calcular o dano fotodinâmico total gerado no tecido.

Entretanto, normalmente, tanto a medida de oxigênio molecular quanto a medida de oxigênio singleto estão dentre as mais complexas de serem realizadas, principalmente de maneira não-invasiva. Em um trabalho publicado por Schouwink et al. (2003), mediuse a pressão do oxigênio $\left(p \mathrm{O}_{2}\right)$ utilizando-se eletrodos inseridos no tecido por meio de agulhas. Nesse trabalho, mostrou-se que há uma depleção de oxigênio na região tumoral tratada. Essa técnica, entretanto, produz uma medida pontual, e é mais invasiva que técnicas ópticas, se mostrando de grande importância em testes pré-clínicos (HENDERSON; BUSCH; SNYDER, 2006; WANG et al., 2004), mas de praticidade reduzida para testes clínicos mais avançados (fase II ou III), ou para o âmbito comercial (CELLI et al., 2010; POGUE et al., 2016).

No estudo publicado por Niedre, Patterson e Wilson (2002) conseguiu-se medir a luminescência do oxigênio singleto no infravermelho próximo (1270 nm), utilizando-se um aparato experimental baseado em uma fotomultiplicadora. Após o trabalho de Niedre, Patterson e Wilson (2002), diversos estudos experimentais foram conduzidos abordando o uso desta técnica dosimétrica (GEMMELL et al., 2013; JARVI; PATTERSON; WILSON, 2012; LEE et al., 2008; NIEDRE et al., 2003; NIEDRE et al., 2005). Embora essa técnica tenha se mostrado promissora na detecção de oxigênio singleto, produzindo até mesmo imagens (com o uso de fotomultiplicadoras), ela se faz muito onerosa, e de baixa praticidade para ser utilizada em testes clínicos, o que dificulta o seu avanço à equipamento comercial. 


\subsubsection{Fluorescência e Fotobranqueamento do Fotossensibilizador}

Dentre as diferentes técnicas que podem ser empregadas, a detecção da fluorescência do fotossensibilizador (FS) constitui-se uma das técnicas mais simples de ser utilizada para o monitoramento da terapia fotodinâmica. Considerando-se a concentração de FS como proporcional à sua fluorescência, a intensidade da fluorescência proveniente de uma dada lesão pode ser considerada como proporcional à concentração de FS na mesma. Apesar de não necessitar de um aparato complexo para ser detectada, a medida dessa grandeza física tem sido relacionada com a eficácia da terapia fotodinâmica, sendo apontada como uma técnica promissora para o monitoramento da TFD (AKOPOV et al., 2017; HENNIG; STEPP; JOHANSSON, 2011; KANICK et al., 2015; POGUE et al., 2016; ROBINSON et al., 1998; SHENG et al., 2007; VOLLET-FILHO et al., 2009). O decaimento mais rápido da fluorescência do FS durante o período de iluminação está relacionado com a concentração de oxigênio molecular, e com a geração de oxigênio singleto (BOERE et al., 2003; SHENG et al., 2007), e consequentemente com o dano fotodinâmico ocasionado no tecido alvo. Por conta disso, essa técnica tem se mostrado extremamente estratégica no monitoramento da TFD, podendo apontar o progresso do tratamento fotodinâmico, em tempo real, indicando a eficácia final da terapia nos primeiros minutos da mesma.

A primeira publicação científica em que se reportou o acumulo preferencial de fotossensibilizador em tecidos neoplásicos, quando comparados com tecidos saudáveis, foi feita por Policard (1924). Desde então, diversos estudos têm utilizado a fluorescência de fotossensibilizadores, tanto na deteç̧ão de regiões neoplásicas, como no monitoramento da terapia fotodinâmica (AKOPOV et al., 2017; CELLI et al., 2010; LAROCHELLE et al., 2017; MARKWARDT et al., 2016; KANICK et al., 2014). Dado que a maior absorção de luz pela PpIX se dá no violeta, região espectral corresponde à banda de Soret dessa molécula, com pico em $407 \mathrm{~nm}$, a maioria dos trabalhos utilizou uma excitação em torno dessa região do espectro (AKOPOV et al., 2017; BOERE et al., 2003; ERICSON et al., 2005; JOHANSSON et al., 2006; KIM et al., 2010; SVANBERG et al., 1998; TYRRELL; CAMPBELL; CURNOW, 2010). Apesar da alta absorção no violeta resultar em uma alta emissão fluorescente, com um pico característico em $633 \mathrm{~nm}$, e outro pico menor em torno de $700 \mathrm{~nm}$, comprimentos de onda na região do violeta têm penetração limitada em tecidos biológicos, dados os altos coeficientes de absorção $\left(\mu_{a}\right)$ e de espalhamento $\left(\mu_{s}\right)$ destes para essa região espectral (JACQUES, 2013; LISTER; WRIGHT; CHAPPELL, 2012).

Para se contornar a limitada penetração da luz violeta em tecidos biológicos, faz-se necessária a utilização de uma outra região espectral, com baixos valores de $\mu_{a}$ e $\mu_{s}$, para a excitação da fluorescência. Para o caso da protoporfirina-IX, é possível se excitar essa molécula com comprimentos de onda na região do vermelho, já que essa molécula possui um pequeno pico de absorção em $633 \mathrm{~nm}$. Nesse caso, seria possível se detectar a fluorescência dessa molécula em torno de $700 \mathrm{~nm}$, no início da região do infravermelho 
próximo (NIR, do termo em inglês, "near infrared"). A utilização dessa faixa espectral, entretanto, produz uma fluorescência consideravelmente mais tênue. Essa diminuição na fluorescência ocorre por três motivos principais: o pico de absorção em $633 \mathrm{~nm}$ é cerca de 30 vezes menor que o pico na banda de Soret; a fluorescência detectável se daria em torno de 700 nm, região cujo pico de emissão é cerca de 5 vezes menor do que em 633 nm; e a diferença espectral entre a excitação e a emissão também diminui (cerca de 3,5 vezes menor), o que dificulta a detecção da fluorescência.

Mesmo em meio às dificuldades inerentes, alguns autores têm reportado o sensoreamento da fluorescência da PpIX em torno de 700 nm, excitada pelo vermelho. Devido à baixa intensidade do sinal de interesse, normalmente essas medições são realizadas por sistemas baseados em espectrômetros (JOHANSSON et al., 2013; KANICK et al., 2014; THOMPSON et al., 2005), ou até mesmo com a ajuda de fotomultiplicadoras para amplificação do sinal medido (SHENG et al., 2007). Apesar dos sistemas com medição pontual conseguirem detectar sinais de fluorescência bem tênues, medidas pontuais podem variar consideravelmente ao longo da lesão, dadas as variabilidades dos parâmetros da lesão. Os sistemas de imageamento, por outro lado, poderiam detectar o perfil de fluorescência ao longo de toda a lesão, estimando a concentração de PpIX, além de seu fotobranqueamento, em toda a área da lesão. Toda essa informação pode ser importante para uma análise do fotobranqueamento da lesão, e para as predições da resposta terapêutica.

Apesar da baixa intensidade da fluorescência excitada no vermelho, alguns autores reportaram a utilização de sistemas de imageamento capazes de detectar (ROBERTS et al., 2018), ou até de medir a concentração de PpIX através de imagens de fluorescência de campo amplo, em torno de 700 nm (FISCHER et al., 2001; LAROCHELLE et al., 2017). No trabalho reportado por Fischer et al. (2001), por exemplo, descreve-se uma análise espacial e espectral da óptica de um sistema para detecção da fluorescência da PpIX em 700 nm, dedicado à lesões de pele. Também são descritos, nesse trabalho, os limites inferiores de detecção (threshold) do sistema para soluções de PpIX dissolvida em DMSO (dimetilsulfóxido, ou sulfóxido de dimetilo), os quais forma de até $1 \mu \mathrm{M}$. O sistema utiliza duas fontes laser de excitação, com até $10 \mathrm{~mW} / \mathrm{cm}^{2}$ cada, uma em $635 \mathrm{~nm}$, e outra em $650 \mathrm{~nm}$, além de dois filtros ópticos para a coleta das imagens, um em $710 \mathrm{~nm}$, e outro em $725 \mathrm{~nm}$. Tanto o laser em $650 \mathrm{~nm}$, quanto o filtro em $725 \mathrm{~nm}$ foram utilizados para se eliminar o background da imagem, buscando melhorar o sinal de fluorescência adquirido. Como detector das imagens, foi utilizada uma câmera digital CCD termicamente resfriada. Quando os sinais de fluorescência eram baixos, uma terceira fonte de excitação foi utilizada, entre $320 \mathrm{~nm}$ e $390 \mathrm{~nm}$, através de uma lâmpada à arco voltaico, conectada à uma fibra óptica líquida de $8 \mathrm{~mm}$ de núcleo, para se excitar a molécula de PpIX na banda de Soret.

Já no trabalho descrito por LaRochelle et al. (2017), duas fontes de excitação distintas foram utilizadas, uma em $405 \mathrm{~nm}$, e outra em $635 \mathrm{~nm}$. Para detecção das 
imagens de fluorescência, uma câmera digital CCD de 14 bits foi utilizada (Pixelfly, PCO, Alemanha), acoplada à uma roda de filtros contendo 10 filtros ópticos distintos. Com a combinação entre as duas excitações e os filtros ópticos, um conjunto de 25 imagens foram utilizadas para compor cada imagem final calculada, somando-se um total de aproximadamente um minuto para a aquisição de todas as imagens. Para tanto, variou-se os filtros ópticos entre $635 \mathrm{~nm}$ e $710 \mathrm{~nm}$, sendo eles do tipo passa-banda, com largura à meia altura (FWHM, do termo em inglês full width at half maximum) de $10 \mathrm{~nm}$ a $20 \mathrm{~nm}$. Os diferentes filtros ópticos, em conjunto com as duas fontes de excitação disponíveis, foram utilizados para compor as imagens finais da contribuição da fluorescência da PpIX, e da contribuição da fluorescência intrínseca da pele, para diferentes comprimentos de onda. Desse modo, foi possível se eliminar a contribuição da fluorescência intrínseca ao tecido, o que contribuiu para diminuir ainda mais o limiar de detecção do dispositivo. Após a captura de cada imagem, outra imagem era capturada, sem excitação, com o mesmo tempo de integração, buscando se eliminar contribuições da luz ambiente, ou acúmulo de carga no sensor CCD.

Para o estudo dos limites de detecção, LAROCHELLE et al. utilizaram phantoms para mimetizar as propriedades ópticas de tecidos biológicos. Para o phantom contendo $2 \%$ de Intralipid (20\% Frenius-Kabi) e 2\% de sangue bovino completo (7200811 Lampire Biological Inc), considerando-se as devidas contribuições da fluorescência intrínseca da pele, foi possível se chegar ao limite de detecção de 10 nM de PpIX. Nesse estudo, também se realizou a TFD de 12 camundongos nude, nos quais foram implantados uma linhagem de células de carcinoma de células escamosas (SCC25). Em cada camundongo tratado, tanto o sistema de campo amplo, quanto um sistema de medições espectrais pontuais foram utilizados, para comparação, produzindo valores de fluorescência bem correlatos. Apesar do baixo limite de detecção, esse sistema leva um considerável tempo para fornecer a imagem final de fluorescência. Durante esse período a dose de luz do tratamento deve estar desligada, o que impede um monitoramento em tempo real da TFD para os protocolos com dose de luz contínua.

No trabalho descrito por (ROBERTS et al., 2018), um microscópio cirúrgico (OPMI Pentero, Carl Zeiss, Alemanhã) foi adaptado para excitar a PpIX no vermelho, e capturar sua fluorescência em torno de $700 \mathrm{~nm}$, para auxiliar cirurgias de remoção de tumores intracranianos. Como excitação, foi utilizada a própria lâmpada de arco voltaico disponível no equipamento, em série com um filtro óptico passa banda centrado em $630 \mathrm{~nm}$, com 20 nm de FWHM. Para a coleta da fluorescência, foi utilizado um filtro sintonizável de cristal líquido (LCTF, do termo em inglês liquid crystal tunable filter), acoplado à um filtro óptico passa alta, de comprimento de onda de corte em $650 \mathrm{~nm}$. Nesse estudo, imagens de fluorescência foram adquiridas durante a craniotomia de 29 pacientes com tumores intracranianos. Foi reportado que a fluorescência excitada no vermelho foi capaz de detectar moléculas de PpIX em camadas mais internas do tecido, enquanto a fluorescência excitada 
pelo violeta conseguiu adquirir sinais de camadas mais superficiais do tecido. Para a aquisição e processamento de cada imagem final, o sistema levou cerca de um minuto.

Apesar de produzir imagens de fluorescência com um baixo limiar de detecção (LAROCHELLE et al., 2017), ou de conseguir embuti-las com sucesso em sistemas comerciais (ROBERTS et al., 2018), os sistemas reportados utilizaram câmeras digitais de custo elevado, ou foram acoplados à dispositivos onerosos, como o LCTF (ROBERTS et al., 2018). Como esses dispositivos não foram desenvolvidos para um monitoramento em tempo real, os mesmos abordaram a coleta dos sinais de fluorescência via diferentes excitações e diferentes filtros de coleta, exigindo a pausa da iluminação de tratamento para realizar suas medições (FISCHER et al., 2001; LAROCHELLE et al., 2017), e onerando o tempo de resposta do equipamento (LAROCHELLE et al., 2017; ROBERTS et al., 2018). A demais, por não serem dedicados ao tratamento fotodinâmico de lesões, esses sistemas também não apresentaram uma fonte de iluminação de tratamento embutida, capaz de fornecer as irradiâncias necessárias à diversos protocolos de TFD para câncer de pele (até $150 \mathrm{~mW} / \mathrm{cm}^{2}$ ) (DOUGHERTY et al., 1998).

\subsection{Objetivos}

O presente trabalho teve por objetivo geral, desenvolver, caracterizar e experimentar um sistema capaz de realizar e monitorar a terapia fotodinâmica de câncer de pele do tipo não melanoma, via imagens de fluorescência da protoporfirina-IX. Procurou-se utilizar a própria iluminação de tratamento, com comprimento de onda de $633 \mathrm{~nm}$, para se excitar a fluorescência de monitoramento, coletada nos comprimentos de onda em torno de $700 \mathrm{~nm}$, o que aumenta significativamente a penetração de luz na pele, além de simplificar a tecnologia. Durante todo o projeto, procurou-se manter a portabilidade, fácil utilização, e baixo custo do sistema.

Como objetivos específicos, buscou-se, primeiramente, encontrar uma óptica capaz de detectar o sinal de interesse, que é a fluorescência da PpIX em torno de 700 nm, mesmo para uma alta irradiância da fonte de excitação, com comprimento de onda próximo da fluorescência de interesse (até $150 \mathrm{~mW} / \mathrm{cm}^{2}$, à $633 \mathrm{~nm}$ ). Também teve-se por objetivo específico o desenvolvimento de um módulo laser, capaz de entregar as irradiâncias normalmente requeridas em tratamentos de câncer de pele (até $150 \mathrm{~mW} / \mathrm{cm}^{2}$ ), culminando na confecção dos circuitos elétricos de alimentação do laser, e de controle de sua temperatura.

Também objetivou-se caracterizar e experimentar o sistema. Para a caracterização, buscou-se mimetizar as propriedades ópticas da pele, analisando-se a sensibilidade, linearidade, e intensidade mínima detectável pelo sistema, em termos de concentração de PpIX. Já na experimentação, procurou-se aplicar o sistema para o tratamento e monitoramento de lesões de pele não melanoma implantadas em camundongos do tipo nude, comparando-se 
a obtenção da fluorescência por um equipamento comercial amplamente empregado, e pela nova tecnologia sob teste. 



\section{TERAPIA FOTODINÂMICA}

A terapia fotodinâmica (TFD) provém da junção de três elementos básicos: fotossensibilizador (FS), oxigênio a nível molecular e luz (Figura 1). Com a junção desses elementos, é possível se produzir espécies reativas de oxigênio (DOLMANS; FUKUMURA; JAIN, 2003), como o oxigênio singleto. As espécies reativas de oxigênio são altamente citotóxicas, podendo ocasionar necrose e apoptose (morte celular) (DOLMANS; FUKUMURA; JAIN, 2003; DOUGHERTY et al., 1998; HENDERSON; DOUGHERTY, 1992).

Figura 1: Diagrama de blocos com os três principais elementos da terapia fotodinâmica: luz, fotossensibilizador e oxigênio molecular. Com estes elementos é possível se formar espécies reativas de oxigênio, e ocasionar morte celular.

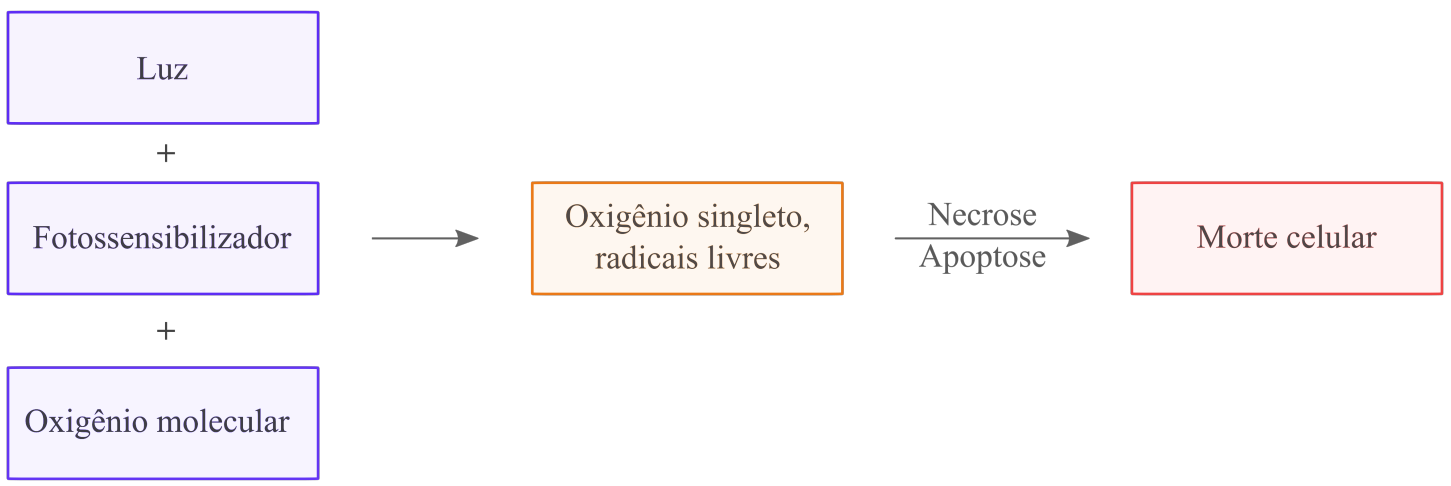

Fonte: elaborada pelo autor.

\subsection{História dos Fotossensibilizadores}

Os primeiros estudos em seres vivos com fotossensibilizadores associados a luz foram realizados por Hausmann (1911). Em seu estudo reportado em 1911, Hausmann abordou os efeitos da administração de hematoporfirina associada a aplicação de luz em protozoários, células vermelhas do sangue e até em camundongos. Dentre as respostas biológicas, foram reportadas a fotossensibilidade e a fototoxicidade.

A primeira publicação científica em que se reportou o acumulo preferencial de fotossensibilizador em tecidos neoplásicos, quando comparados com tecidos saudáveis, foi feita por Policard (1924). Neste estudo, Policard iluminou camundongos que tinham sarcoma utilizando luz ultravioleta, observando uma fluorescência vermelha sendo emanada da região em que o tecido neoplásico se situava. Após a publicação de Policard, começaram uma série de estudos buscando se utilizar porfirinas para localização de neoplasias (ACKROYD et al., 2001; AULER; BANZER, 1942; FIGGE; WEILAND, 1948). 
Dentre os primeiros estudos, pode-se citar o de Auler e Banzer (1942), que utilizou porfirinas administradas exogenamente em tumores malignos, e reportou a fluorescência e a localização dos mesmos. Posteriormente, Figge e Weiland (1948) reportaram a administração de diferentes porfirinas, em um estudo com tumores induzidos e transplantados em 240 camundongos. Nesse estudo, foi reportado que todas as porfirinas apresentaram fluorescência, em cada um dos tipos de tumores. Não foi observada fluorescência em tecidos normais, exceto em linfonodos, no omento, no tecido fetal e placentário e em feridas sobre cicatrização.

Em uma estudo realizado por Schwartz et al. (1955), mostrou-se que a hematoporfirina utilizado nos estudos anteriores é composta por uma mistura de porfirinas. Buscando-se melhorar a substância já existente, encontrou-se um derivado da hematoporfirina, nomeado de $\mathrm{HpD}$ (proveniente do inglês, "hematoporphyrin derivative") que apresentou propriedades melhores de fototoxicidade e seletividade na localização de tecidos neoplásicos, quando comparados com a hematoporfirina crua (LIPSON; BALDES, 1960; LIPSON; BALDES; OLSEN, 1961).

Na sequência, várias pesquisas utilizaram HpD para a localização de tecidos tumorais (ACKROYD et al., 2001), sendo que em boa parte delas se utilizou lâmpadas de arco voltaico como fonte luminosa. Dentre esses estudos, pode-se destacar o de Gregorie et al. (1968), um estudo em larga escala no qual se analisaram 226 pacientes, dos quais 173 foram acometidos por tumores malignos e 53 por lesões benignas. Dentre os tumores analisados, foi detectada fluorescência em $84 \%$ dos adenocarcinomas, $77 \%$ dos carcinomas espinocelular, $62,5 \%$ dos sarcomas e $22 \%$ das lesões benignas. Pelas estatísticas percentuais observadas, pôde-se concluir que a baixa especificidade limita o uso dessa técnica para detecção de tumores.

Anos depois, no começo da década de 90, um novo conceito de fotossensibilização endógena foi descoberto. Divaris, Kennedy e Pottier (1990) correlacionaram a administração de ácido $\delta$-aminolevulínico (ALA) com o aparecimento de protoporfirina-IX (PpIX) em camundongos. No caminho biossintético da heme, o ALA, que não possui efeito fotossensibilizante, é um precursor natural da PpIX, um fotossensibilizador produzido neste ciclo (Figura 2). Dessa maneira, um novo caminho para se ter uma absorção bem mais efetiva de fotossensibilizador pelas células tumorais seria a administração de ALA, e sua posterior metabolização em PpIX pelo tecido tumoral (KENNEDY; POTTIER, 1992).

A descoberta feita por Divaris, Kennedy e Pottier trouxe um grande avanço para a área de diagnóstico e tratamento de lesões tumorais. Esse avanço se deu pois a PpIX possui várias vantagens com relação aos fotossensibilizadores utilizados até então. Dentre suas vantagens, há o curto período de fotossensibilização, normalmente não ultrapassa o período de 24 h (KENNEDY; POTTIER, 1992). Uma outra vantagem é a sua acumulação mais seletiva em tecidos neoplásicos, com relação aos outros fotossensibilizadores (ACKROYD 
Figura 2: Molécula (a) de ácido $\delta$-aminolevulínico (ALA), e molécula (b) de Protoporfirina-IX (PpIX).

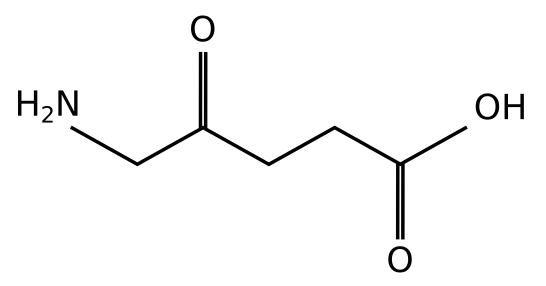

(a)

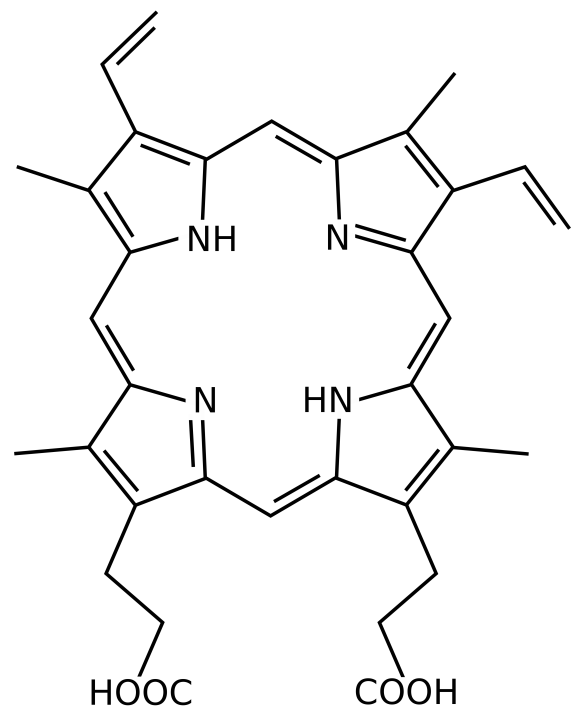

(b)

Fonte: elaborada pelo autor.

et al., 2001; BEDWELL et al., 1992).

\subsection{Efeito Fotodinâmico}

Na Figura 3 se observa o diagrama de Jablonski para a excitação luminosa de um fotossensibilizador. Ao absorver um fóton, essa molécula pode ser excitada do estado fundamental singleto $\left(S_{0}\right)$ para o primeiro estado singleto excitado $\left(S_{1}\right)$. Estando excitado, o fotossensibilizador pode apresentar um cruzamento intersistema para o estado tripleto excitado $\left(T_{1}\right)$, representado na Figura 3 pela constante de cruzamento intersistema, $k_{I S C}$ (CELLI et al., 2010), ou perder energia via fluorescência, com a emissão de um fóton, representada na figura pela constante $k_{f}$. Quando o fotossensibilizador apresenta um cruzamento interatômico para seu estado $T_{1}$, o mesmo pode perder energia para outras moléculas através do fenômeno chamado de quenching, o qual será melhor descrito no próximo capítulo. Para a TFD baseada em PpIX, o principal mecanismo fotodinâmico ocorre com a transferência de energia do fotossensibilizador no estado $T_{1}$ para o oxigênio $\left({ }^{3} \mathrm{O}_{2}\right)$ via quenching, gerando-se oxigênio singleto $\left({ }^{1} \mathrm{O}_{2}\right)$, o qual é altamente reativo e oxidativo, com potencial de causa morte celular (CELLI et al., 2010)(Figura 3).

Para a maioria dos fotossensibilizadores comumente utilizados em TFD, o estado excitado singleto possui um tempo de vida, $\tau_{S}$, bem curto, da ordem de nanossegundos. Já o estado excitado tripleto possui um tempo de vida, $\tau_{T}$, da ordem de microssegundos até milissegundos (CELLI et al., 2010; HENDERSON; DOUGHERTY, 1992). Ambos os estados excitados singleto e tripleto podem transferir energia para a reação fotoquímica 
Figura 3: Diagrama de Jablonski para a excitação de um fotossensibilizador por um fóton. Neste esquema estão representadas as transições eletrônicas relativas à fluorescência $\left(k_{f}\right)$, ao cruzamento intersistema $\left(k_{I C S}\right)$, e ao quenching $\left(k_{q}\right)$, durante a TFD, até causar morte celular.

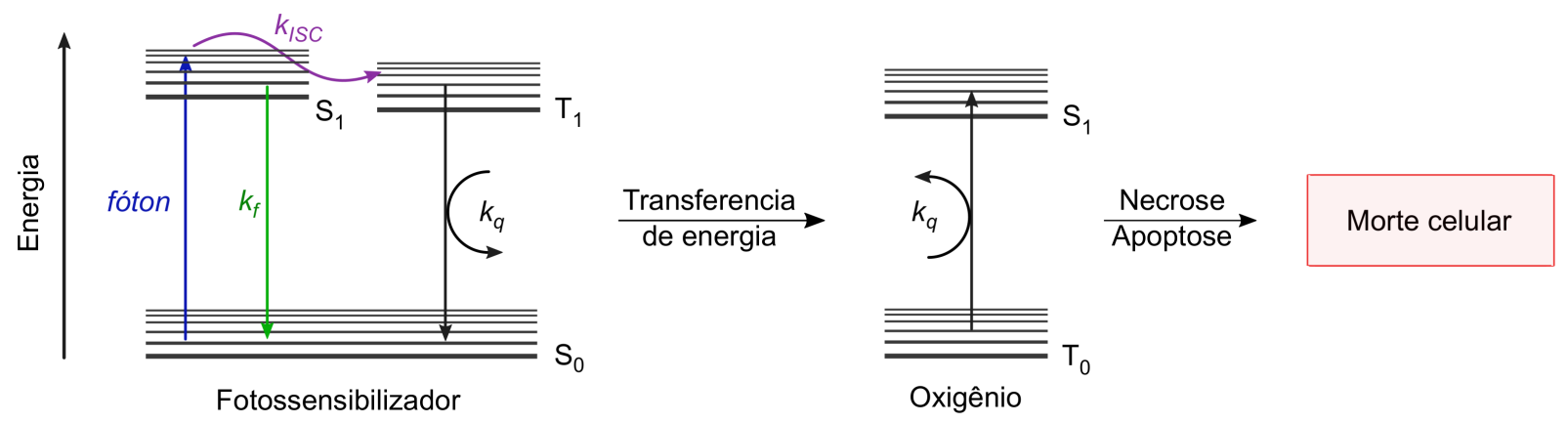

Fonte: elaborada pelo autor.

que caracteriza a fototerapia dinâmica. Entretanto, como o estado tripleto possui um tempo de vida significativamente maior quando comparado com o singleto, o mesmo é normalmente considerado como o estado excitado relevante para o processo fotoquímico em questão (CELLI et al., 2010; DOLMANS; FUKUMURA; JAIN, 2003; HENDERSON; DOUGHERTY, 1992).

Após estar em seu estado excitado, o fotossensibilizador pode proceder por dois caminhos. No primeiro caminho, a molécula excitada pode reagir com o substrato, ou com seu solvente, transferindo-lhe um átomo de hidrogênio ou um elétron, formando radicais livres (conhecido como reação tipo I). Nesse caso, o substrato em questão pode ser a membrana celular, ou uma organela de uma célula tumoral (DOLMANS; FUKUMURA; JAIN, 2003). Outro caminho possível seria a molécula excitada fornecer energia diretamente ao oxigênio molecular, formando o oxigênio singleto (reação tipo II). As reações tipo I e tipo II podem ocorrer simultaneamente, em proporções que dependem da disponibilidade de oxigênio a nível celular, do fotossensibilizador, e das condições do substrato e do solvente (HENDERSON; DOUGHERTY, 1992).

\subsection{Monitoramento da TFD}

O sucesso da terapia fotodinâmica está altamente ligado a inserção de novas tecnologias de monitoramento em tempo real da mesma, dentro do ambiente clínico. É de grande relevância o atual cenário da TFD em torno do mundo, o qual tem apresentado altas taxas de cura, por exemplo para câncer de pele não melanoma, resolvendo um problema de saúde mundial (BUZZÁ et al., 2019; DOUGHERTY et al., 1998; ROOZEBOOM et al., 2013; SZEIMIES et al., 2008). Entretanto, a imprevisibilidade da resposta de cada lesão ao tratamento, juntamente a utilização dos mesmos parâmetros de protocolo para uma ampla gama de lesões, possivelmente têm ocasionado um uso não otimizado da terapia, e a falta de sua adoção em meio aos médicos (POGUE et al., 2016). 
Para se aumentar as taxas de cura dessa modalidade terapêutica, otimizando seus resultados, e propiciando uma ampla aceitação médica, faz-se interessante a utilização de técnicas dosimétricas capazes de prever os resultados de cada lesão à terapia, e de indicar quais parâmetros podem estar ocluindo seu sucesso terapêutico. Dentre as técnicas utilizadas atualmente, a detecção da intensidade de fluorescência do fotossensibilizador tem se destacado na previsão da eficácia da TFD (AKOPOV et al., 2017; HENNIG; STEPP; JOHANSSON, 2011; KANICK et al., 2015; POGUE et al., 2016; ROBINSON et al., 1998; SHENG et al., 2007). Apesar de ser uma técnica de simples implementação, o monitoramento da fluorescência do FS tem o potencial de indicar possíveis fatores de falha do tratamento.

A concentração inicial de FS após seu período de incubação, assim como a cinética de seu consumo durante a iluminação, está ligada às características intrínsecas de cada lesão tratada, assim como à interação de cada lesão com os parâmetros de protocolo empregados. Portanto, é possível se utilizar a intensidade de fluorescência adquirida durante a iluminação como apontador dos possíveis parâmetros que poderiam impedir o sucesso do tratamento. Por exemplo, se uma lesão apresenta uma considerável intensidade de fluorescência antes da iluminação, mas apresenta um lento decaimento da mesma durante o tratamento, pode ser um indicativo de que há pouca disponibilidade de oxigênio molecular no tecido alvo, ou a irradiância aplicada no tratamento não está sendo entregue eficientemente a todo o volume de tumor. Doutra maneira, para o caso em que a intensidade de fluorescência adquirida antes do período de iluminação seja baixa, pode ser um indicativo de que a entrega de fármaco ao tecido não tenha sido eficaz, o que provavelmente irá limitar o sucesso terapêutico. Cada uma dessas constatações, dentre outras possíveis, indica quais parâmetros de protocolo podem ser alterados, ou necessitam da inserção de outras tecnologias, a fim de viabilizar o sucesso terapêutico.

Essa relação entre as características intrínsecas da lesão, e os parâmetros de protocolo aplicados, fazem com que a detecção da fluorescência do FS seja um importante candidato, não só à monitorização da TFD, mas também à customização de seu protocolo. Sendo as lesões diferentes entre si, com uma alta variabilidade de seus parâmetros fisiológicos e ópticos, faz-se importante a utilização de um protocolo que também varie de acordo com os parâmetros de cada cenário. A utilização de um protocolo customizado vem sendo abordada como extremamente importante e necessária para o desenvolvimento da TFD, e para uma ampla adoção dessa modalidade terapêutica como tratamento padrão de câncer de pele não melanoma (SHENG et al., 2007; KANICK et al., 2015; POGUE et al., 2016; AKOPOV et al., 2017).

Para o caso da utilização da intensidade de fluorescência do PS, tanto para o monitoramento da terapia, quanto para a customização do protocolo, é possível se obter uma malha de realimentação fechada, como apresentada na Figura 4. Nessa malha fechada, 
a realimentação é provida pela intensidade de fluorescência medida, juntamente com um algoritmo de decisão, que irá dizer se há necessidade de se continuar iluminando a lesão, ou não. Sendo similar aos diagramas de realimentação da teoria de controle, o algoritmo de decisão é semelhante à função de transferência na malha de realimentação. Através dessa malha de realimentação, é possível se controlar o tratamento fotodinâmico, de maneira a propiciar a cura de uma gama mais ampla de lesões, sem se incorrer em sobredose ou subdose dos parâmetros terapêuticos.

Figura 4: Malha de realimentação fechada para uma terapia fotodinâmica com protocolo customizado. O algoritmo de decisão para o desligamento da iluminação de tratamento deve se basear no sinal de intensidade de fluorescência do fluoróforo, detectado pelo sistema de medição.

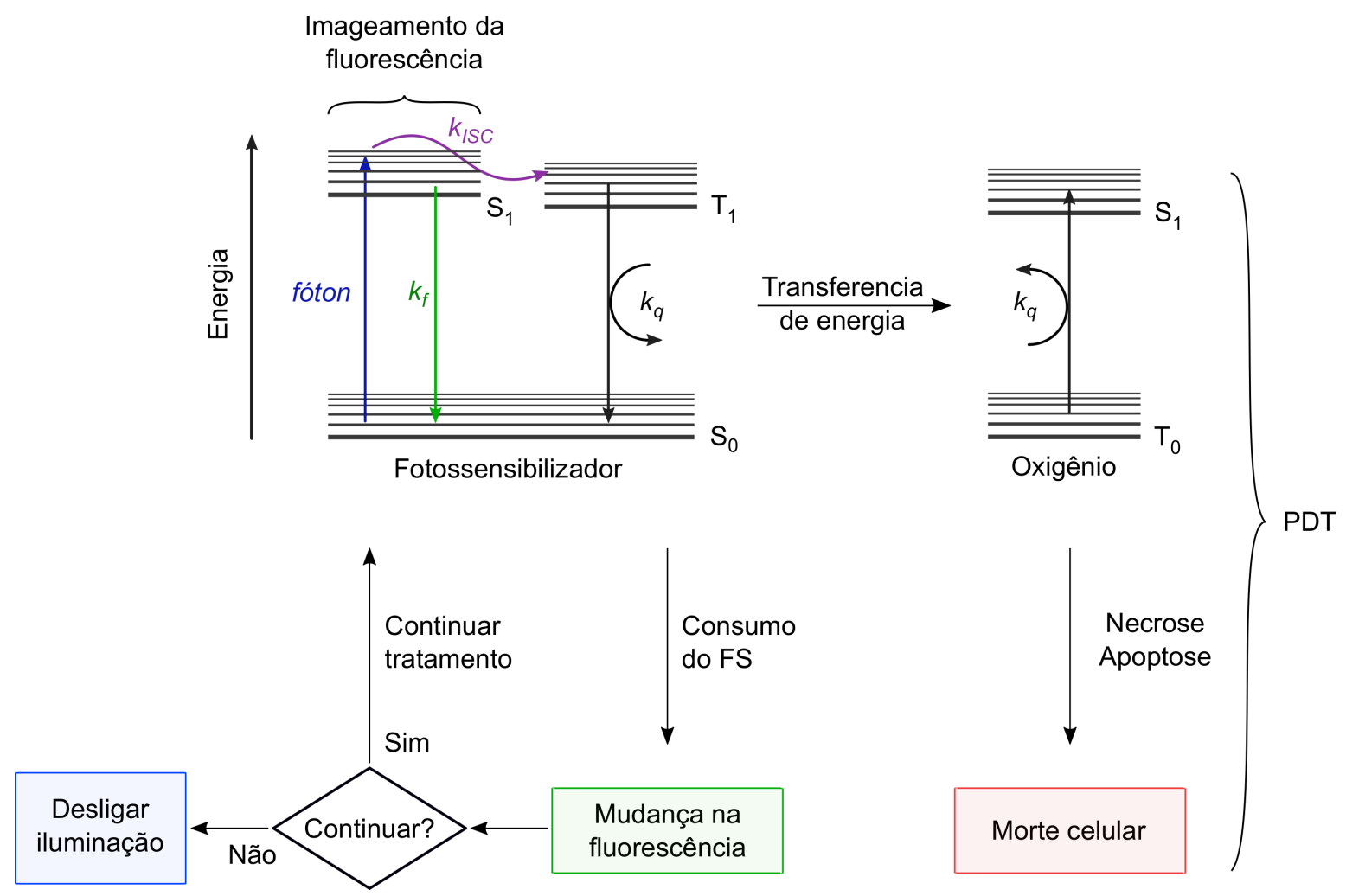

Fonte: elaborada pelo autor.

Para o feitio do algoritmo de decisão, um estudo clínico amplo se faz necessário, juntamente com um estudo de cunho mais fundamental. Nesse estudo, deve se buscar entender quais são os principais fatores que podem impedir uma resposta completa da lesão à terapia, e quais são as soluções mais viáveis propostas para eles, em termos de parâmetros de protocolo. Essas soluções vão desde a mudança dos valores desses parâmetros, durante sua aplicação, até a utilização de novas tecnologias na entrega dos mesmos. Por exemplo, se não há formação de PpIX em uma dada lesão, pode ser um indício de que novas técnicas de aplicação de fármaco sejam necessárias. Para o caso de uma lesão superficial, por exemplo, em que o consumo de FS é rápido, uma opção interessante seria se diminuir o período de 
iluminação, de moda a continuar com uma dose de luz adequada para essa lesão específica, sem sobredose de iluminação.

Visando a otimizar a terapia fotodinâmica, diversos métodos de sensoreamento da intensidade de fluorescência do fotossensibilizador vêm sendo empregados. Em sua grande maioria, as técnicas abordadas são baseadas na excitação da PpIX com comprimentos de onda na região espectral do violeta, atingindo-se a banda de Soret dessa molécula, região com o maior absorção dessa molécula dentro do espectro visível, com pico em torno de 407 nm (ANDRADE et al., 2014; BLANCO et al., 2015; BUZZÁ et al., 2019; CELLI et al., 2010; GRECCO et al., 2015) (Figura 5).

Figura 5: Absorbância e e emissão de fluorescência normalizadas para uma solução de $5 \mu \mathrm{M}$ de PpIX dissolvida em DMSO (dimetilsulfóxido ou sulfóxido de dimetilo), juntamente com a transmitância simplificada para o filtro de fluorescência utilizado pelo equipamento desenvolvido.

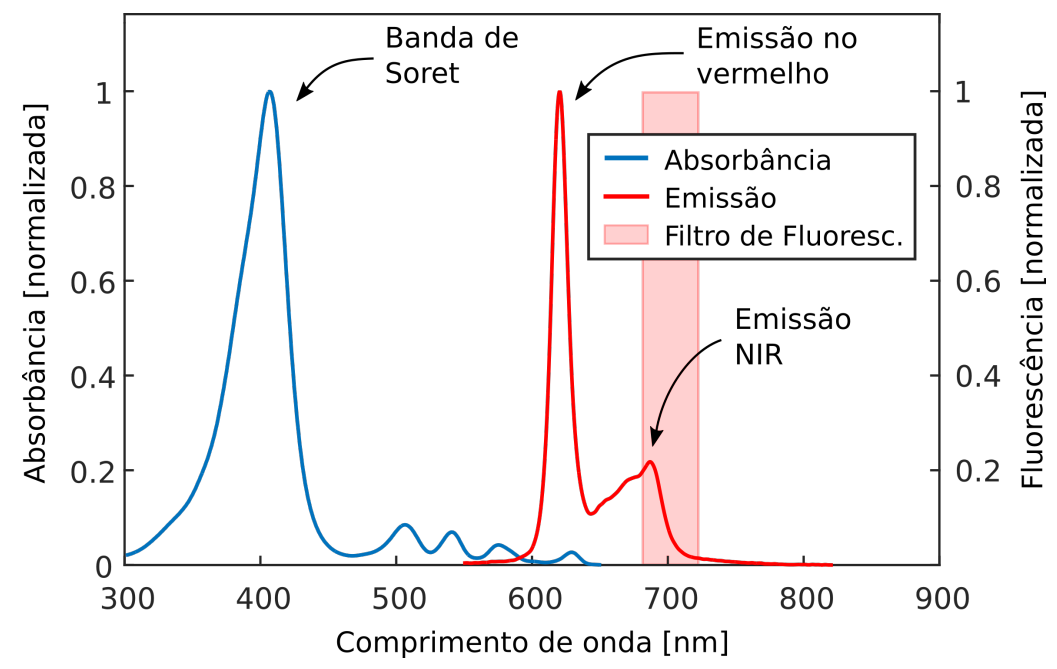

Fonte: elaborada pelo autor.

A excitação da banda de Soret irá produzir uma forte fluorescência, com um pico de emissão mais evidente no vermelho (em $633 \mathrm{~nm}$ ), e outro pico cinco vezes menor em $700 \mathrm{~nm}$, no início da região espectral do infravermelho próximo (NIR, do termo em inglês near-infrared). Entretanto, dados os altos coeficientes de espalhamento $\left(\mu_{s}\right)$ e absorção $\left(\mu_{a}\right)$ de tecidos biológicos para a região do violeta, os comprimentos de onda dessa região espectral têm uma penetração significativamente atenuada. Moléculas como a hemoglobina, a melanina, e a bilirrubina têm altos valores de $\mu_{a}$ para fótons violeta (JACQUES, 2013; LISTER; WRIGHT; CHAPPELL, 2012). Do mesmo modo, as proteínas filamentosas, como a queratina na epiderme, e o colágeno na derme, fazem com que o $\mu_{s}$ seja acrescido na região espectral do violeta (LISTER; WRIGHT; CHAPPELL, 2012).

Já na região espectral do vermelho e infravermelho próximo, há uma redução considerável dos valores de $\mu_{a}$ e $\mu_{s}$, permitindo que a luz penetre mais nos tecidos biológicos. A penetração nesse caso é tão acrescida, que justifica a utilização de comprimentos de 
onda nessa região do espectro (em torno de $633 \mathrm{~nm}$ ) para a iluminação de tratamento da terapia fotodinâmica baseada em PpIX, mesmo considerando-se o fato de que a absorção da PpIX nessa região é cerca de 30 vezes menor do que sua absorção na banda de Soret (Figura 5) (ACKROYD et al., 2001; BUZZÁ et al., 2019; DOUGHERTY et al., 1998).

Tendo em vista o aumento da penetração de luz nos comprimentos de onda do vermelho ao infravermelho próximo, da mesma maneira que é interessante se tratar as lesões com comprimentos de onda nessa região, também é interessante se utilizar essa faixa espectral para a dosimetria das mesmas. Desse modo, poder-se-á provar regiões mais internas do tumor, indagando-se maiores volumes de tecido. Isso iria fornecer uma informação mais completa sobre o tratamento fotodinâmico, contemplando o tumor como um todo. Portanto, o desenvolvimento de tecnologias capazes de adquirir a fluorescência da PpIX excitada no vermelho irá prover a dosimetria de uma maior gama de lesões, principalmente as mais espessas. 


\section{FLUORESCÊNCIA E SENSOREAMENTO}

A luminescência é a emissão de luz por uma substância devido a excitação luminosa de seus estados eletrônicos, sendo que a mesma pode ser dividida em duas categorias principais, fluorescência e fosforescência (LAKOWICZ, 2006; TUCHIN, 2015). A diferença de classificação entre fluorescência e fosforescência dá-se pela natureza do estado excitado. Para o caso da fluorescência, o elétron no orbital excitado está emparelhado com o elétron no orbital fundamental, o que faz com que sua volta ao orbital fundamental seja permitida, e ocorra com a emissão de um fóton. Por esse motivo, este fenômeno tem uma alta eficiência quântica, e ocorre rapidamente (na ordem de nanossegundos) (LAKOWICZ, 2006; TUCHIN, 2015). Já para o caso da fosforescência, o elétron no orbital excitado não está emparelhado com o elétron no orbital fundamental, o que faz com que sua volta ao orbital fundamental se caracterize como uma transição "proibida". Por consequência, a eficiência quântica desse fenômeno é baixa, e o mesmo demora mais para ocorrer (de microssegundos a até vários minutos) (LAKOWICZ, 2006; TUCHIN, 2015).

Para que a fluorescência ocorra em uma molécula, é necessário que a mesma absorva um fóton, cuja energia pode ser determinada pela equação (JELÍNKOVÁ, 2013):

$$
E=h \nu=\frac{h c}{\lambda},
$$

em que $h$ é a constante de Planck $\left(6,6256 \times 10^{-34} \mathrm{~J} \mathrm{~s}\right), \nu$ é a frequência da radiação propagante, $c$ é a velocidade de propagação da luz no vácuo $\left(2,9979 \times 10^{8} \mathrm{~m} / \mathrm{s}\right)$, e $\lambda$ é o comprimento de onda da perturbação.

Na Figura 6 se apresenta o de diagrama de Jablonski para a molécula de um fluoróforo no estado $S_{0}$, sendo excitada para o estado $S_{1}$ pela absorção de um fóton de energia $h \nu$. Nesse diagrama é possível se observar as possíveis transições eletrônicas decorrentes da excitação da molécula, por exemplo a fluorescência e a fosforescência. Ademais, na Figura 6 também se apresentam outras transições eletrônicas, como o relaxamento não-radioativo, relacionado a constante $k_{n r}$, no qual o elétron excitado decai ao estado fundamental sem emissão de fóton. Ademais, também se apresenta na Figura 6 o cruzamento intersistema, representado pela constante $k_{I C S}$, que ocorre quando há uma transição eletrônica entre estados de diferente multiplicidade de spin, por exemplo do estado singleto para o estado tripleto. Essa transição, também não-radioativa, abre espaço para o fenômeno da fosforescência, descrito anteriormente.

\subsection{Quenching da Fluorescência}

A intensidade da fluorescência emitida por um fluoróforo pode ser diminuída por uma série motivos, como reações de estado excitado, rearranjos moleculares, ou formação de 
Figura 6: Diagrama de Jablonski para a absorção de um fóton por uma molécula, com as possíveis transições eletrônicas relacionadas. $S_{0}$ corresponde ao estado eletrônico singleto fundamental, $S_{1}$ e $T_{1}$ correspondem ao estado eletrônico singleto e tripleto excitados, respectivamente.
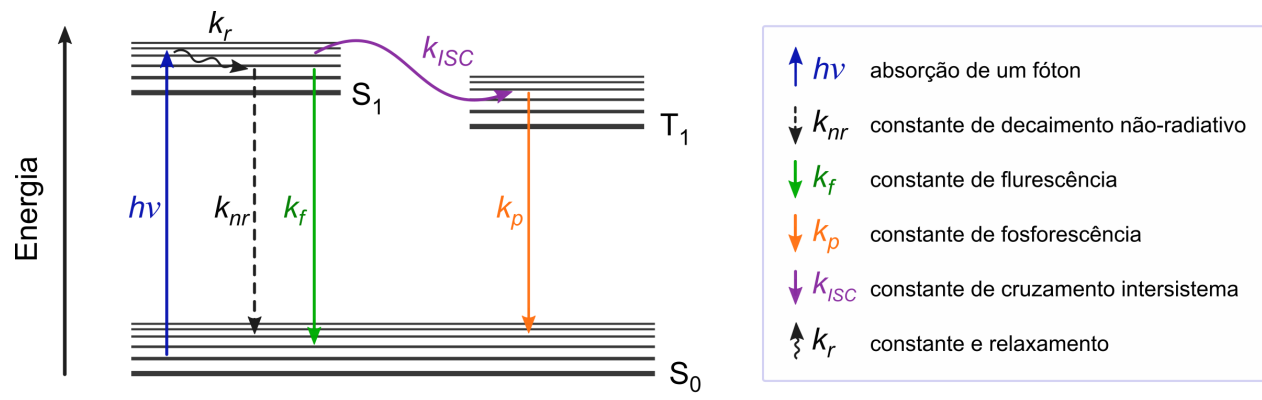

Fonte: elaborada pelo autor.

complexos com o fluoróforo em seu estado fundamental. Todos esses processos são chamados de "quenching" da fluorescência (LAKOWICZ, 2006). Os processos mais elementares de quenching, por exemplo, diminuição da intensidade luminosa incidente no fluoróforo, alta densidade óptica, turbidez do meio ou absorção de luz por outros elementos, normalmente não são considerados ao se citar o termo quenching.

O quenching colisional, que é o fenômeno normalmente considerado ao se citar quenching, ocorre quando há o contato entre o fluoróforo em seu estado excitado com o chamado "quencher", ocasionando uma queda na fluorescência, descrita pela equação de Stern-Volmer (LAKOWICZ, 2006):

$$
\frac{F_{0}}{F}=1+K_{D}[Q]=1+k_{q} \tau_{0}[Q] .
$$

Os termos $F_{0}$ e $F$ representam as intensidades de fluorescência na ausência e na presença do quencher. O termo $K_{D}$ é a constante de quenching de Stern-Volmer, $[Q]$ a concentração do quencher, $k_{q}$ a constante de quenching biomolecular, e $\tau_{0}$ o tempo de vida de fluorescência do fluoróforo na ausência do quencher.

\subsection{Fotobranqueamento}

Fotobranqueamento é o processo pelo qual uma molécula fluorescente, após excitada um certo número de vezes, degrada-se e perde a sua capacidade de fluorescer (LAKOWICZ, 2006). A fotoestabilidade $\left(\mu_{b}\right)$ de um fluoróforo é determinada pelo número de vezes que o mesmo tem a capacidade de fluorescer antes de apresentar fotobranqueamento, dada pelo inverso do rendimento quântico de fotobranqueamento $\left(Q_{b}\right)$ :

$$
\mu_{b}=\frac{1}{Q_{b}} .
$$

Na Figura 7 é apresentado o diagrama de Jablonski, de maneira mais completa, considerando-se também o fotobranqueamento e o quenching da fluorescência, tanto 
para o estado singleto $\left(k_{q s}\right.$, e $k_{b s}$, respectivamente) quanto para o tripleto $\left(k_{q t}\right.$, e $k_{b t}$, respectivamente).

Figura 7: Diagrama de Jablonski para a absorção de um fóton por uma molécula, com as possíveis transições eletrônicas relacionadas, considerando também o quenching e o fotobranqueamento. $S_{0}$ é o estado eletrônico singleto fundamental, $S_{1}$ e $T_{1}$ são os estados eletrônicos singleto e tripleto excitados, respectivamente.
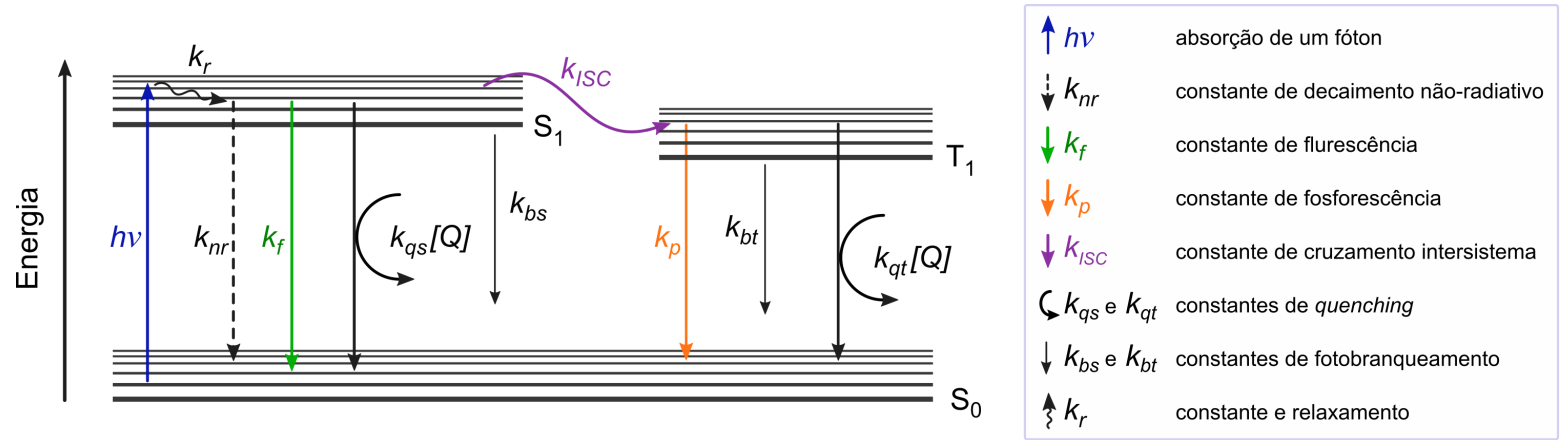

Fonte: elaborada pelo autor.

\subsection{Fluorescência na Terapia Fotodinâmica}

A TFD ocorre quando há um quenching da molécula do fotossensibilizador, de maneira a provocar dano celular. Prioritariamente, o quenching ocorre quando essa molécula encontra-se em seu estado tripleto, já que o tempo de vida desse estado é consideravelmente maior que o do estado singleto (CELLI et al., 2010). Para o caso da TFD baseada em ALA, ou em algum de seus derivados, o quenching mais relevante ocorre quando há transferência de energia para a molécula de oxigênio em seu estado fundamental $\left({ }^{3} \mathrm{O}_{2}\right)$, dando origem ao oxigênio singleto $\left({ }^{1} \mathrm{O}_{2}\right)$, que é altamente reativo, e ocasiona morte celular (ACKROYD et al., 2001; DOUGHERTY et al., 1998). Portanto, de maneira geral, o cruzamento intersistema é a transição eletrônica que irá proporcionar o efeito fotodinâmico.

A eficiência quântica $(Q)$ de um evento induzido por radiação resume-se a divisão do número de vezes que o dado evento ocorre, pelo número de fótons absorvidos. Para o caso da eficiência quântica de fluorescência do fluoróforo representado na Figura 7, pode-se escrever:

$$
Q_{f}=\frac{k_{f}}{k_{n r}+k_{f}+k_{q s}[Q]+k_{b s}+k_{I C S}},
$$

na qual $k_{f}$ corresponde à constante de fluorescência, e $k_{I C S}$ à constante de cruzamento intersistema. Já as constantes $k_{n r}, k_{q s}[Q]$, e $k_{b s}$ estão relacionadas aos processos de decaimento não radioativos, ao quenching da molécula em seu estado singleto, e ao fotobranqueamento da mesma no estado singleto, respectivamente. Já para o caso do cruzamento intersistema, a eficiência quântica pode ser calculada por:

$$
Q_{I C S}=\frac{k_{I C S}}{k_{n r}+k_{f}+k_{q s}[Q]+k_{b s}+k_{I C S}} .
$$


Dessa maneira, da observância das equações 3.4 e 3.5, pode-se notar que parte dos fótons absorvidos irá provocar fluorescência, e outra parte irá induzir a molécula ao cruzamento intersistema. Esses fenômenos ocorrem simultaneamente em um meio biológico submetido à TFD, durante o período de iluminação, tendo cada um uma dada eficiência quântica, ou seja, um dada probabilidade de ocorrer. Portanto, faz-se possível o monitoramento da fluorescência do fotossensibilizador durante o tratamento, sem se influenciar no rendimento quântico do mesmo para geração de espécies citotóxicas. Para o caso da tecnologia utilizada no presente trabalho, em que a fluorescência a ser medida é excitada pela própria iluminação de tratamento (em $633 \mathrm{~nm}$ ), além de não se influenciar na geração de espécies citotóxicas, também não se faz necessário fracionar a entrega da dose de luz terapêutica para a utilização de diferentes comprimentos de onda na excitação do fluoróforo.

A intensidade de fluorescência de um fotossensibilizador pode ser descrita pela seguinte equação:

$$
F=E_{f} k_{f}\left[S_{0}\right] \frac{\sigma_{S 0} \Phi}{h \nu}
$$

onde $E_{f}$ é a eficiência de coleta do instrumento de medição, $\left[S_{0}\right]$ a concentração de fotossensibilizador no estado fundamental, $\sigma_{S 0}$ a secção de choque do fotossensibilizador, e $\Phi$ a irradiância da excitação. Considerando-se constantes os valores de $E_{f}, k_{f}, \sigma_{S 0}, \Phi$, e $h \nu$, pode-se assumir que a intensidade de fluorescência é proporcional à concentração de fotossensibilizador presente no meio $\left(F \propto\left[S_{0}\right]\right)$. Com essas considerações, é possível se estimar $\left[S_{0}\right]$ em um dado meio biológico, medindo-se a fluorescência proveniente do mesmo.

Para o caso da TFD, é de grande importância se medir ou estimar [ $\left.S_{0}\right]$, pois esta grandeza física está relacionada com a dose fotodinâmica entregue ao tecido tratado (AKOPOV et al., 2017; KANICK et al., 2015; ROBINSON et al., 1998; SHENG et al., 2007), sendo que esta pode ser definida como a concentração de espécies citotóxicas depositadas no tecido. Por consequência, através da medida da intensidade de fluorescência do fotossensibilizador, é possível se estimar a dose fotodinâmica, diretamente relacionada ao dano causado no tecido alvo. Tendo em vista essa relação, faz-se interessante desenvolver um equipamento capaz de realizar a TFD e monitorar a fluorescência do fotossensibilizador em tempo real, via imagens de fluorescência, que foi o objetivo deste trabalho. 


\section{CONSTRUÇÃO DO PROTÓTIPO}

\subsection{Caracterização dos Filtros Ópticos e do Laser}

Antes da construção do protótipo, buscou-se uma óptica capaz de adquirir os sinais de fluorescência de interesse. Inicialmente, tentou-se excitar as moléculas de PpIX utilizando-se fontes do tipo LED, coletando-se a fluorescência através de filtros ópticos do tipo passa alta, mas esse conjunto não produziu imagens de fluorescência com contraste adequado, de maneira que praticamente não se podia identificar a fluorescência de interesse. Alterando-se o filtro óptico de coleta para filtros do tipo passa banda, também não foi possível se obter imagens com contraste adequado. Fez-se necessário, portanto, excitar a PpIX por meio de um laser de diodo encapsulado, filtrar o sinal de excitação por meio de um filtro passa baixa, coletando-se o sinal de fluorescência emitido por meio de um filtro passa banda adequado.

Como a fonte de excitação deve fornecer potência o suficiente para realizar o tratamento da lesão, o que normalmente é traduzido em irradiâncias relativamente elevadas (cerca de até $150 \mathrm{~mW} / \mathrm{cm}^{2}$ para alguns protocolos (DOUGHERTY et al., 1998)), utilizou-se um laser multimodos de diodo encapsulado, com potência óptica nominal de 1 W (WSLD635-001-2, WaveSpectrum, China). Na Figura 8 se apresenta a curva de emissão do diodo laser utilizado, com pico de emissão em 633 nm, e 8 nm de FWHM.

Figura 8: Curva de emissão do laser de diodo encapsulado utilizado (WSLD-635-001-2, WaveSpectrum, China).

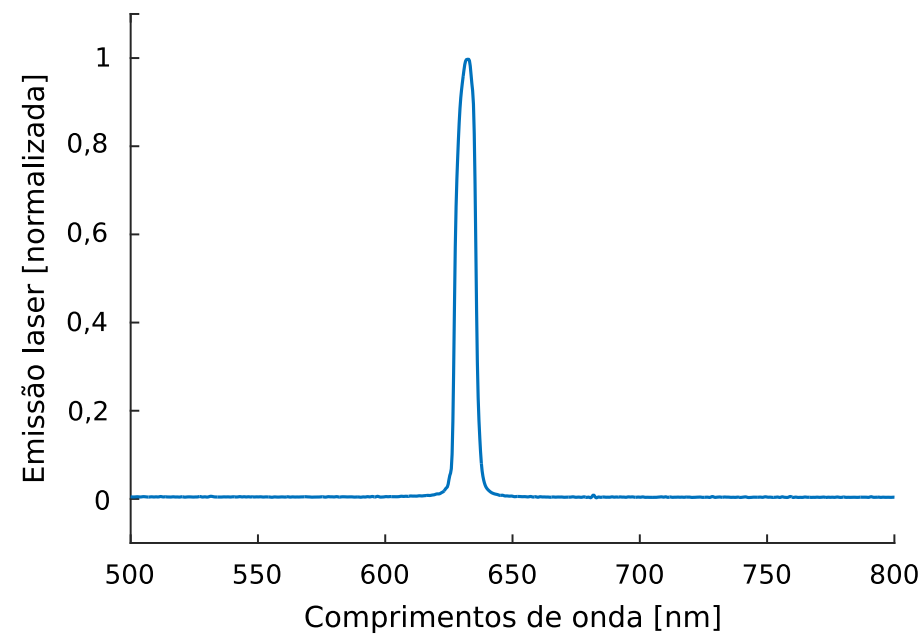

Fonte: elaborada pelo autor.

Buscando se filtrar o sinal de interesse, a emissão fluorescente da PpIX em torno de $700 \mathrm{~nm}$, dois filtros ópticos do tipo passa banda foram testados. O primeiro filtro testado foi fabricado pela Proteon, com comprimento de onda central em $700 \mathrm{~nm}$, e $20 \mathrm{~nm}$ de 
FWHM, cuja transmitância (T) é apresentada na Figura 9(a). Já o segundo filtro testado, também com comprimento de onda central em 700 nm, possui 40 nm de FWHM (FB700-40, Thorlabs, EUA). Na Figura 9(b) se apresenta a curva de transmitância normalizada para o segundo filtro. Ambas as curvas de transmitância foram adquiridas por meio de um espectrofotômetro Cary 50 UV-VIS (Varian, EUA).

Figura 9: Transmitância normalizada para os filtros ópticos do tipo passa banda com comprimento de onda central em $700 \mathrm{~nm}$, (a) fabricado pela Proteon, com $20 \mathrm{~nm}$ de FWHM, e (b) fabricado pela Thorlabs, com $40 \mathrm{~nm}$ de FWHM, obtidas com o espectrofotômetro Cary 50 UV-VIS (Varian, EUA).

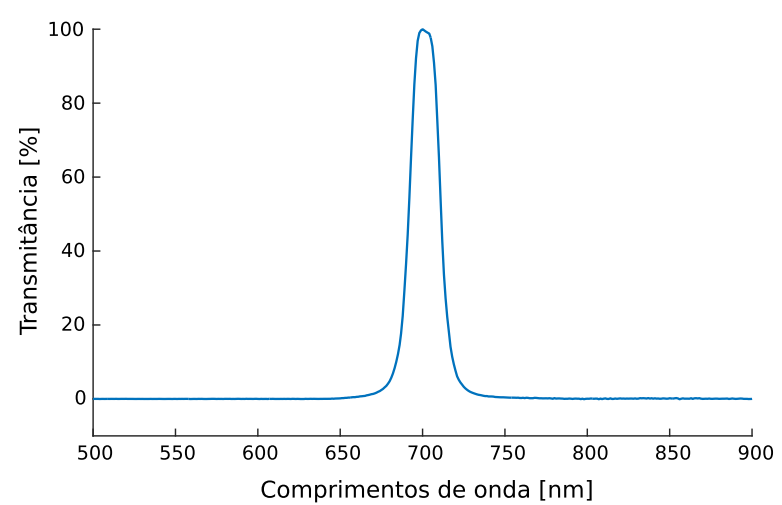

(a)

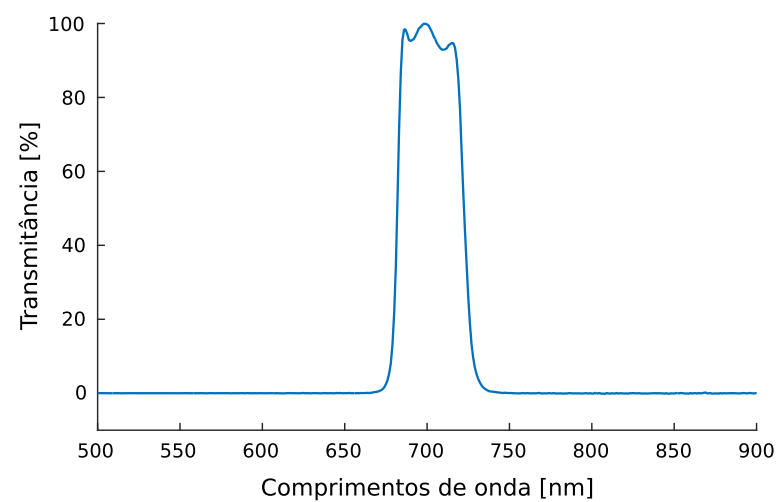

(b)

A princípio, buscou-se utilizar um filtro óptico com baixo valor de FWHM. Entretanto, como a utilização do filtro óptico da Proteon não permitiu a obtenção de imagens de fluorescência com contraste adequado, buscou-se utilizar o filtro óptico de maior FWHM, da Thorlabs, o qual foi mais eficaz na coleta do sinal de fluorescência. Para se caracterizar espectralmente a óptica a ser utilizada, montou-se o aparato experimental mostrado esquematicamente na Figura 10. Nesse experimento, mediu-se o espectro proveniente do laser, após interferir com os componentes ópticos dispostos em um porta-filtros. Como sensor, utilizou-se um espectrômetro (USB2000, OceanOptics, EUA).

Primeiramente, utilizou-se os filtros ópticos do tipo passa banda no porta-filtros do aparato montado, de moda a se obter as curvas de transmissão de luz da fonte de excitação pelos filtros. Nas figuras 11(a) e 11(b) se apresentam as transmissões normalizadas, para os casos em que o filtro da Proteon, e da Thorlabs são utilizados, respectivamente. É interessante se notar, que a normalização foi realizada pelo valor de pico da transmissão do laser pelo filtro óptico passa banda da Thorlabs, Figura 11(b), por ser o maior valor dentre as transmissões.

Como é possível se observar, das curvas obtidas, o filtro óptico da Thorlabs foi capaz de filtrar melhor os comprimentos de onda em torno de $700 \mathrm{~nm}$, apesar de ter o dobro de FWHM. Entretanto, em ambos os casos existem fótons com comprimento de onda de $700 \mathrm{~nm}$ chegando ao detector. Portanto, faz-se necessário impedir que a lesão a 
Figura 10: Aparato experimental montado para a caracterização espectral dos componentes ópticos utilizado.

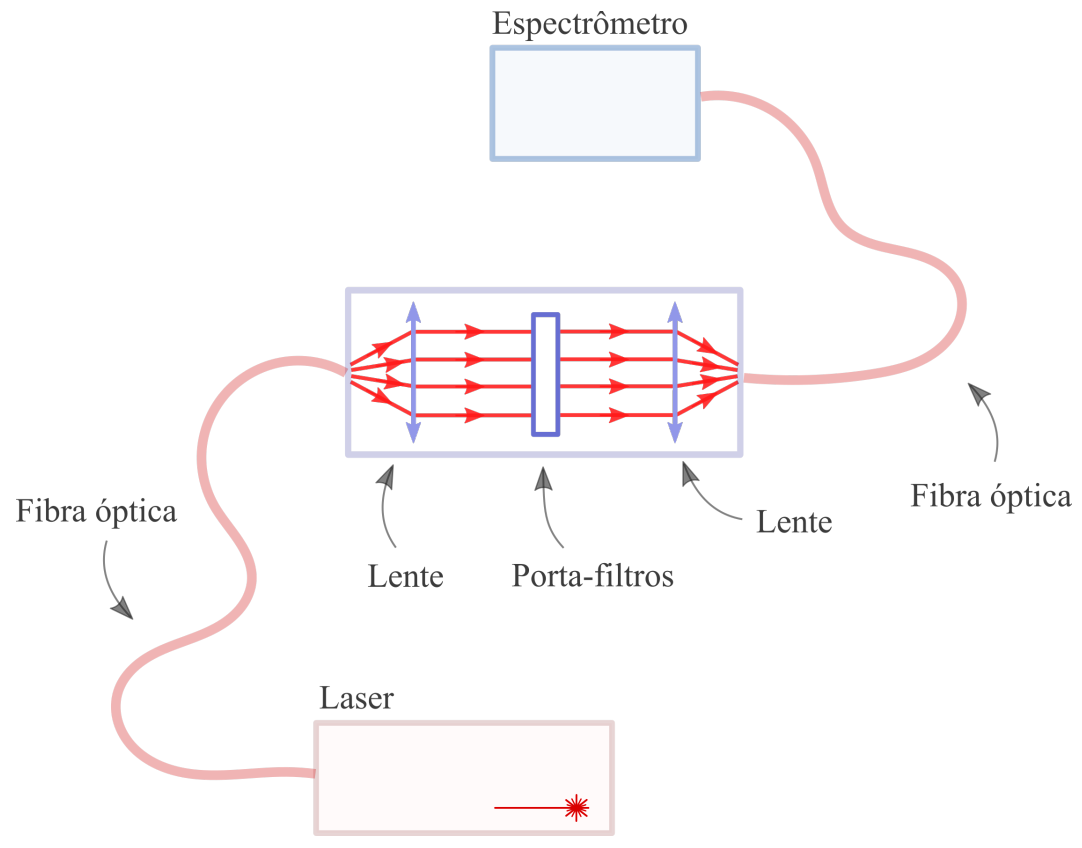

Fonte: elaborada pelo autor.

Figura 11: Curvas de transmissão do laser de $633 \mathrm{~nm}$ pelo filtro passa banda de $700 \mathrm{~nm}$ (a) da Proteon, e (b) da Thorlabs, obtidas com 40 ms de tempo de integração, média de 10 amostragens, e filtradas.

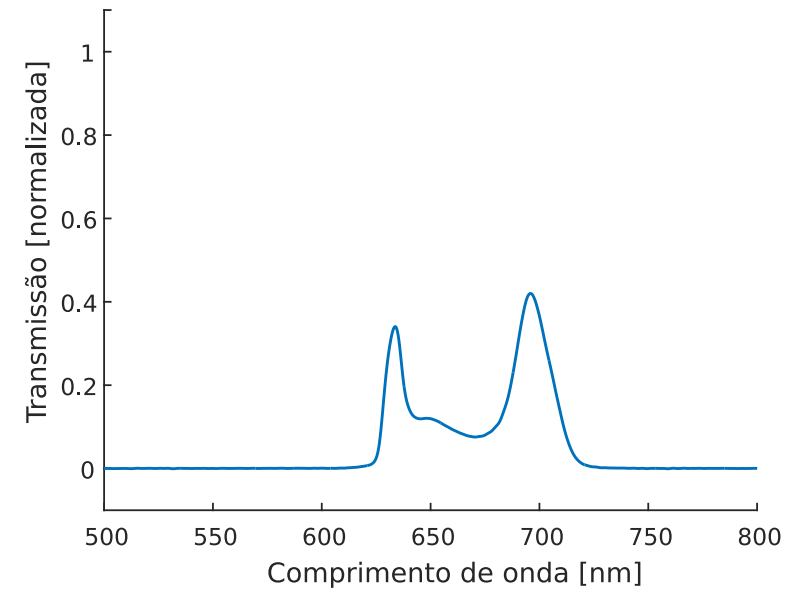

(a)

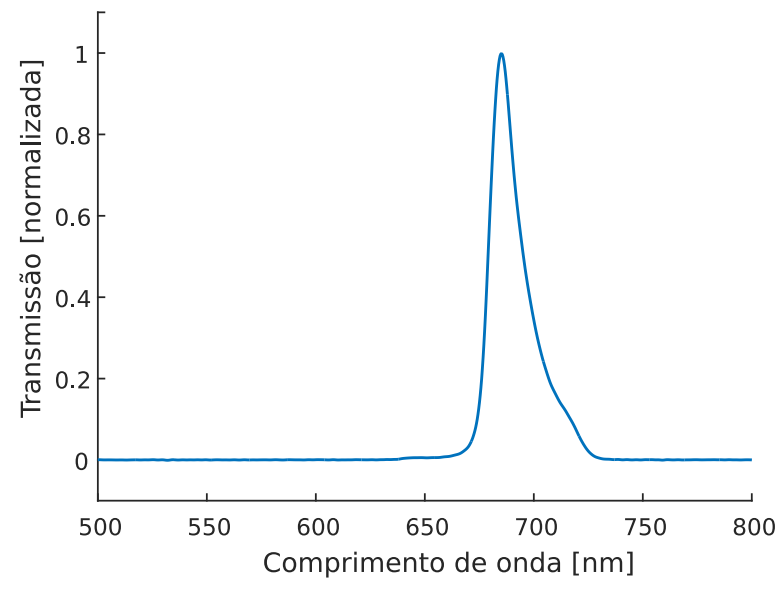

(b) 
ser tratada seja excitada com fótons em torno da região de interesse $(700 \mathrm{~nm})$, para que o sistema de detecção não confunda esses fótons com a fluorescência da PpIX. Para tanto, utilizou-se o filtro FES0650 (Thorlabs, EUA), que atenua comprimentos de onda acima de $650 \mathrm{~nm}$ (comprimento de onda de corte em $\lambda_{c}=650 \mathrm{~nm}$ ). A curva de transmitância para esse filtro está apresentada na Figura 12, adquirida pelo espectrofotômetro (Cary 50 UV-VIS).

Figura 12: Curva de transmitância para o filtro passa baixa com comprimento de onda de corte $\lambda_{c}=650 \mathrm{~nm}$ (FES0650 Thorlabs, EUA), obtida pelo espectrofotômetro Cary 50 UV-VIS (Varian, EUA).

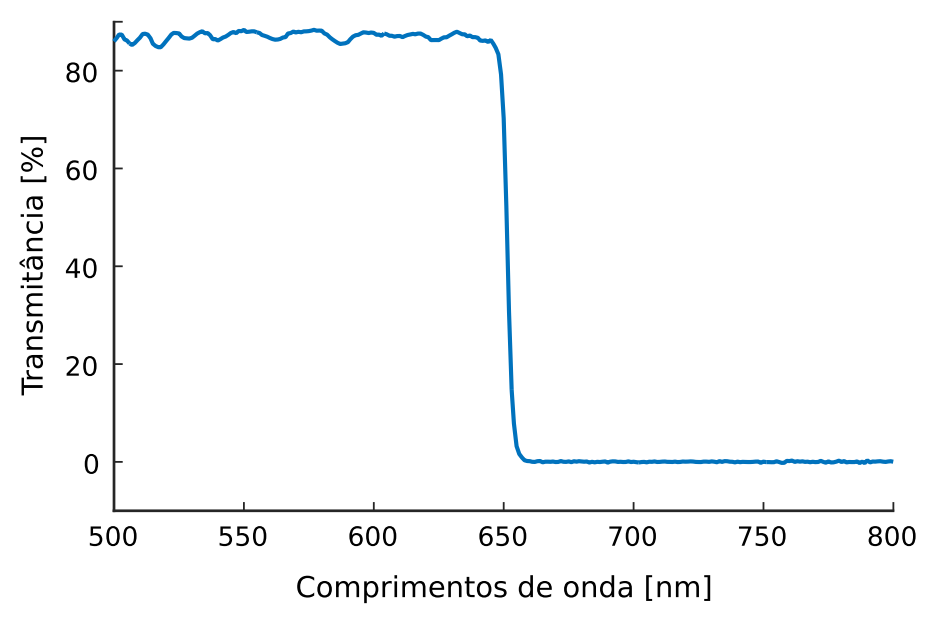

Fonte: elaborada pelo autor.

Adicionando-se o filtro passa baixa de comprimento de onda de corte $\lambda_{c}=650 \mathrm{~nm}$ no porta-filtros, em série com algum dos filtros passa banda, no mesmo aparato experimental (Figura 10), é possível se analisar espectralmente a interferência da fonte de excitação com a possível óptica a ser utilizada. Nas figuras 13(a) e 13(b) se apresentam os gráficos da luz transmitida pelos filtros, para os casos: porta-filtros contendo o filtro passa baixa em série com o passa banda da Proteon, e porta-filtros contendo o filtro passa baixa em série com o passa banda da Thorlabs, respectivamente. Da mesma forma que anteriormente, ambas as figuras estão normalizadas pelo valor de pico da transmissão do laser pelo filtro passa banda da Thorlabs, Figura 11(b), para comparação.

Das figuras 13(a) e 13(b) é possível notar-se que, com a utilização do filtro passa banda da Thorlabs em série com o filtro passa baixa, pode se obter uma considerável atenuação da intensidade luminosa proveniente da fonte de excitação. A existência de uma intensidade de luz remanescente (pequeno pico em torno de $640 \mathrm{~nm}$ ) indica que haverá um incremento pequeno e constante (offset, do termo em inglês) no valor da intensidade final medida, ou seja, na fluorescência adquirida pela câmera.

A diferença espectral obtida entre os filtros da Proteon e da Thorlabs provavelmente se dá por conta dos valores de transmissão ligeiramente maiores daquele, para as regiões 
Figura 13: Curvas de transmissão do laser de $633 \mathrm{~nm}$ pelo filtro passa baixa de $650 \mathrm{~nm}$ (a) em série com o filtro passa banda de $700 \mathrm{~nm}$ da Proteon, e (b) em série com o filtro passa banda de $700 \mathrm{~nm}$ da Thorlabs, obtidas com $40 \mathrm{~ms}$ de tempo de integração, média de 10 amostragens, e filtradas.

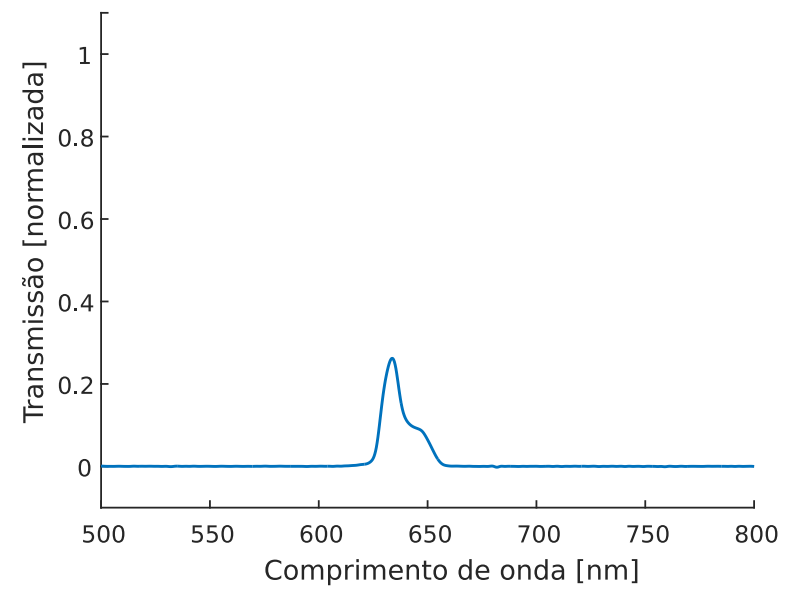

(a)

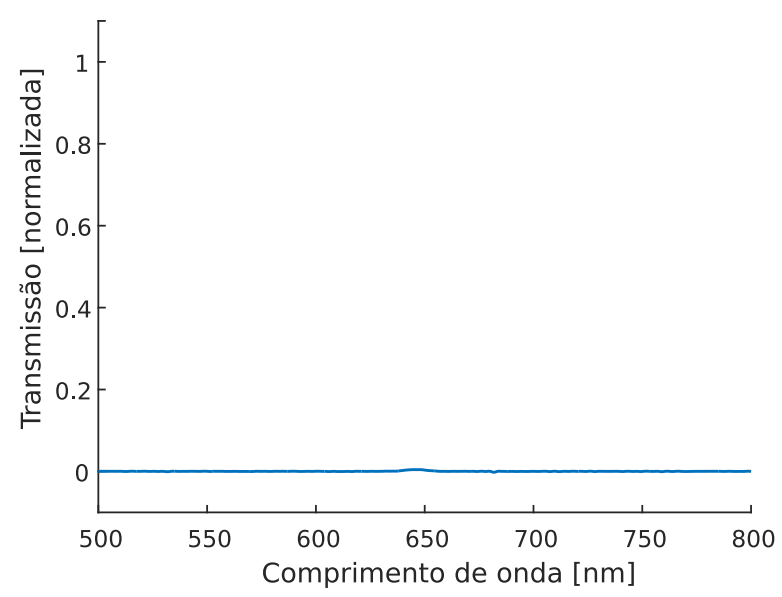

(b)

mais basais da curva de transmissão desses filtros. Na Figura 14 se apresenta a região inferior das curvas de transmissão dos filtros passa banda da Proteon e da Thorlabs, onde é possível se ver que os valores de transmissão do filtro da Proteon são ligeiramente maiores para a região entre $640 \mathrm{~nm}$ e $675 \mathrm{~nm}$, e para comprimentos de onda maiores que $736 \mathrm{~nm}$. Portanto, achou-se interessante utilizar o filtro óptico FB700-40 para integrar o projeto do sistema. Com a utilização dessa óptica, foi possível se obter imagens de fluorecência com bom contraste, as quais serão apresentadas no capítulo seguinte.

Figura 14: Comparação da transmitância dos dois filtros ópticos passa banda de $700 \mathrm{~nm}$ utilizados, da Proteon (linha azul), com $20 \mathrm{~nm}$ de FWHM, e da Thorlabs (linha alaranjada), com $40 \mathrm{~nm}$ de FWHM.

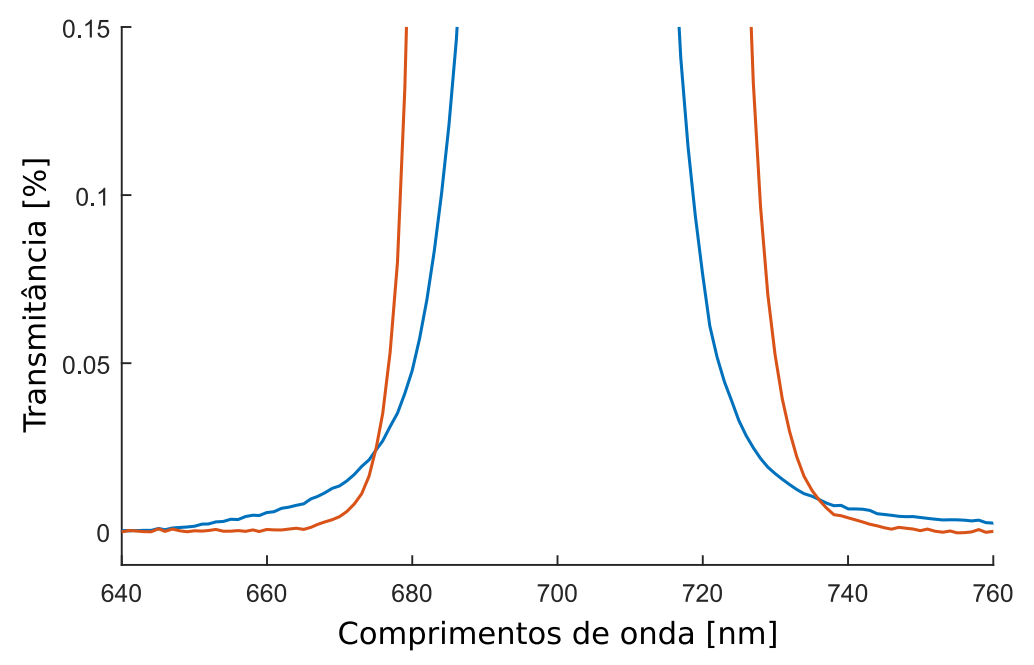

Fonte: elaborada pelo autor. 


\subsection{Construção do Protótipo}

Após se obter uma óptica capaz de medir a fluorescência de interesse, partiu-se para a construção do protótipo propriamente dito. O protótipo desenvolvido pode ser dividido em três partes fundamentais: parte de excitação, parte de detecção e parte elétrica. Na Figura 15 se apresenta um diagrama esquemático do protótipo, com cada uma de suas partes. A parte de excitação compreende o módulo laser, a fibra óptica, e o filtro óptico passa baixa. Já a parte de detecção compreende: fotodetector acoplado a fibra óptica, filtro óptico passa banda, jogo de lentes, câmera digital, e placa de aquisição. A parte elétrica, formada por 4 circuitos, compreende o circuito de controle de temperatura, o circuito de alimentação do laser, o circuito de fotodetecção, e o circuito de alimentação, o qual fornece energia a todos os demais. Nos tópicos seguintes serão destritas cada uma das partes, detalhadamente.

Figura 15: Diagrama esquemático do protótipo desenvolvido, contendo suas três partes fundamentais: de excitação, e de emissão, e elétrica.

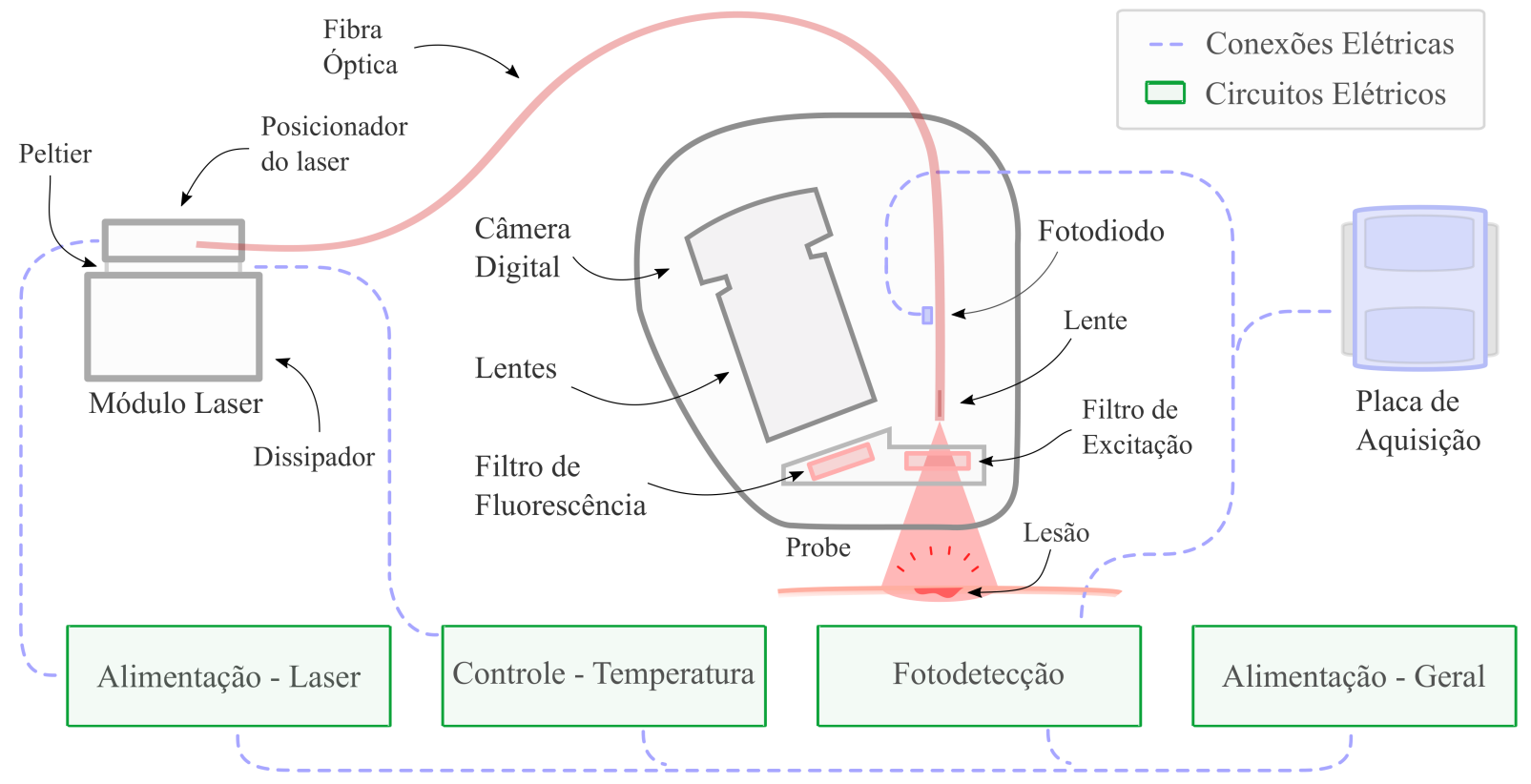

Fonte: elaborada pelo autor.

Buscando-se a portabilidade do sistema, a parte elétrica, a placa de aquisição, e o módulo laser foram dispostos em uma caixa preta de dimensões $30 \mathrm{~cm} \times 34 \mathrm{~cm} \times 8 \mathrm{~cm}$, como mostrada na Figura 16(a). O laptop mostrado na Figura 16(a) foi utilizado para controlar o sistema, via algorítimo escrito em Labview (National Instruments, EUA). Para adequar o sistema de imageamento às necessidades clínicas, uma ponta de prova foi projetada para acomodar: fibra óptica, filtros ópticos, lente objetiva, câmera digital, e fotodiodo. Pesando aproximadamente 460 gramas, e com dimensões de $10 \mathrm{~cm} \times 12 \mathrm{~cm} \times 7 \mathrm{~cm}$, a ponta de prova é leve, e de fácil manuseio, sendo fabricada via impressão 3D em poliácido láctico 
(PLA), um polímero biodegradável.

Figura 16: Fotografia (a) do sistema desenvolvido, com a ponta de prova, o laptop, e a caixa preta contendo a parte elétrica, o módulo laser e a placa de aquisição. À direita, também se mostra (b) a ponta de prova com seu porta-filtros removível, contendo o filtro de excitação e o filtro de fluorescência.

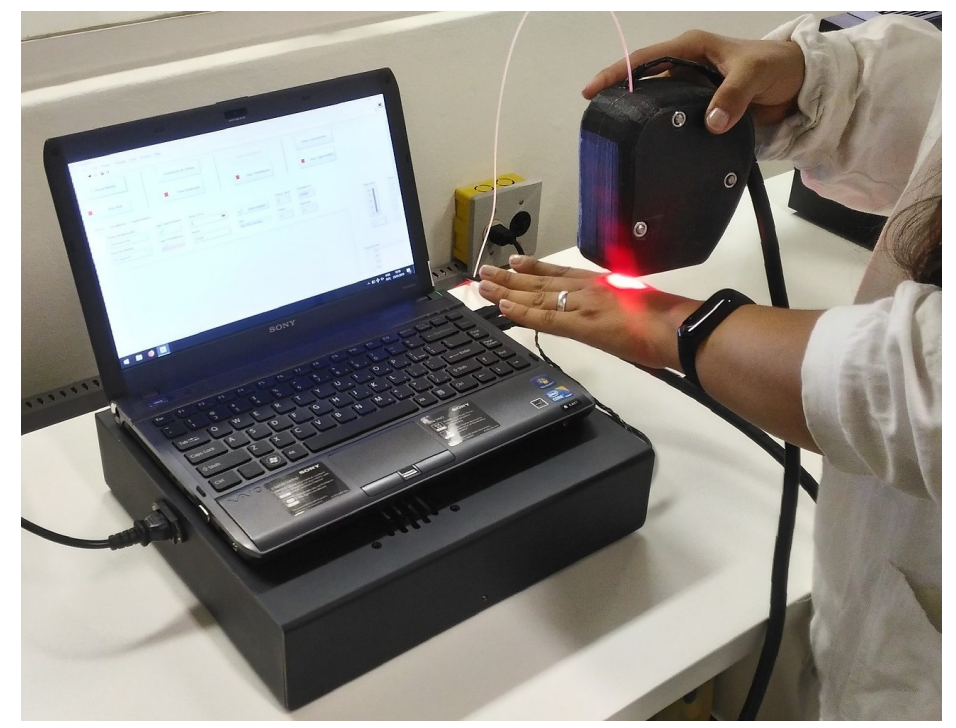

(a)

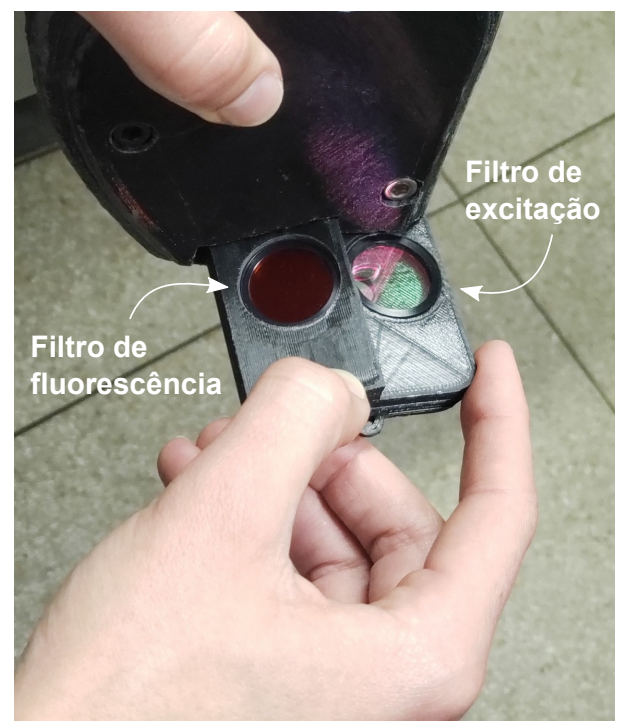

(b)

Fonte: elaborada pelo autor.

A ponta de prova também contém um porta-filtros removível (Figura 16(b)), capaz de acomodar o filtro de excitação e o filtro de fluorescência, dotado de uma pequena alça para possibiliar a troca dos filtros. Para o imageamento da fluorescência, a câmera digital foi posicionada de maneira a manter, em seu campo de visão, todo o spot óptico que irá atingir a lesão a ser tratada. Para tanto, posicionou-se o eixo da lente objetiva (que atinge a parte central do detector da câmera) à 20 graus do eixo da fibra óptica (como se pode ver pelo projeto mecânico da ponta de prova, disposto no Apêndice A).

\subsubsection{Parte de Excitação}

A parte de excitação é dedicada a excitar a molécula de PpIX, tanto para realização da TFD, quanto para produção da fluorescência que será sensoreada. Essa parte compreende o módulo laser, a fibra óptica (FD1-1646, Medlight, Suíça), e o filtro óptico passa baixa $\left(\lambda_{c}=650 \mathrm{~nm}\right)$, ou filtro de excitação, como mostrado esquematicamente na Figura 17. A fibra óptica utilizada é própria para aplicações médicas, possuindo um núcleo de $600 \mu \mathrm{m}$ de diâmetro, e uma microlente em sua ponta (Figura 17), para produzir um spot óptico circular e de intensidade homogênea em sua saída. A homogeneidade do spot óptico permitirá a entrega de uma dose de luz homogênea no tecido a ser tratado. 
Figura 17: Desenho esquemático da parte de excitação, compreendendo o módulo laser, a fibra óptica, e o filtro de excitação.

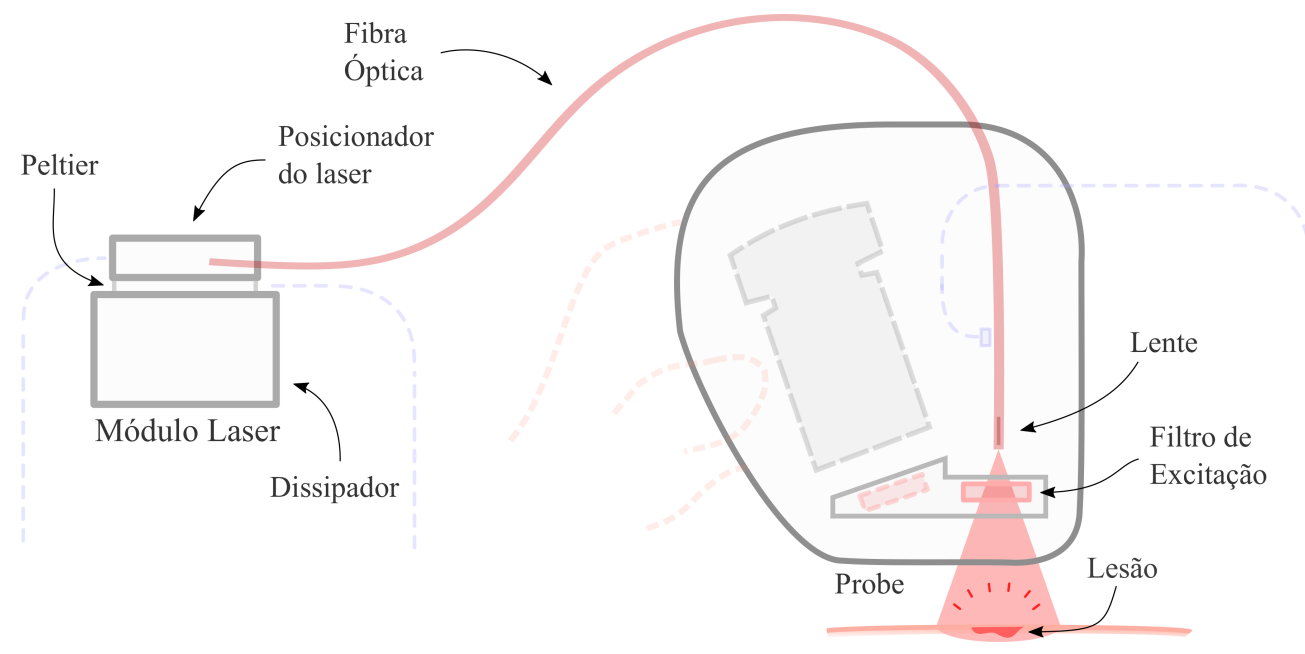

Fonte: elaborada pelo autor.

\subsubsection{Módulo Laser}

O módulo laser foi concebido para se manter a temperatura do laser constante ao longo de sua utilização. Baseado no laser de diodo encapsulado descrito anteriormente (WSLD-635-001-2, WaveSpectrum, China), o módulo laser é composto por uma estrutura metálica contendo o laser, uma célula Peltier, e um dissipador térmico, sendo eles conectados termicamente entre si, como disposto na Figura 18. A estrutura de alumínio que acomoda o laser é própria para o encapsulamento TO5 de $9 \mathrm{~mm}$, e acopla a luz emitida por ele à fibra óptica via conector SMA. Apesar de não se utilizar lentes para acoplar luz à fibra, como a fibra utilizada possui um núcleo de 600 um de diâmetro, foi possível se obter bom acoplamento óptico diminuindo-se a distância entre a saída do diodo laser e a entrada do conector SMA. Para se sensorear a temperatura do diodo encapsulado, um furo lateral foi extrudado até uma distância de aproximadamente $1 \mathrm{~mm}$ do diodo, onde um termistor foi posicionado.

A célula Peltier é utilizada para drenar o calor de sua parte fria, conectada à estrutura metálica contendo o laser, para sua parte quente, conectada ao dissipador de calor. O dissipador, por sua vez, é composto por uma parte metálica com várias aletas, conectada à uma ventoinha convencional (Figura 18). Na face metálica em contato com a célula Peltier, o dissipador possui uma camada de cobre, para diminuir a resistência térmica dessa região.

\subsubsection{Parte de Detecção}

A parte de detecção é dedicada a estimar a intensidade óptica propagada na fibra, e a sensorear a fluorescência emitida pela lesão. Apresentada esquematicamente na Figura 19, 
Figura 18: Módulo laser, composto pela estrutura metálica que contém o laser, a célula Peltier, e um dissipador metálico acoplado à uma ventoinha.

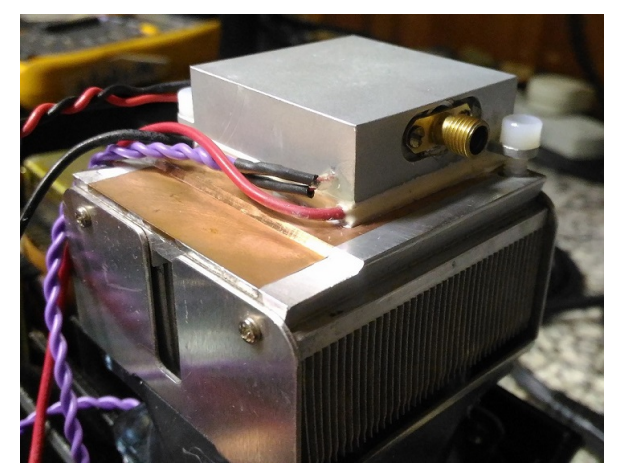

Fonte: elaborada pelo autor.

essa parte é composta por: fotodiodo, placa de aquisição, filtro óptico passa banda (FB70040, Thormlabs, EUA), lente objetiva, e câmera digital (DCC-1545M, Thorlabs, EUA). Neste projeto, utilizou-se o fotodiodo de silício BPW 34, rápido e sensível o bastante para a presente aplicação. O fotodiodo é conectado ao circuito de fotodetecção, que calcula a intensidade luminosa experimentada pelo fotodiodo. O sinal de saída do circuito de fotodetecção é adquirido pela placa de aquisição, processado e salvo pelo computador.

Figura 19: Desenho esquemático da parte óptica de detecção, compreendendo o fotodetector acoplado à fibra óptica, a placa de aquisição USB-6008, o filtro óptico passa banda de $700 \mathrm{~nm}$, a objetiva e a câmera digital.

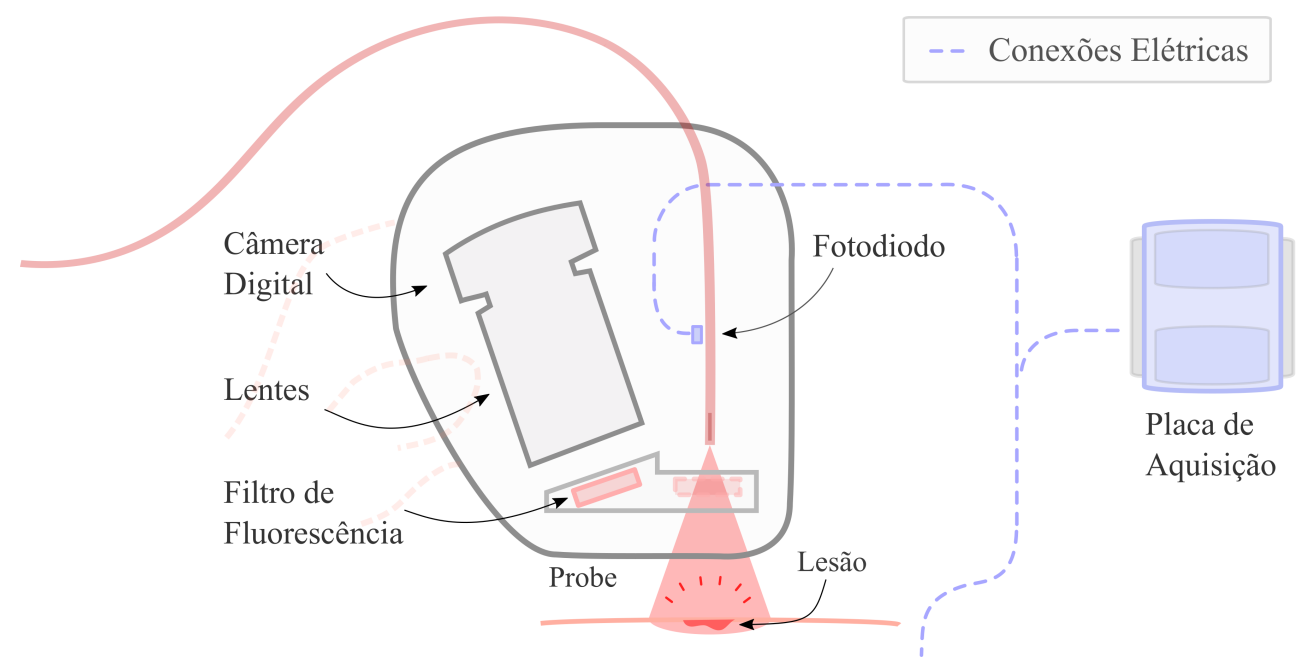

Fonte: elaborada pelo autor.

A placa de aquisição utilizada neste trabalho foi a USB-6008 (National Instruments, EUA), mostrada esquematicamente na Figura 20, juntamente com seu diagrama de pinos. Em suas entradas analógicas, a USB-6008 possui 12 bits de resolução, divididos em faixas de tensão controláveis. Apesar de sua tensão máxima de entrada ser de $\pm 10 \mathrm{~V}$ para suas 
entradas diferenciais (podendo se utilizar de 0 a $20 \mathrm{~V}$, ou de 0 a $-20 \mathrm{~V}$ ), essa placa possui um amplificador de ganho programável, possibilitando que seus 12 bits de resolução sejam divididos em faixas de tensão menores. Como os sinais medidos neste trabalho se deram entre $-10 \mathrm{mV}$ e $600 \mathrm{mV}$, programou-se essa placa para distribuir seus bits de resolução nessa faixa de tensão. A USB-6008 possui uma taxa de amostragem máxima de $10 \mathrm{kS} / \mathrm{s}$, divididas em suas 8 portas analógicas. Tendo em vista que somente uma entrada diferencial foi utilizada, a taxa de amostragem resultante foi mais do que o suficiente para se medir os sinais provenientes do circuito fotodetector.

Figura 20: Desenho esquemático da placa de aquisição USB-6008, com seu diagrama de pinos.

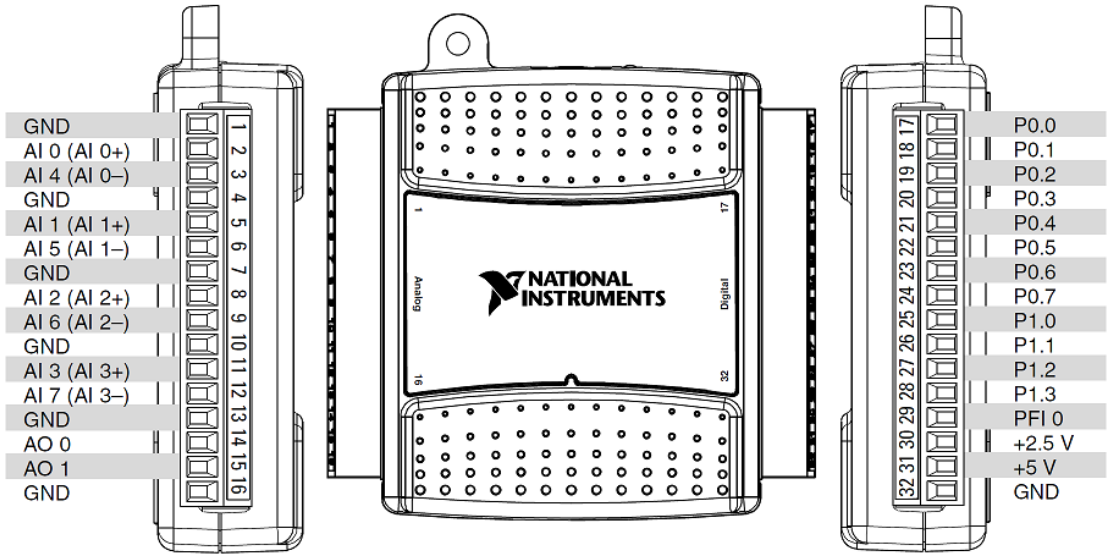

Fonte: National Instruments.

O filtro óptico de fluorescência utilizado foi do tipo passa banda, centrado em 700 nm, com 40 nm de FWHM (FB700-40, Thorlabs, EUA). A câmera digital utilizada foi a DCC-1545M (Thorlabs, EUA), cujas especificações mais importantes para o presente trabalho estão dispostas na Tabela 1. Dentre essas especificações, é interessante se citar a eficiência quântica dessa câmera na detecção de fótons com comprimento de onda de $700 \mathrm{~nm}$, que é de 46\%. Considerando-se essa eficiência quântica para a aquisição de imagens de fluorescência na região de interesse, nota-se que a DCC-1545M possui um custo significativamente reduzido (US\$ 377) em comparação com as câmeras científicas utilizadas nos trabalhos em que se reportou a detecção dessa mesma fluorescência (FISCHER et al., 2001; LAROCHELLE et al., 2017; ROBERTS et al., 2018)

\subsubsection{Parte Elétrica}

Em sua parte elétrica, o protótipo é composto por quatro circuitos principais: o circuito de controle de temperatura do laser, o circuito de alimentação do laser, o circuito de fotodetecção, e o circuito de alimentação geral. Os tópicos a seguir descrevem cada uma das partes separadamente. 
Tabela 1: Especificações da câmera DCC1545-M (Thorlabs, EUA).

\begin{tabular}{lc}
\hline Especificação & Descrição \\
\hline Tecnologia do sensor & CMOS \\
\hline Profundidade de píxel & 8 bits \\
\hline Eficiência quântica à $700 \mathrm{~nm}$ & $46 \%$ \\
\hline Resolução & 1280 x 1024 pixels (1,31 Megapixel) \\
\hline Tamanho do pixel & $5,20 \mu \mathrm{m}$, quadrado \\
\hline Modelo do sensor & MT9M001 (monocromático) \\
\hline Dimensões do sensor (mm) & USB mini-B \\
\hline Conexão com computador & 5 a 43 \\
\hline Range de pixel clock (MHz) & 1,016 a 25,015 \\
\hline Range de quadros por segundo (fps) & 0,037 a 983,948 \\
\hline Range de tempo de exposição (ms) &
\end{tabular}

Fonte: elaborada pelo autor.

\subsubsection{Circuito de Alimentação Geral}

O circuito de alimentação geral utilizado neste equipamento é uma fonte linear baseada no regulador de tensão LM338K. Seu diagrama esquemático se encontra no Apêndice A, juntamente com os demais circuitos. As fontes de alimentação lineares são volumosas, pesadas, e possuem uma baixa eficiência energética, quando comparadas com as fontes chaveadas. Entretanto, as fontes lineares possuem importantes vantagens, como: baixa regulação de carga e de linha, baixa ondulação residual, e, principalmente, baixo nível de ruido harmônico. Essas vantagens se tornam bem evidentes em aplicações sensíveis às variações de tensão e corrente, como é o caso de equipamentos médicos que utilizam laser de diodo encapsulado.

Para proteção, dois fusíveis de 7 A foram utilizados na entrada elétrica do sistema, onde se previu a conexão com a rede na tensão de 127 V RMS (do termo em inglês, Root Mean Square). Na sequência dos fusíveis, a tensão de entrada de 127 V RMS foi conectada à entrada do circuito de alimentação. Tendo em vista as altas correntes necessárias ao controle de temperatura, e à alimentação do laser, buscou-se dispositivos que suportassem esse nível de corrente. Para tanto, utilizou-se diodos GI820 nas pontes de retificação, os quais suportam uma corrente elétrica de até $5 \mathrm{~A}$ quando polarizados diretamente, seguidos de reguladores de tensão LM338K, os quais também suportam até 5 A de corrente elétrica, com um encapsulamento TO-3, que prevê dissipação.

Como o LM338K é um regulador essencialmente positivo, para se fornecer uma 
regulação simétrica de $12 \mathrm{~V}$ (positiva e negativa com relação à referência), fez-se necessário utilizar duas regulações distintas, para só depois, na saída das mesmas, torná-las dependentes. Para tanto, necessitou-se de dois transformadores, duas pontes de diodos, cada uma conectada à um regulador distinto, formando um circuito de dois braços. Para que um braço forneça a tensão positiva, e o outro forneça a tensão negativa, conectou-se a referência de um dos braços à tensão regulada do outro, de modo a formar a referência final do circuito (ou seja, a referência da tensão simétrica) (Apêndice A). Apesar dessa técnica necessitar de dois transformadores e duas pontes de diodos, a mesma foi necessária para a utilização do LM338K para a geração de uma tensão regulada simétrica, sendo esse um dispositivo que suporta elevadas correntes.

\subsubsection{Alimentação do Laser}

O circuito de alimentação do laser é dedicado fornecer uma corrente elétrica estável e controlada de até 1,6 A ao laser de diodo. Sendo uma fonte híbrida, esse circuito é capaz de fornecer corrente tanto à diodos com ânodo aterrado, quanto à diodos de cátodo aterrado, bastando alterar o tipo de transistor utilizado, e as conexões entre os nós de nome: PAD1, PAD2, PAD3, e PAD4 (Apêndice A). Como o diodo laser utilizado neste projeto não possui carcaça aterrada, qualquer um dos casos pode ser utilizado. Optando-se pela utilização da configuração cátodo aterrado, fez-se necessário conectar o PAD1 no PAD2, o PAD4 na alimentação positiva $(+12 \mathrm{~V})$, e utilizar um transistor do tipo NPN no braço de potência (TIP122). Dessa maneira, uma corrente elétrica é drenada da alimentação positiva para a referência, passando pelo diodo laser, pelo resistor de referência, e pelo resistor R7. Para dissipação da potência térmica gerada no transistor, utilizou-se um dissipador de alumínio contendo várias aletas, juntamente à uma ventilação mecânica forçada por uma ventoinha.

Tanto o resistor R7 quanto o resistor de referência possuem uma baixa resistência $(1 \Omega)$, para dissipar pouca potência, um baixo coeficiente térmico $\left(100 \mathrm{ppm} /{ }^{\circ} \mathrm{C}\right)$, além de um dissipador metálico, para arrefecimento. O resistor de referência serve para realimentar o circuito de polarização do transistor, fechando a malha do sistema de controle, por isso se faz necessário que sua resistência seja aproximadamente constante com a variação de temperatura. Para a tensão de referência, utilizou-se o LM4140, um circuito integrado capaz de fornecer uma tensão de referência com alta precisão, com uma baixa queda de tensão. A regulação de linha máxima desse circuito integrado é de 250 ppm, a regulação de carga máxima é de $150 \mathrm{ppm}$, e seu coeficiente térmico máximo é de $10 \mathrm{ppm} /{ }^{\circ} \mathrm{C}$.

\subsubsection{Controle de Temperatura}

O circuito de controle de temperatura proporciona um controle PID (proporcional, integrador e derivativo) da temperatura do laser, utilizando-se um termistor, localizado à aproximadamente $1 \mathrm{~mm}$ do diodo laser, e uma célula Peltier para retirar calor do mesmo. 
Esse circuito, apresentado esquematicamente no Apêndice A, baseia-se na utilização do AMP01, um amplificador de instrumentação de alta precisão e baixo ruído, cuja tensão de referência é fornecida por um LM4140.

Para seu funcionamento, primeiramente escolhe-se a temperatura de ajuste $\left(T_{\text {ajuste }}\right)$, que é o valor final de temperatura na qual o laser irá operar. O circuito de controle, então, irá trabalhar para manter esse valor de temperatura no laser de maneira estável. Em termos de circuito, esse ajuste de temperatura é feito por meio do ajuste da resistência de um potenciômetro (R31, no diagrama esquemático do Apêndice $\mathrm{A}$ ), posicionado em paralelo com o termistor. Sendo o termistor e o potenciômetro conectados na entrada do AMP01, a diferença entre a resistência dos mesmos entra como sinal de realimentação da malha de controle. O resultado dessa comparação é submetido à um ganho PID, gerado por 3 amplificadores operacionais nas configurações: proporcional, integrador e derivativo, sendo esses ganhos somados para compor o sinal de controle que será aplicado à célula Peltier.

O braço de potência do circuito recebe o sinal de controle, proveniente do controlador PID, amplifica a potência do mesmo, e aplica-o na célula Peltier, a qual irá atuar na temperatura do laser, de modo à controlá-la para o valor $T_{\text {ajuste }}$. Para tanto, são utilizados dois transistores de potência na configuração Darlington: TIP122, e TIP127, conectados à alimentação positiva, e à negativa, respectivamente. Como a célula Peltier pode drenar até $4 \mathrm{~A}$ de corrente elétrica, fez-se necessária a utilização de um dissipador de potência nos transistores. Além do dissipador de alumínio, forçou-se uma ventilação mecânica nos mesmos através da ventoinha descrita na seção anterior, a qual ficou dividida entre o circuito de controle de temperatura, e o circuito de alimentação do laser.

\subsubsection{Circuito de Fotodetecção}

O circuito de fotodetecção é dedicado à condicionar o sinal proveniente do fotodiodo, para que o mesmo seja medido pela placa de aquisição (USB-6008, National Instruments, EUA). Baseado na configuração integradora do amplificador operacional LM741, esse circuito é do tipo transimpedância, produzindo uma saída de tensão linear com a variação da corrente elétrica de entrada, obtida nos terminais do fotodiodo analisado. A sinal de saída gerado é diretamente conectado à placa de aquisição, a qual envia os dados medidos ao software de controle.

\subsubsection{Controle via Software}

Utilizando-se a plataforma Labview (National Instruments, EUA), foi possível se desenvolver um algoritmo para se controlar a placa de aquisição (USB-6008), a câmera digital (DCC-1545M), e um espectrômetro USB2000 (OceanOptics, EUA), quando utilizado. O algoritmo possui uma interface gráfica amigável ao usuário (Figura 21), e pode se dividir 
em 4 módulos principais: módulo de teste do fotodetector, módulo de teste do espectrômetro, módulo de visualização da câmera e escolha de seus parâmetros de aquisição, e módulo de medida. Na Figura 22 se apresenta um fluxograma para descrever, em forma resumida, o funcionamento do algoritmo desenvolvido.

Nos módulos de teste, o usuário pode controlar os parâmetros de aquisição dos dados. Para o teste do fotodetector, por exemplo, pode se controlar a taxa de amostragem do circuito de fotodetecção. Já para o teste do espectrômetro, pode-se controlar, por exemplo, o tempo de integração da medida, e o número de medidas utilizadas para compor um espectro final médio. No módulo de visualização da câmera, pode ser realizada uma primeira visualização das imagens a serem adquiridas. Nesse módulo, o usuário pode ligar a câmera, iniciar a visualização, adquirir imagens, salvá-las em sua pasta de preferência, além de alterar parâmetros de aquisição. É interessante se notar que, a escolha dos parâmetros de aquisição desse módulo são utilizados para alimentar o módulo de medida em suas medições futuras. Os parâmetros escolhidos pelo usuário no módulo de visualização são: tempo de exposição do sensor, quadros por segundo, e clock do píxel.

O módulo de medida é dedicado ao controle do aparato durante a realização de um experimento, ou durante a terapia fotodinâmica. Além de coletar e salvar os dados medidos, esse módulo apresenta os gráficos de cada sinal medido, além da imagem de fluorescência adquirida em cada instante, como mostrado na Figura 21. Antes de cada medida, deve-se escolher qual o tipo de tempo de exposição será utilizado, e qual o passo entre cada medida. Para o tipo do tempo de exposição, o programa oferece duas opções: exposição fixa, e exposição variável. Para ambos os casos, os parâmetros utilizados para a aquisição das imagens são sempre os últimos parâmetros escolhidos pelo módulo de visualização da câmera. No caso da exposição variável, o valor do tempo de exposição é alterado a cada medida, de acordo com as necessidades de cada imagem. O cálculo dessa grandeza é realizado medindo-se o número de pixeis saturados, e o maior valor de intensidade de pixel, em cada imagem, para diferentes tempos de exposição, até se encontrar um tempo de exposição otimizado. 


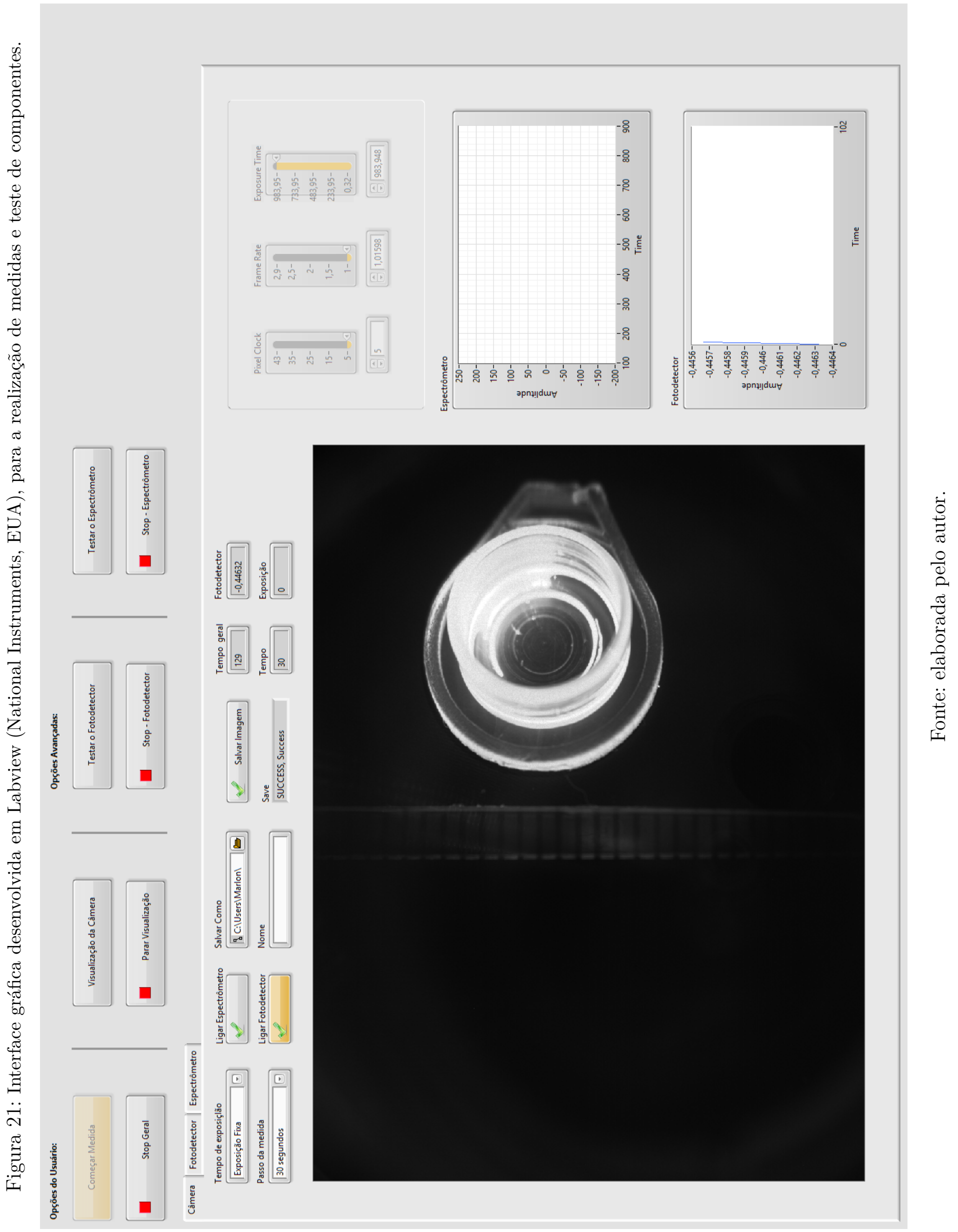


Figura 22: Fluxograma do algoritmo desenvolvido em Labview (National Instruments, EUA) para controle do sistema, contemplando a seus quatro módulos.

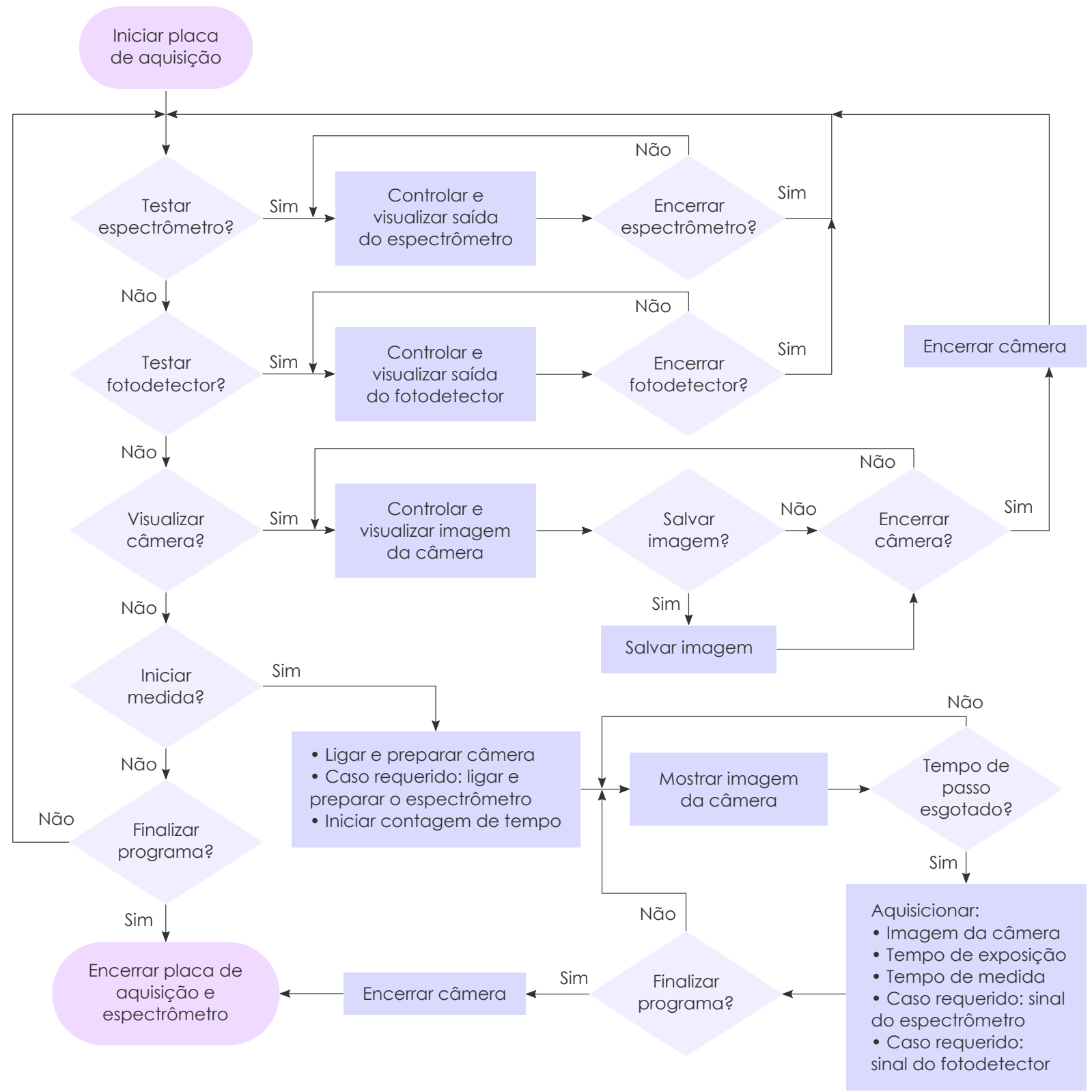

Fonte: elaborada pelo autor. 


\section{CARACTERIZAÇÃO E EXPERIMENTAÇÃO}

\subsection{Metodologia}

\subsubsection{Caracterização do Sistema}

Montado o sistema, buscou-se fazer a caracterização da linearidade e da sensibilidade do sistema. Para tanto, o protótipo foi utilizado para se medir a intensidade de fluorescência de diferentes concentrações de protoporfirina-IX. Procurou-se simular o monitoramento de uma lesão de pele sob tratamento fotodinâmico, portanto a solução de PpIX a ser medida foi posicionada no interior de um phantom óptico feito para se mimetizar o espalhamento de luz da pele humana. O phantom óptico, do tipo líquido, foi preparado com $99 \%$ de água deonizada, e $1 \%$ de Lipofundin MCT/LCT 20 \% (B.Braun Melsungen AG, Alemanha), uma emulsão lipídica com elementos prioritariamente espalhadores.

Para esse experimento, colocou-se a ponta de prova quase em contato com o phantom a ser medido, como mostrado no diagrama esquemático da Figura 23. No interior do phantom, posicionou-se um pequeno tubo de teste (aproximadamente $4 \mathrm{~mm}$ de diâmetro externo) contendo a solução de PpIX, de modo a formar um ângulo $\alpha=46^{\circ}$ com a superfície inferior e superior do phantom (Figura 23). Posicionado o tubo de teste, utilizou-se o sistema para excitar o phantom à uma irradiância de aproximadamente $50 \mathrm{~mW} / \mathrm{cm}^{2}$, coletando-se imagens de fluorescência para as diferentes soluções de PpIX a serem medidas. As soluções de PpIX foram todas dissolvidas em DMSO (dimetilsulfóxido ou sulfóxido de dimetilo), varrendo-se concentrações desde $50 \mathrm{nM}$ à $20 \mu \mathrm{M}$.

\subsubsection{Experimento em Phantom}

Um experimento em phantom óptico foi realizado, buscando se simular a utilização do protótipo para o tratamento e monitoramento da terapia fotodinâmica de uma lesão de pele. Nesse experimento, o protótipo foi utilizado para irradiar o phantom com a iluminação de tratamento, e adquirir imagens de fluorescência durante o período de irradiação. Mantendo-se o phantom quase em contato com a ponta de prova, como realizado no experimento de caracterização (Figure 23), aplicou-se uma irradiância de aproximadamente $115 \mathrm{~mW} / \mathrm{cm}^{2}$. As imagens de fluorescência foram adquiridas de $30 \mathrm{em}$ 30 segundos. Para o cálculo da intensidade de fluroescência, integrou-se a intensidade dos pixeis em uma região de interesse (ROI, do termo em inglês, region of interest), na parte central do phantom, dividindo-se o valor integrado pelo número de pixeis.

Buscando se mimetizar as propriedades ópticas da pele humana, utilizou-se um phantom de agar de $30 \mathrm{~mL}$, contendo $2 \%$ de Lipofundin ${ }^{\circledR}$ MCT/LCT $20 \%$ (B. Braun Melsungen AG, Alemanha), que é predominantemente espalhador, e 0,017\% de Nankin 
Figura 23: Desenho esquemático do setup óptico para a caracterização da linearidade e da sensibilidade do sistema de medição, para diferentes concentrações de PpIX.

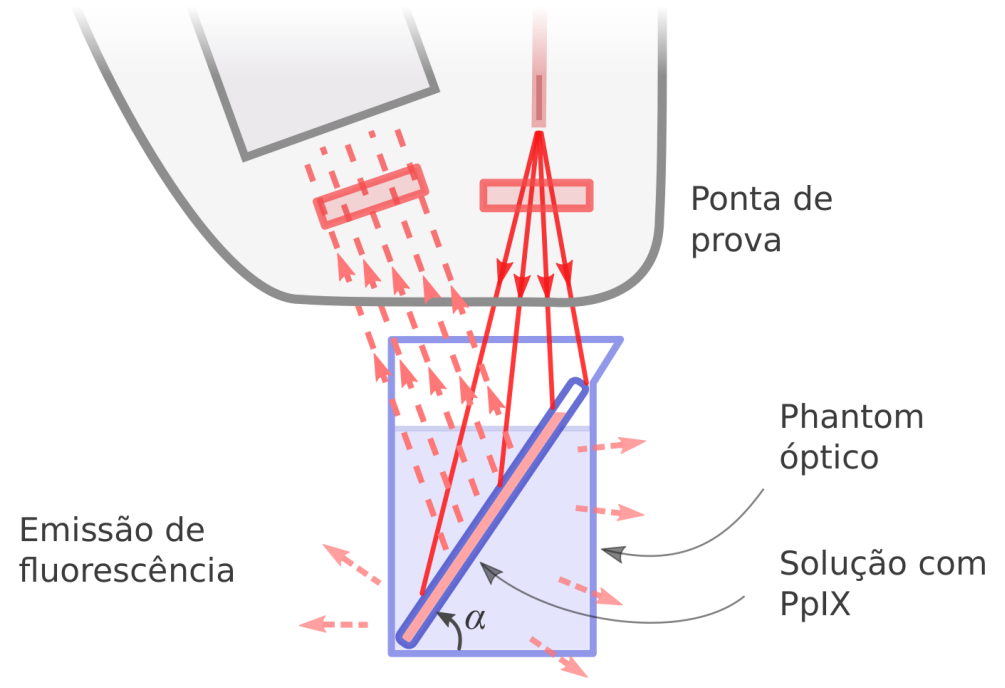

Fonte: elaborada pelo autor

(Trident, Brasil), predominantemente absorvedor, substâncias já utilizadas anteriormente na confecção de phantoms ópticos (ANDRADE et al., 2010; GERALDE et al., 2014). Para o feitio do phantom, utilizou-se $5 \%$ de Agar (A7002, from Sigma-Aldrich, EUA), em massa, e adicionou-se uma solução de PpIX dissolvida em DMSO, buscando-se uma concentração final de $20 \mu \mathrm{M}$ de PpIX no phantom.

\subsubsection{Modelo Animal}

Para o estudo em modelo alimal, seis camundongos fêmeas heterogênicos da linhagem balb/c, do tipo nude, foram utilizados. Dos seis caumdongos, dois foram utilizados em um teste piloto, e quatro foram utilizados posteriormente, em um experimento mais detalhado. Sendo da linhagem balb/c, esses animais têm o sistema imunológico deficiente, o que permite estudos com tumores heterotransplantados. Primeiramente, para se induzir tumores xenográficos, uma injeção intradérmica contendo $10^{6}$ células da linhagem carcinoma espinocelular (CEC) (A-431 ATCC $^{\circledR}$ CRL-1555 ${ }^{\mathrm{TM}}$ ) foi aplicada no flanco do animal.

No estudo piloto, os tumores cresceram intradermicamente, ficando mais profundos na pele. Após atingirem um volume final maior do que $30 \mathrm{~mm}^{2}$, realizou-se a terapia fotodinâmica monitorada desses tumores. Por conta de seu crescimento intradérmico, o volume dos tumores não pode ser facilmente estimado. Para os quatro camundongos que compõem o estudo mais detalhado, a terapia fotodinâmica monitorada foi realizada após os tumores atingirem um volume de aproximadamente $30 \mathrm{~mm}^{2}$ (estimados com as medidas de um paquímetro, aplicadas ao volume de um elipsoide). Para todos os camundongos, o 
acúmulo de PpIX se deu com a utilização de metil-aminolevulinato (MAL), à concentração de $20 \%$, aplicado topicamente na região tumoral.

Nesse estudo, preferiu-se utilizar um protocolo padrão, em vez de um protocolo personalizado (que adapta-se em tempo real), para comparação com a literatura. Após um período de incubação do fármaco de uma hora, utilizou-se o sistema desenvolvido para fornecer a iluminação de tratamento, à irradiância de $50 \mathrm{~mW} / \mathrm{cm}^{2}$, durante aproximadamente 40 minutos, totalizando a entrega de $120 \mathrm{~J} / \mathrm{cm}^{2}$ de fluência. Durante o período de iluminação, coletou-se imagens de fluorescência da região iluminada, tanto com um sistema comercial já amplamente utilizado (LINCE, MMOptics, Brasil) (GRECCO et al., 2015), quanto com o sistema desenvolvido. O sistema comercial excita as moléculas de PpIX na banda de Soret, utilizando-se um LED de $407 \mathrm{~nm}$, à uma irradiância de aproximadamente $35 \mathrm{~mW} / \mathrm{cm}^{2}$, e oferece uma óptica para se visualizar a fluorecência emitida acima de $590 \mathrm{~nm}$. Já o protótipo, excita a lesão com um laser de $633 \mathrm{~nm}$, tanto para o tratamento, quanto para a coleta de sua fluorescência em torno de $700 \mathrm{~nm}$.

Como não é possível se adquirir imagens de fluorescência com o sistema comercial durante o período de iluminação, moveu-se o camundongo sob tratamento até o sistema comercial, a cada 4 minutos, para a aquisição das imagens de fluorescência. Nesse período, o camundongo não recebeu a dose de luz vermelha, de modo que, a cada 4 minutos, o animal ficava, em média, 45 segundos sem a iluminação de tratamento. Para a aquisição das imagens excitadas pelo equipamento comercial, acoplou-se uma câmera modelo DCC1545M (Thorlabs, Brasil) ao visor do mesmo. No caso do protótipo desenvolvido, colheu-se imagens de fluorescência a cada 15 segundos, juntamente com o sinal do fotodetector.

Para o cálculo da fluorescência, utilizou-se duas ROI's distintas, uma na região central do tumor, onde a fluorescência é mais bem comportada, e outra de maneira a se englobar toda a região tumoral. As imagens não foram pré-processadas, e suas intensidades de fluorescência foram medidas da integração do valor de intensidade dos pixeis no ROI escolhido, dividido pelo número de pixeis integrados. Dado que a concentração da PpIX é proporcional à sua fluorescência $([\mathrm{PpIX}] \propto F)$, pode se assumir que a fluorescência adquirida dos tumores é proporcional à sua concentração de PpIX na região. Como o fotobranqueamento da PpIX é reportado como um decaimento de duas fases (SHENG et al., 2007), utilizou-se a seguinte função biexponencial para se fitar o decaimento na fluorescência da PpIX:

$$
F(t)=F_{0 f} e^{-t / \tau_{f}}+F_{0 s} e^{-t / \tau_{s}}+I_{b g}
$$

no qual $F(t)$ é a intensidade de fluorescência para um dado tempo ( $t$, em segundos), $F_{0 f}$ e $F_{0 s}$ são as intensidades de fluorescência inicias do decaimento rápido e lento, respectivamente. Na equação 5.1, $I_{b g}$ é a intensidade do sinal de fundo adquirido (background), que 
representa, por exemplo a fluorescência de outras compostos endógenos, ou a intensidade de luz, proveniente da fonte de excitação, que é retroespalhada pela lesão e consegue atravessar o filtro de fluorescência. Dado que $\tau_{f}$ e $\tau_{s}$ são os tempos médios de decaimento rápido e lento, respectivamente, o tempo médio de decaimento total pode ser calculado da média entre essas duas grandezas, ponderada pelos valores de $F_{0 f}$ e $F_{0 s}$.

No caso do experimento piloto, a equação biexponencial não produziu um ajuste adequado para o decaimento da fluorescência excitada pelo vermelho. Dessa maneira, somente para o experimento piloto, optou-se por utilizar a seguinte equação monoexponencial para produzir a curva de ajuste do decaimento dessa fluorescência:

$$
F(t)=F_{0} e^{-t / \tau}+I_{b g}
$$

na qual $F(t)$ é a intensidade de fluorescência para um dado tempo ( $t$, em segundos), e $F_{0}$ a intensidade de fluorescência inicial.

Após a TFD, todos os animais foram eutanasiados. Imediatamente após a eutanásia, para o grupo de quatro camundongos, coletou-se uma biópsia do tumor, a qual foi congelada utilizando-se o composto Tissue-Tek ${ }^{\circledR}$ O.C.T. ${ }^{\text {тм }}$ (Sakura Finetek USA Inc, EUA), e mantida sob resfriamento à $-80^{\circ}$. Posteriormente laminou-se as amostras com ajuda de um criostato (Leica, CM1850, EUA), em espessuras de $30 \pm 1 \mu \mathrm{m}$. Para análise das lâminas, utilizou-se um microscópio confocal (LSM 780, Zeiss, Jena, Alemanha), excitando-se a amostra em $405 \mathrm{~nm}$, e coletando sua fluorescência em dois canais distintos: um para a emissão da PpIX (630 nm à $670 \mathrm{~nm})$, e outro para a fluorescência intrínseca do tecido (500 nm-600 nm). Na Figura 24 se apresenta o exemplo de um tumor analisado pelo confocal, onde se apresenta a imagem de fluorescência, superposta à imagem branca, para melhor visualização. Das imagens de microscopia, foi possível se obter a espessura média dos tumores $(w)$, e o valor médio da epiderme dos mesmos (e), como exemplificado na Figura 24.

\subsection{Resultados}

\subsubsection{Caracterização do Sistema}

As imagens adquiridas não foram pré-processadas, e a intensidade de fluorescência foi adquirida dos valores de intensidade dos pixeis. Em cada solução medida, o valor de intensidade de fluorescência foi obtido da parte central do tubo de teste, na região em que o tubo começa a ser imergido no phantom. Nessa região há um pequeno aumento no valor de fluorescência detectado (pequeno pico), por conta do espalhamento de luz do meio. Na Figura 25 se apresenta o gráfico obtido para a intensidade de fluorescência normalizada, por concentração de PpIX, em escala logarítmica. Também se apresenta nessa figura a curva de ajuste, obtida por meio de uma regressão linear utilizando-se o método dos mínimos quadrados. 
Figura 24: Imagem de fluorescência de uma das lâminas tumorais, superposta à sua imagem de transmissão, obtidas por microscopia confocal (LSM 780, Zeiss, Jena, Alemanha), excitada em $405 \mathrm{~nm}$, e coletada entre $630 \mathrm{~nm}$ e $670 \mathrm{~nm}$. As variáveis: $w_{1}, w_{2}, w_{3}, e_{1}, e_{2}$, e $e_{3}$ são exemplos de como foram extraídas as espessuras do tumor e da epiderme, respectivamente.

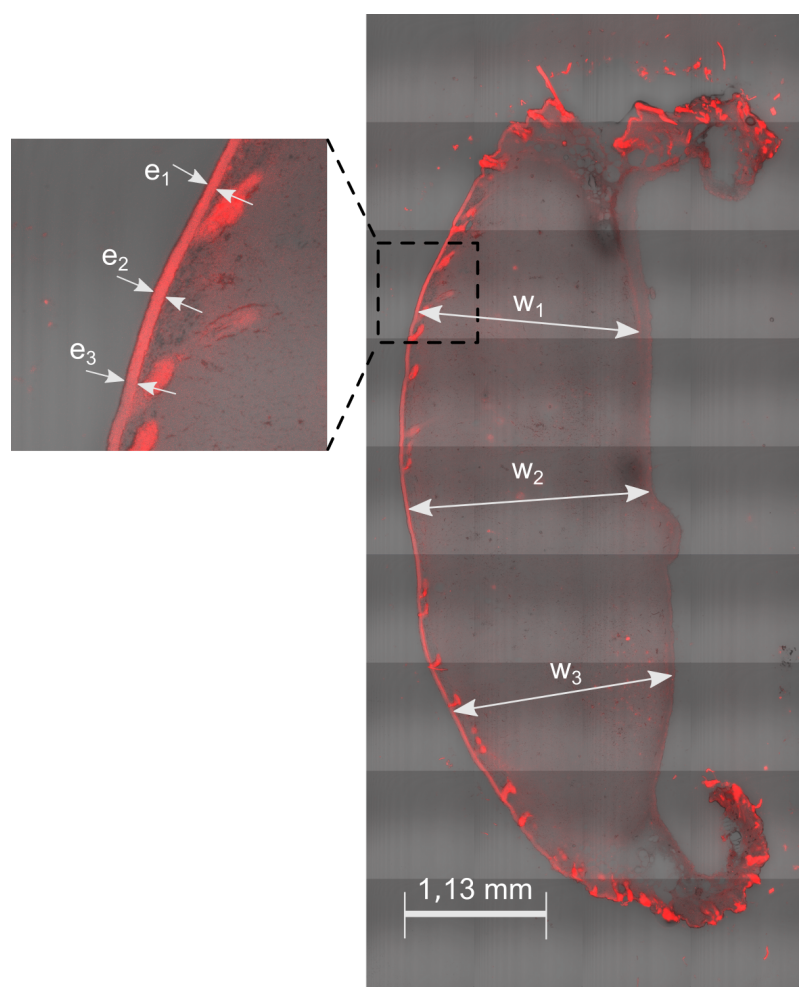

Fonte: elaborada pelo autor

Figura 25: Gráfico da intensidade de fluorescência normalizada, por concentração de PpIX, em escala logarítmica, considerando-se concentrações de PpIX de $50 \mathrm{nM}$ à $20 \mu \mathrm{M}$, juntamente com a curva de ajuste, calculada por regressão linear utilizando-se o método dos mínimos quadrados.

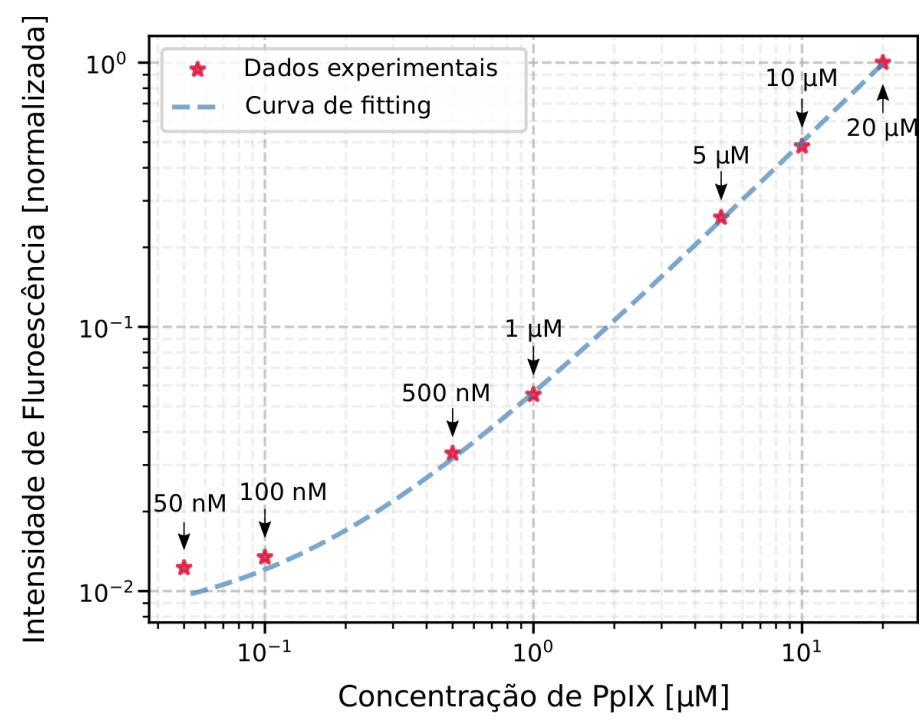

Fonte: elaborada pelo autor 
Os dados obtidos neste experimento apresentam alta linearidade (Figura 25), com um coeficiente de determinação, e um valor de probabilidade de: $r^{2}=0,9997$ e $p=1,95 \times 10^{-9}$, respectivamente, com respeito à curva de ajuste. Dos dados obtidos, pode se extrair o valor de sensibilidade do sistema, que é de 50, em unidades de intensidade de fluorescência normalizada, por nM de concentração de PpIX. Com relação ao limite de detecção, foi possível se observar, com bom contraste, soluções de até $500 \mathrm{nM}$ de concentração de PpIX, limiar de deteç̧ão também observado por LaRochelle et al. (2017), para a fluorescência calculada sem se considerar a fluorescência intrínseca da pele.

\subsubsection{Experimento em Phantom}

Procedendo-se como descrito na Seção 5.1.2, foi possível realizar a degradação da PpIX do phantom, obtendo-se as imagens de fluorescência da mesma. Na Figura 26 se apresentam alguns exemplos das imagens obtidas, apresentadas em uma escala de cores falsas, para diferentes valores de dose de luz entregue ao phantom. Da obtenção das intensidades de fluorescência das imagens, foi possível se obter a curva de degradação apresentada na Figura 27.

Figura 26: Imagens de fluorescência do phantom, obtidas para comprimentos de onda em torno de $700 \mathrm{~nm}$, para (a) 0, (b) $350 \mathrm{~J} / \mathrm{cm}^{2}$, (c) $1400 \mathrm{~J} / \mathrm{cm}^{2}$, e (d) $4470 \mathrm{~J} / \mathrm{cm}^{2}$ de dose de luz entregue na superfície do mesmo, à uma irradiância de $115 \mathrm{~mW} / \mathrm{cm}^{2}$.

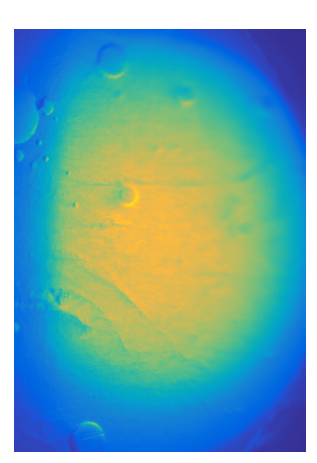

(a)

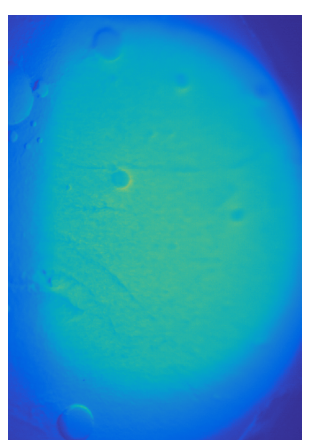

(b)

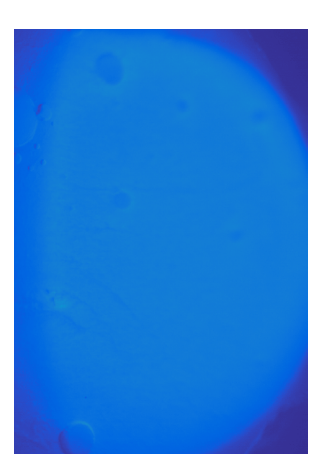

(c)

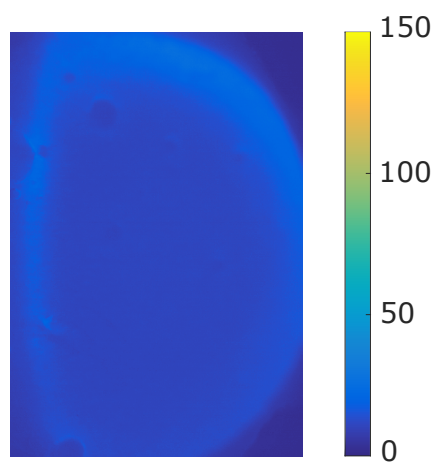

(d)

Fonte: elaborada pelo autor

\subsubsection{Modelo Animal}

\subsubsection{Teste Piloto}

Procedendo-se como descrito na Seção 5.1.3, foi possível se obter as imagens de fluorescência para os camundongos do teste piloto, tanto com o sistema comercial, quanto com o protótipo confeccionado. Na Figura 28 se apresentam as imagens de fluorescência adquiridas para a excitação violeta (aparelho comercial), e para a excitação vermelha (protótipo desenvolvido), obtidas no início, no meio, e ao final do tratamento, para o primeiro camundongo. Já na Figura 29 se apresentam, do mesmo modo, as imagens para 
Figura 27: Intensidade de fluorescência adquirida no experimento em phantom, por dose de luz entregue, obtida através de um ROI na região central das imagens de fluorescência.

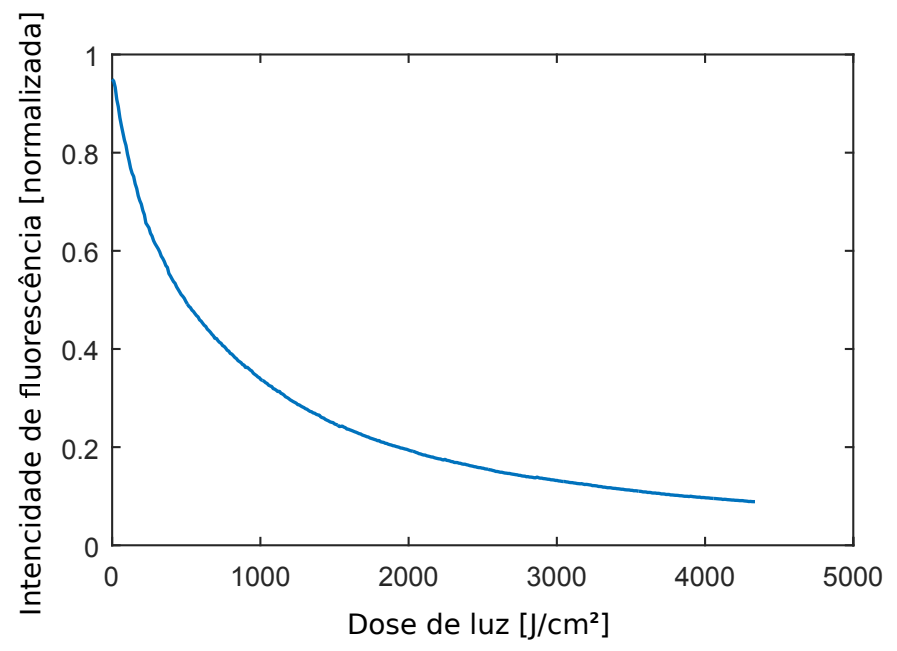

Fonte: elaborada pelo autor

o segundo camundongo tratado. Para fins comparativos, apresentam-se na Figura 30 as imagens obtidas ao final do tratamento, para ambas excitações, e para ambos camundongos. Como se pode observar dessa figura, mesmo ao final do período de irradiação, as lesões apresentaram considerável nível de fluorescência quando excitadas por comprimentos de onda vermelhos, mas níveis de fluorescência baixos ao serem excitadas pelo violeta.

Calculando-se a intensidade de fluorescência na ROI selecionada, para cada uma das imagens aquisicionadas, foi possível se obter as curvas de decaimento da fluorescência ao longo de todo o tratamento. Na Figura 31 se apresentam as curvas de decaimento, obtidas tanto pelo aparato desenvolvido quanto para o equipamento comercial, para o primeiro (figuras 31(a) e 31(c)), e para o segundo camundongo (figuras 31(b) e 31(d)), para uma ROI englobando toda a lesão (figuras 31(a) e 31(b)), e para uma ROI em sua região central (figuras 31(c) e 31(d)). Juntamente com os dados experimentais dessas curvas, também se mostram suas respectivas curvas de ajuste, obtidas pelo método dos mínimos quadrados, utilizando-se a Equação 5.2 para a fluorescência excitada no vermelho (decaimento monoexponencial), e a Equação 5.1 para a fluorescência excitada no violeta (decaimento biexponencial). Para a análise da fluorescência obtida sem a interferência do sinal de fundo, apresentam-se nas figuras 31(e) e 31(f) as curvas de ajuste obtidas para uma ROI englobando toda a lesão, decrescidas de seu termo $I_{b g}$, para o primeiro e para o segundo camundongo, respectivamente.

Através das curvas de ajuste para as intensidades de fluorescência, foi possível se obter os tempos médios de decaimento para a excitação violeta $\left(\tau_{v}\right)$ e para a excitação vermelha $\left(\tau_{r}\right)$, os quais estão apresentados na Tabela 2, para ambos os camundongos estudados no experimento piloto. Também se mostra nessa tabela a razão entre os tempos 
Figura 28: Imagens de fluorescência excitadas pelo protótipo desenvolvido, no vermelho, para (a) 0, (b) $77,6 \mathrm{~J} / \mathrm{cm}^{2}$, e (c) $152,8 \mathrm{~J} / \mathrm{cm}^{2}$ de dose de luz entregue; e excitadas pelo sistema comercial, no violeta, para (d) 0, (e) $77,6 \mathrm{~J} / \mathrm{cm}^{2}$, e (f) $152,8 \mathrm{~J} / \mathrm{cm}^{2}$ de dose de luz entregue, para o primeiro camundongo do teste piloto.

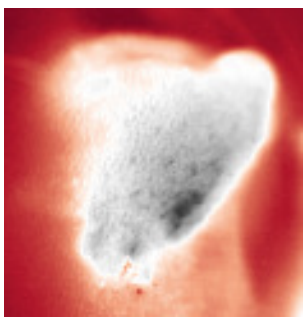

(a) $0\left[\mathrm{~J} / \mathrm{cm}^{2}\right]$

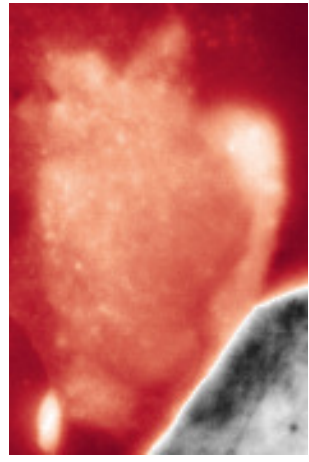

(d) $0\left[\mathrm{~J} / \mathrm{cm}^{2}\right]$

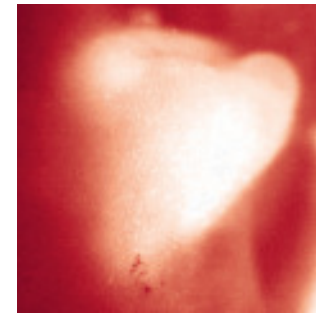

(b) $71,2\left[\mathrm{~J} / \mathrm{cm}^{2}\right]$

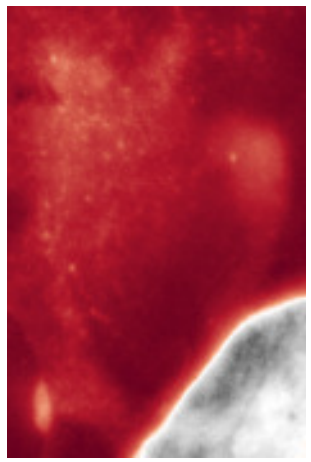

(e) $71,2\left[\mathrm{~J} / \mathrm{cm}^{2}\right]$

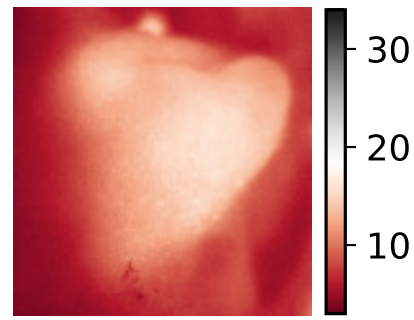

(c) $145,6\left[\mathrm{~J} / \mathrm{cm}^{2}\right]$

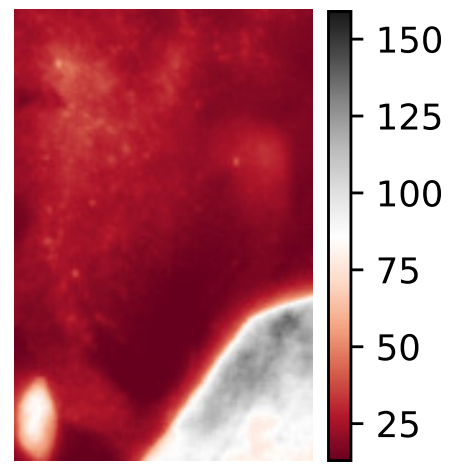

(f) $145,6\left[\mathrm{~J} / \mathrm{cm}^{2}\right]$

Fonte: elaborada pelo autor

Figura 29: Imagens de fluorescência excitadas pelo protótipo desenvolvido, no vermelho, para (a) 0, (b) $71,2 \mathrm{~J} / \mathrm{cm}^{2}$, e (c) $145,6 \mathrm{~J} / \mathrm{cm}^{2}$ de dose de luz entregue; e excitadas pelo sistema comercial, no violeta, para (d) 0 , (e) $71,2 \mathrm{~J} / \mathrm{cm}^{2}$, e (f) $145,6 \mathrm{~J} / \mathrm{cm}^{2}$ de dose de luz entregue, para o segundo camundongo do teste piloto.

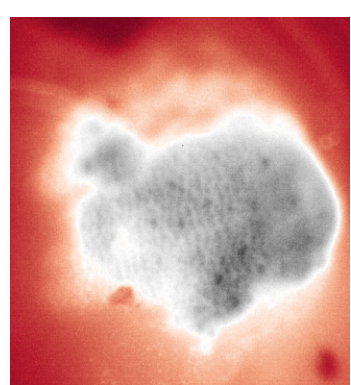

(a) $0\left[\mathrm{~J} / \mathrm{cm}^{2}\right]$

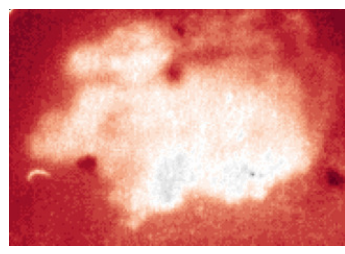

(d) $0\left[\mathrm{~J} / \mathrm{cm}^{2}\right]$

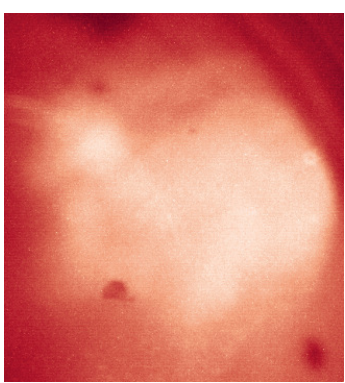

(b) $77,6\left[\mathrm{~J} / \mathrm{cm}^{2}\right]$

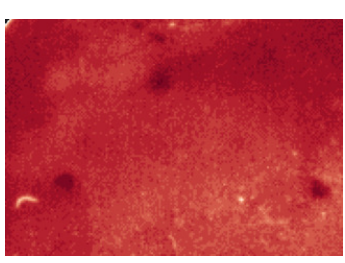

(e) $77,6\left[\mathrm{~J} / \mathrm{cm}^{2}\right]$

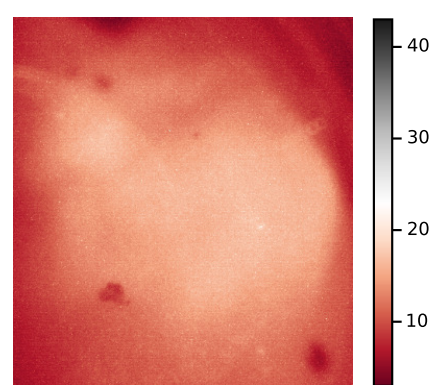

(c) $152,8\left[\mathrm{~J} / \mathrm{cm}^{2}\right]$

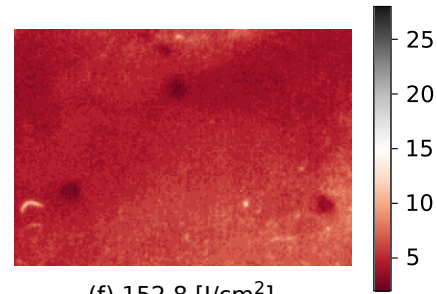

(f) $152,8\left[\mathrm{~J} / \mathrm{cm}^{2}\right]$

Fonte: elaborada pelo autor 
Figura 30: Imagens de fluorescência adquiridas ao final do tratamento, (a) com o equipamento comercial (excitação violeta) e (b) com o protótipo desenvolvido (excitação vermelha), para o primeiro camundongo; e (c) com o equipamento comercial (excitação violeta) e (d) com o protótipo desenvolvido (excitação vermelha), para o segundo camundongo.

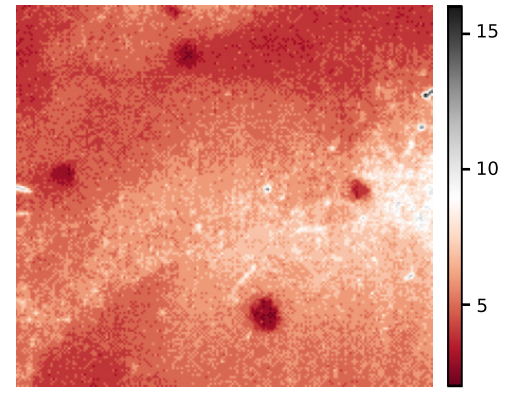

(a) Excitada pelo violeta

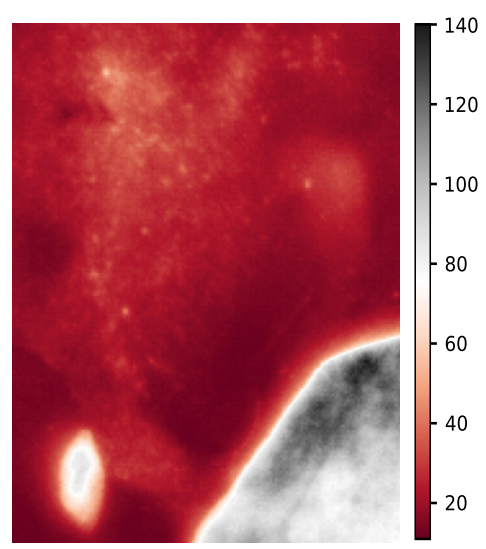

(c) Excitada pelo violeta

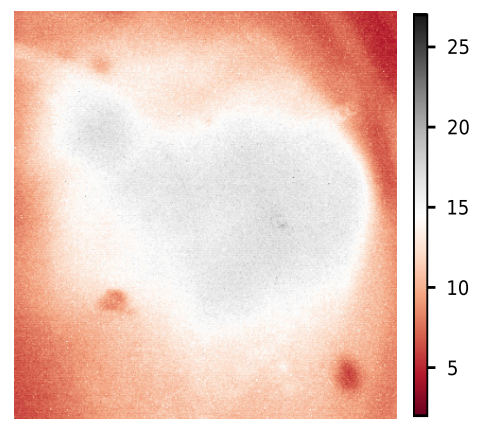

(b) Excitada pelo vermelho

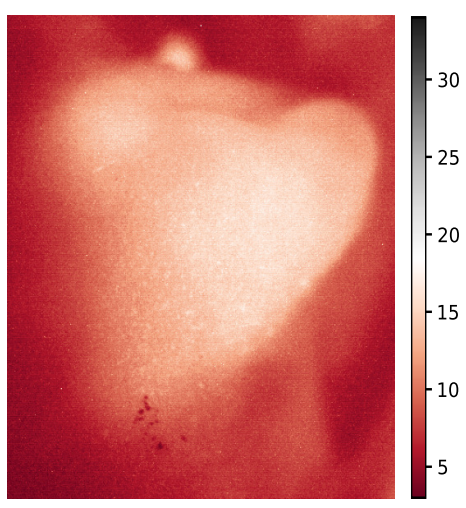

(d) Excitada pelo vermelho

Fonte: elaborada pelo autor

médios de decaimento do vermelho e do violeta $\left(\tau_{r} / \tau_{v}\right)$, para comparação.

Tabela 2: Tempo médio de decaimento para a fluorescência excitada no vermelho $\left(\tau_{r}\right)$, e no violeta $\left(\tau_{v}\right)$, obtidos das curvas de ajuste, para os dois animais do experimento piloto, considerando-se uma ROI englobando toda a lesão, juntamente com a razão entre os tempos de decaimento do vermelho e do violeta, $\tau_{r} / \tau_{v}$.

\begin{tabular}{c|c|c|c}
\hline Camundongo & $\tau_{r}(\mathrm{~s})$ & $\tau_{v}(\mathrm{~s})$ & $\tau_{r} / \tau_{v}$ \\
\hline 1 & $4850 \pm 1030$ & $580 \pm 100$ & $8,4 \pm 3,2$ \\
\hline 2 & $1060 \pm 50$ & $500 \pm 60$ & $2,1 \pm 0,4$ \\
\hline
\end{tabular}

Fonte: elaborada pelo autor

\subsubsection{Experimento Detalhado}

Esse experimento foi conduzido de acordo com o descrito na Seção 5.1.3, obtendo-se imagens de fluorescência tanto para o equipamento comercial, quanto para o protótipo 
Figura 31: Curvas de fotodegradação adquiridas para o primeiro camundongo ((a) e (c)), e para o segundo camundongo ((b) e (d)), juntamente com as curvas de ajuste, para uma ROI em toda a lesão ((a), (b)), e para uma ROI na região central da lesão ((c) e (d)). Também se apresentam as curvas de ajuste, decrescidas de seu termo $I_{b g}$, para o primeiro (e) e para o segundo (f) camundongo, para uma ROI em toda a lesão.
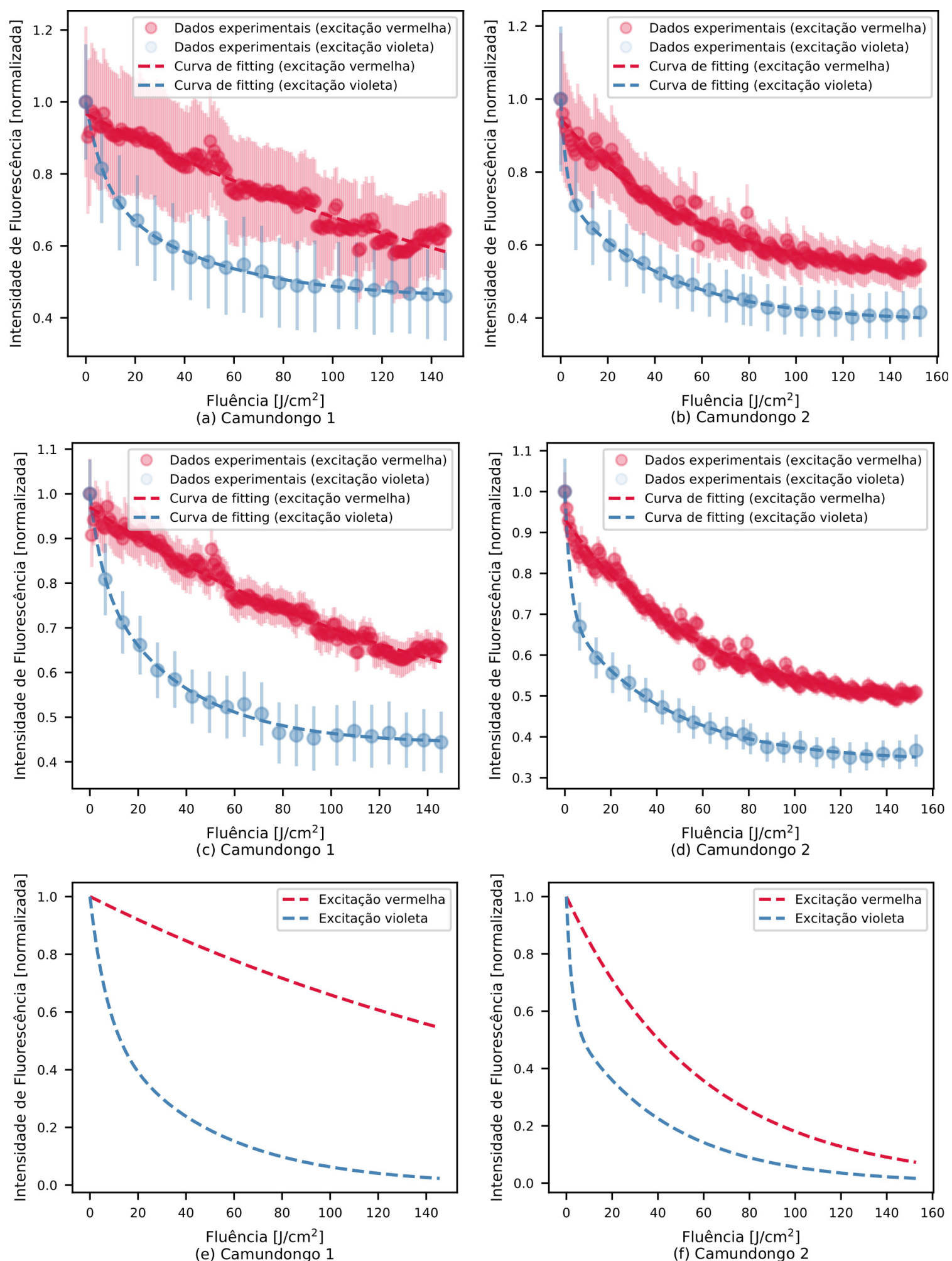

Fonte: elaborada pelo autor 
desenvolvido, para 4 camundongos distintos. Para facilitar a exposição de dados dos resultados, os camundongos foram enumerados de 1 a 4 . Nas figuras 32, 33, 34, e 35 se apresentam as imagens de fluorescência adquiridas no início, no meio, e ao final do tratamento, tanto com o equipamento comercial (excitadas na banda de Soret), quanto com o protótipo desenvolvido (excitadas no vermelho), para cada um dos camundongos.

Figura 32: Imagens de fluorescência excitadas pelo protótipo desenvolvido, no vermelho, para (a) 0, (b) $63,2 \mathrm{~J} / \mathrm{cm}^{2}$, e (c) $128 \mathrm{~J} / \mathrm{cm}^{2}$ de dose de luz entregue; e excitadas pelo sistema comercial, no violeta, para (d) 0 , (e) $63,2 \mathrm{~J} / \mathrm{cm}^{2}$, e (f) $128 \mathrm{~J} / \mathrm{cm}^{2}$ de dose de luz entregue, para o primeiro camundongo do experimento detalhado.

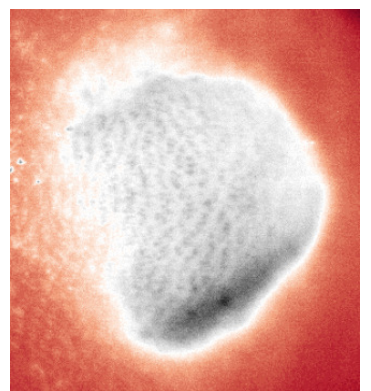

(a) $0\left[\mathrm{j} / \mathrm{cm}^{2}\right]$

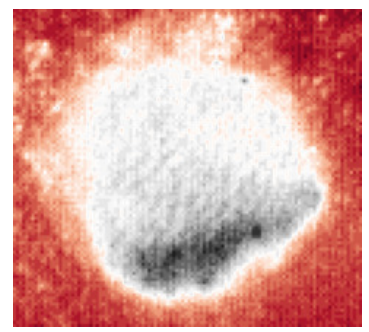

(d) $0\left[\mathrm{~J} / \mathrm{cm}^{2}\right]$

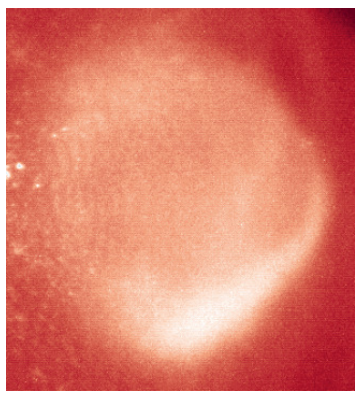

(b) $63,2\left[\mathrm{j} / \mathrm{cm}^{2}\right]$

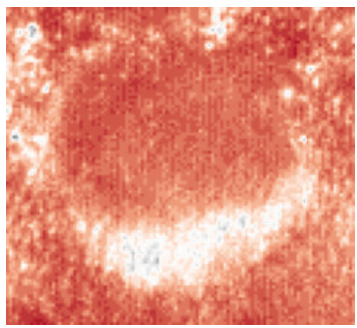

(e) $63,2\left[\mathrm{j} / \mathrm{cm}^{2}\right]$

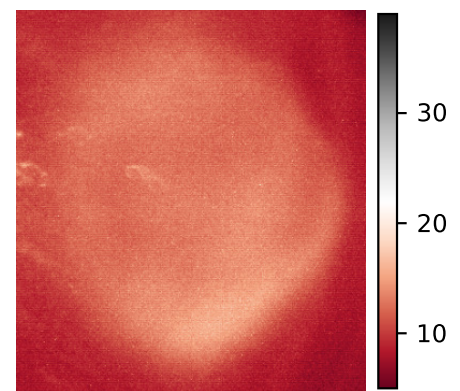

(c) $128\left[\mathrm{~J} / \mathrm{cm}^{2}\right]$

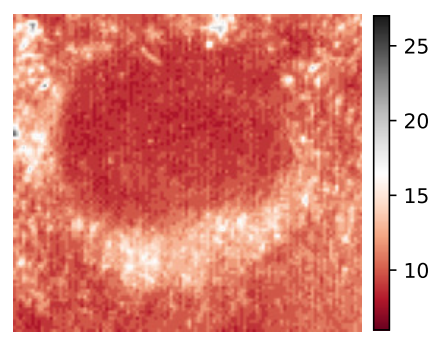

(f) $128\left[\mathrm{~J} / \mathrm{cm}^{2}\right]$

Fonte: elaborada pelo autor

Na Figura 36 se apresentam as imagens de luz branca da região tumoral dos 4 camundongos, juntamente com as imagens de fluorescência obtidas ao final do tratamento, tanto com o Lince (MMOptics, Brasil), quanto com equipamento desenvolvido. Calculandose a intensidade de fluorescência para cada uma das imagens adquiridas, para uma ROI englobando toda a lesão, pôde se obter as curvas de fotodegradação da PpIX para os 4 animais, como mostrado na Figura 37, apresentadas juntamente com suas curvas de ajuste biexponenciais. Já para uma ROI escolhida no centro da lesão, obtiveram-se as curvas apresentadas na Figura 38, também com as respectivas curvas de ajuste.

As curvas de ajuste, para as fluorescências excitadas no vermelho e no violeta, podem apresentar diferentes valores de $I_{b g}$, mesmo para um mesmo animal. Portanto, faz-se interessante a apresentação das curvas de ajuste decrescidas de seu valor de $I_{b g}$, para uma melhor comparação entre o decaimento das fluorescências excitadas no vermelho e no violeta. Na Figura 39 se apresentam as curvas de ajuste, decrescidas de seu valor de $I_{b g}$ para os quatro animais, para o caso em que a ROI englobando toda a lesão. 
Figura 33: Imagens de fluorescência excitadas pelo protótipo desenvolvido, no vermelho, para (a) 0, (b) $64,8 \mathrm{~J} / \mathrm{cm}^{2}$, e (c) $128,8 \mathrm{~J} / \mathrm{cm}^{2}$ de dose de luz entregue; e excitadas pelo sistema comercial, no violeta, para (d) 0 , (e) $64,8 \mathrm{~J} / \mathrm{cm}^{2}$, e (f) $128,8 \mathrm{~J} / \mathrm{cm}^{2}$ de dose de luz entregue, para o segundo camundongo do experimento detalhado.

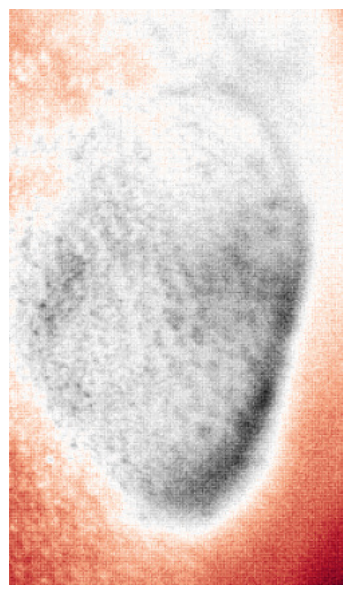

(a) $0\left[\mathrm{~J} / \mathrm{cm}^{2}\right]$

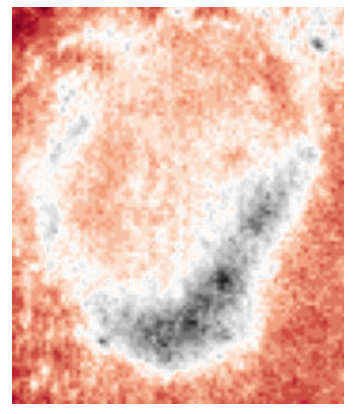

(d) $0\left[\mathrm{~J} / \mathrm{cm}^{2}\right]$

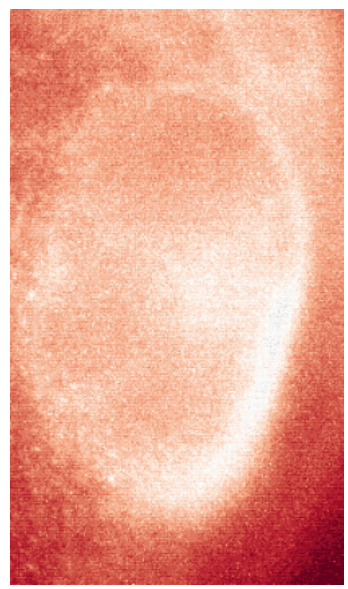

(b) $64,8\left[\mathrm{~J} / \mathrm{cm}^{2}\right]$

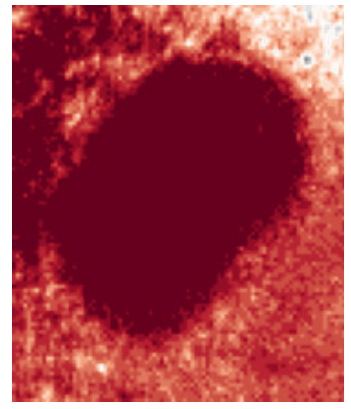

(e) $64,8\left[\mathrm{~J} / \mathrm{cm}^{2}\right]$

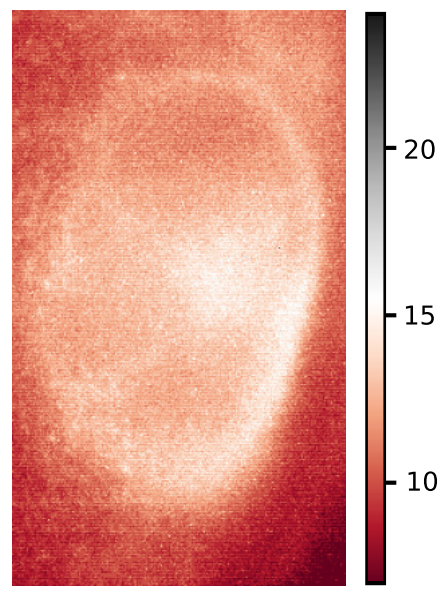

(c) $128,8\left[\mathrm{~J} / \mathrm{cm}^{2}\right]$

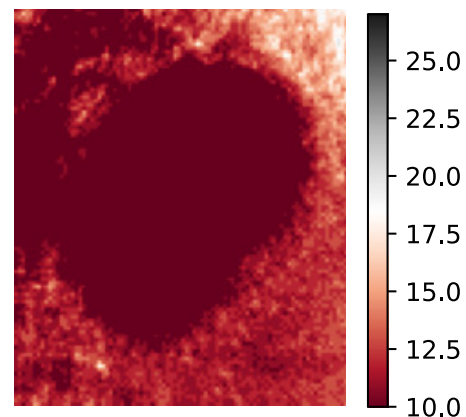

(f) $128,8\left[\mathrm{~J} / \mathrm{cm}^{2}\right]$

Fonte: elaborada pelo autor

Durante todo o período de iluminação, o fonte de luz teve sua intensidade monitorada pelo circuito de fotodetecção, através de um fotodiodo posicionado na ponta de prova. Procedendo-se dessa maneira para todos os animais, foi possível se obter os sinais de tensão normalizados, adquiridos do circuito de fotodetecção, pela placa de aquisição, como mostrado na Figura 40.

Utilizando-se as imagens de microscopia confocal, foi possível se encontrar os valores médios de espessura da epiderme $(e)$, e de espessura do tumor $(w)$, como delineado na Seção 5.1.3. Nas tabelas 3 e 4 se apresentam os valores de $e$ e de $w$ para todos os camundongos, juntamente com os tempos de decaimento médio, obtidos das curvas de ajuste, para a fluorescência excitada no vermelho $\left(\tau_{r}\right)$, e para a excitada no violeta $\left(\tau_{v}\right)$, considerando-se uma ROI englobando toda a lesão (Tabela 3), e uma ROI em sua região central (Tabela 4). Também se apresentam nessa tabela a razão entre os tempos de decaimento excitados no vermelho, e excitados no violeta, $\tau_{r} / \tau_{v}$. 
Figura 34: Imagens de fluorescência excitadas pelo protótipo desenvolvido, no vermelho, para (a) 0, (b) $63,2 \mathrm{~J} / \mathrm{cm}^{2}$, e (c) $127,2 \mathrm{~J} / \mathrm{cm}^{2}$ de dose de luz entregue; e excitadas pelo sistema comercial, no violeta, para (d) 0 , (e) $63,2 \mathrm{~J} / \mathrm{cm}^{2}$, e (f) $127,2 \mathrm{~J} / \mathrm{cm}^{2}$ de dose de luz entregue, para o terceiro camundongo do experimento detalhado.

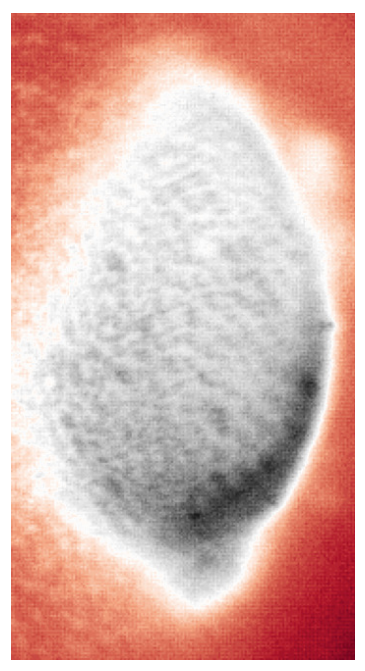

(a) $0\left[\mathrm{~J} / \mathrm{cm}^{2}\right]$

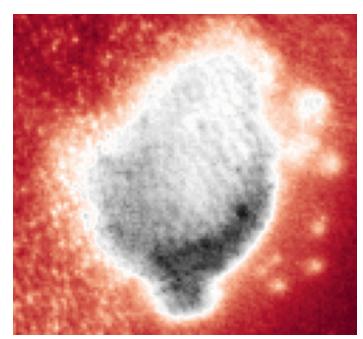

(d) $0\left[\mathrm{~J} / \mathrm{cm}^{2}\right]$

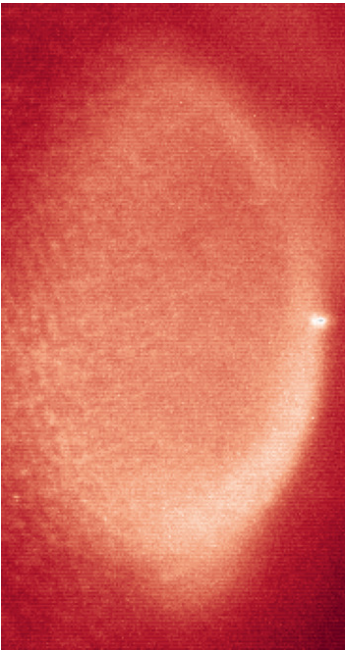

(b) $63,2\left[\mathrm{~J} / \mathrm{cm}^{2}\right]$

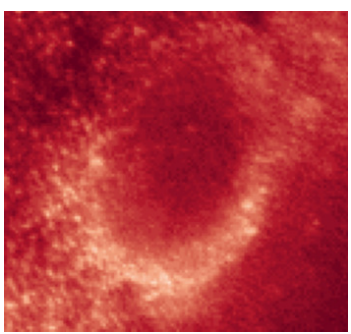

(e) $63,2\left[\mathrm{~J} / \mathrm{cm}^{2}\right]$

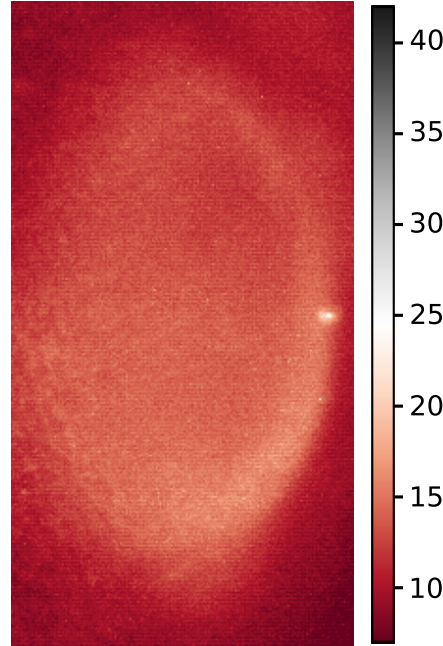

(c) $127,2\left[\mathrm{~J} / \mathrm{cm}^{2}\right]$

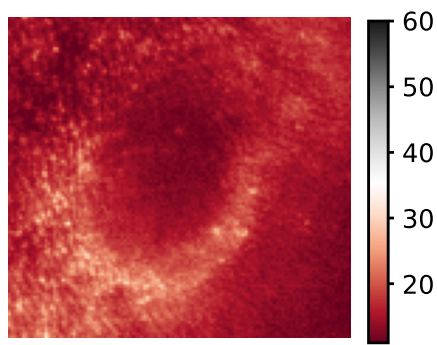

(f) $127,2\left[\mathrm{~J} / \mathrm{cm}^{2}\right]$

Fonte: elaborada pelo autor

Tabela 3: Tempo médio de decaimento para a fluorescência excitada no vermelho $\left(\tau_{r}\right)$, e no violeta $\left(\tau_{v}\right)$, obtidos das curvas de ajuste, para todos os animais, considerando-se uma ROI englobando toda a lesão, juntamente com a razão entre os tempos de decaimento, $\tau_{r} / \tau_{v}$. Também se apresentam os valores médios da espessura do tumor $(w)$ e da epiderme (e) para todos os animais.

\begin{tabular}{c|c|c|c|c|c}
\hline Camundongo & $\tau_{r}(\mathrm{~s})$ & $\tau_{v}(\mathrm{~s})$ & $\tau_{r} / \tau_{v}$ & $\begin{array}{c}w \\
(\mathrm{~mm})\end{array}$ & $\begin{array}{c}e \\
(\mu \mathrm{m})\end{array}$ \\
\hline 1 & $1300 \pm 300$ & $530 \pm 80$ & $2,6 \pm 0.9$ & $1,6 \pm 0,1$ & $34 \pm 2$ \\
\hline 2 & $600 \pm 200$ & $170 \pm 100$ & $3 \pm 2$ & $1,0 \pm 0,2$ & $22 \pm 3$ \\
\hline 3 & $930 \pm 80$ & $600 \pm 500$ & $2 \pm 2$ & $1,5 \pm 0,2$ & $26 \pm 2$ \\
\hline 4 & $790 \pm 70$ & $800 \pm 200$ & $1,0 \pm 0,3$ & $1,6 \pm 0,3$ & $22 \pm 3$ \\
\hline
\end{tabular}

Fonte: elaborada pelo autor 
Figura 35: Imagens de fluorescência excitadas pelo protótipo desenvolvido, no vermelho, para (a) 0 , (b) $63,2 \mathrm{~J} / \mathrm{cm}^{2}$, e (c) $128 \mathrm{~J} / \mathrm{cm}^{2}$ de dose de luz entregue; e excitadas pelo sistema comercial, no violeta, para (d) 0 , (e) $63,2 \mathrm{~J} / \mathrm{cm}^{2}$, e (f) $128 \mathrm{~J} / \mathrm{cm}^{2}$ de dose de luz entregue, para o quarto camundongo do experimento detalhado.

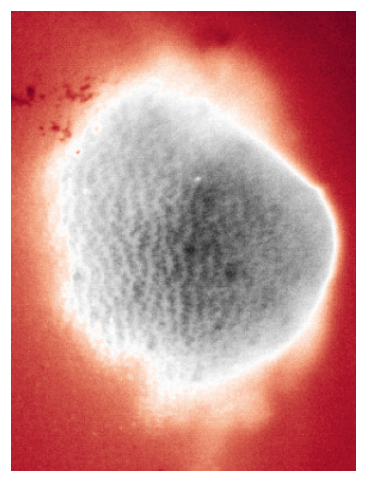

(a) $0\left[\mathrm{~J} / \mathrm{cm}^{2}\right]$

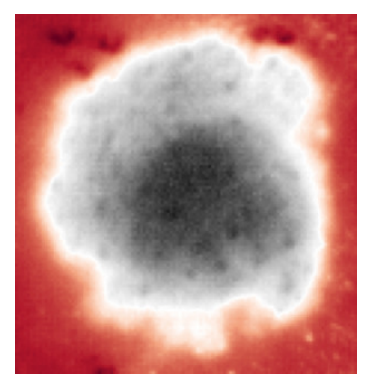

(d) $0\left[\mathrm{~J} / \mathrm{cm}^{2}\right]$

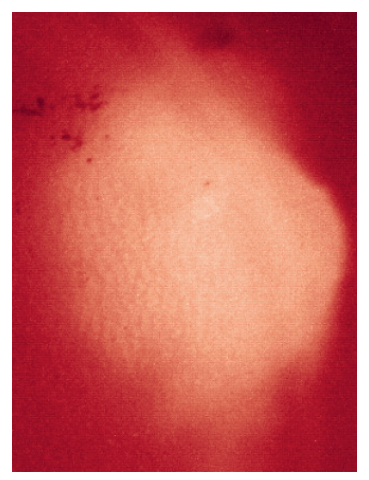

(b) $63,2\left[\mathrm{~J} / \mathrm{cm}^{2}\right]$

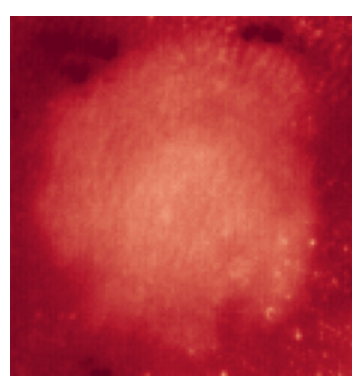

(e) $63,2\left[\mathrm{j} / \mathrm{cm}^{2}\right]$

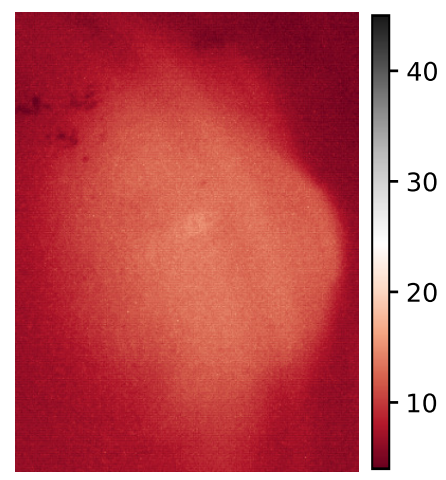

(c) $128\left[\mathrm{~J} / \mathrm{cm}^{2}\right]$

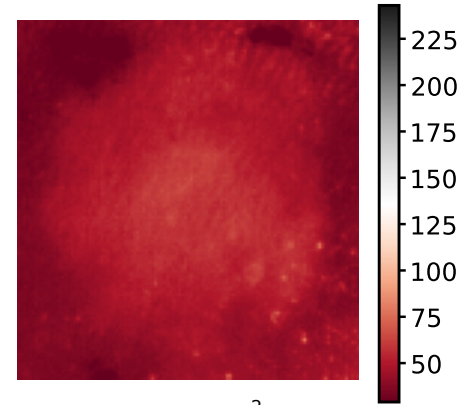

(f) $128\left[\mathrm{~J} / \mathrm{cm}^{2}\right]$

Fonte: elaborada pelo autor

Tabela 4: Tempo médio de decaimento para a fluorescência excitada no vermelho $\left(\tau_{r}\right)$, e no violeta $\left(\tau_{v}\right)$, obtidos das curvas de ajuste, para todos os animais, considerando-se uma ROI na região central da lesão, juntamente com a razão entre os tempos de decaimento, $\tau_{r} / \tau_{v}$. Também se apresentam os valores médios da espessura do tumor $(w)$ e da epiderme (e) para todos os animais.

\begin{tabular}{c|c|c|c|c|c}
\hline Camundongo & $\tau_{r}(\mathrm{~s})$ & $\tau_{v}(\mathrm{~s})$ & $\tau_{r} / \tau_{v}$ & $\begin{array}{c}w \\
(\mathrm{~mm})\end{array}$ & $\begin{array}{c}e \\
(\mu \mathrm{m})\end{array}$ \\
\hline 1 & $1150 \pm 200$ & $500 \pm 60$ & $2,3 \pm 0.7$ & $1,6 \pm 0,1$ & $34 \pm 2$ \\
\hline 2 & $550 \pm 200$ & $200 \pm 120$ & $2,8 \pm 2,7$ & $1,0 \pm 0,2$ & $22 \pm 3$ \\
\hline 3 & $640 \pm 40$ & $430 \pm 350$ & $1,5 \pm 1,3$ & $1,5 \pm 0,2$ & $26 \pm 2$ \\
\hline 4 & $700 \pm 50$ & $800 \pm 200$ & $0,9 \pm 0,3$ & $1,6 \pm 0,3$ & $22 \pm 3$ \\
\hline
\end{tabular}

Fonte: elaborada pelo autor 
Figura 36: Imagens de luz branca, da fluorescência excitada no violeta, e da fluorescência excitada pelo vermelho, para os camundongos 1 ((a),(b), e (c), respectivamente), 2 ((d),(e), e (f), respectivamente), $3((\mathrm{~g}),(\mathrm{h})$, e (i), respectivamente), e $4((\mathrm{j}),(\mathrm{k})$, e (l), respectivamente), estudados na experimento em modelo animal.

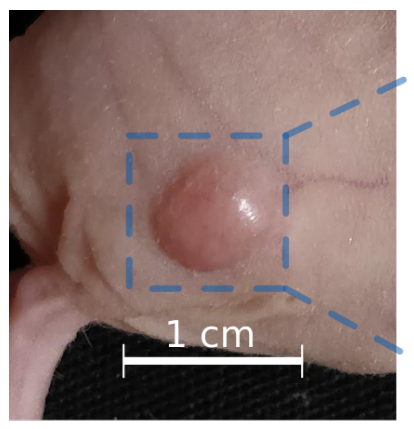

(a) Luz branca

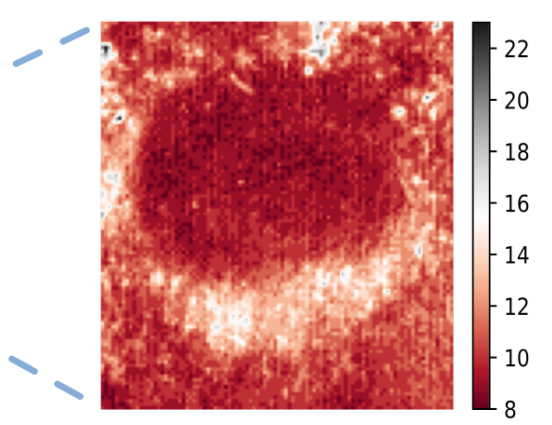

(b) Excitada pelo violeta

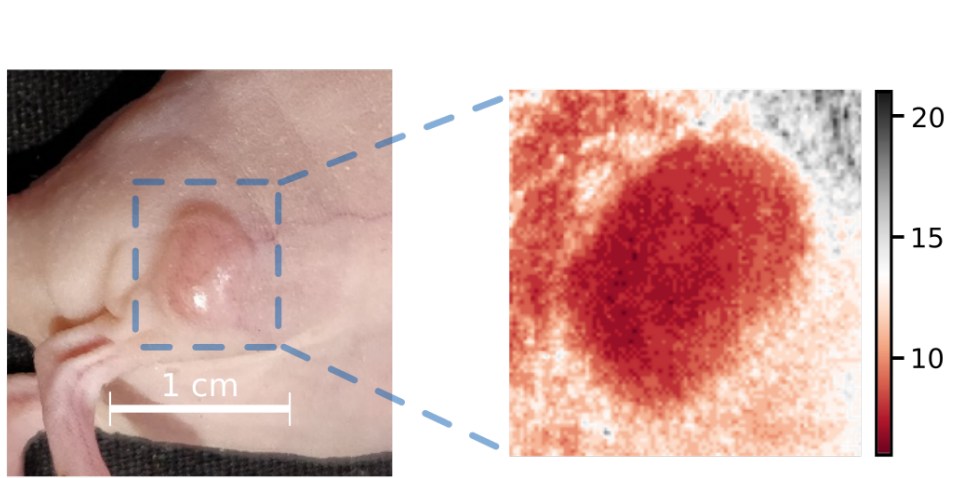

(d) Luz branca

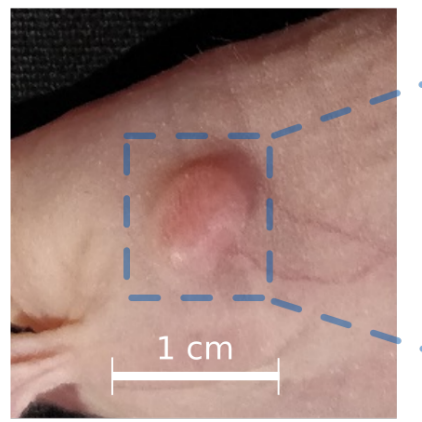

(g) Luz branca

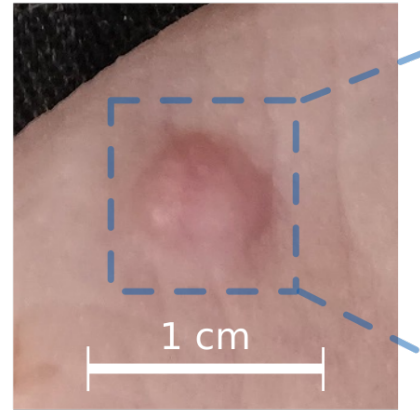

(j) Luz branca (e) Excitada pelo violeta

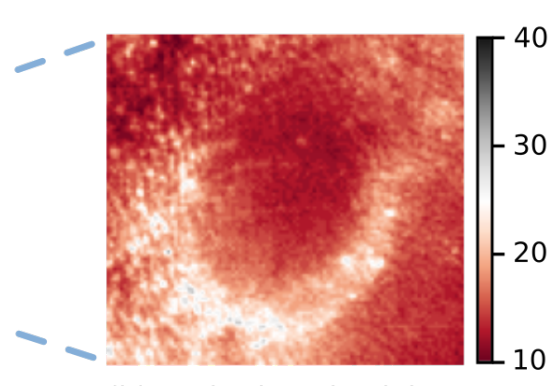

(h) Excitada pelo violeta $(\mathrm{f})$

(f) Excitada pelo vermelho

(c) Excitada pelo vermelho
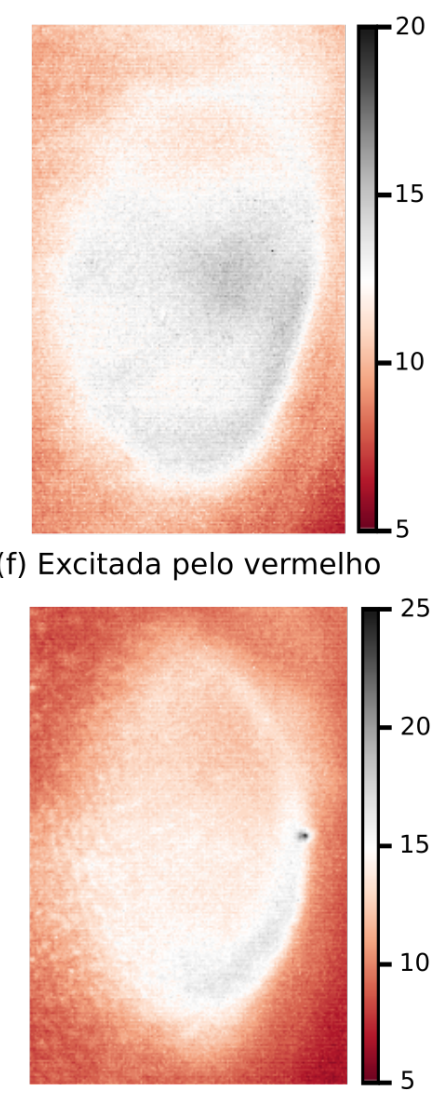

(i) Excitada pelo vermelho

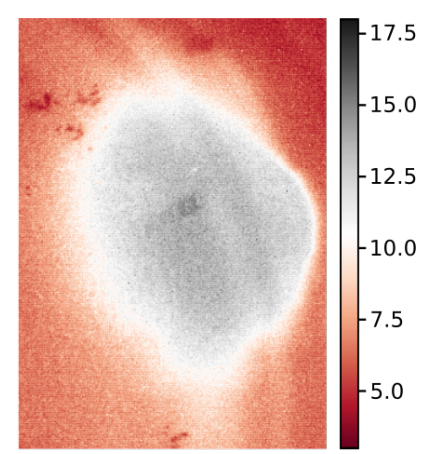

(I) Excitada pelo vermelho

Fonte: elaborada pelo autor 
Figura 37: Curvas de decaimento da intensidade de fluorescência normalizada, por fluência entregue, para uma ROI englobando toda a lesão, juntamente com as curvas de ajuste, calculadas pelo método dos mínimos quadrados para a Equação 5.1, adquiridas para os camundongos (a) 1, (b) 2 , (c) 3 , e (d) 4 .

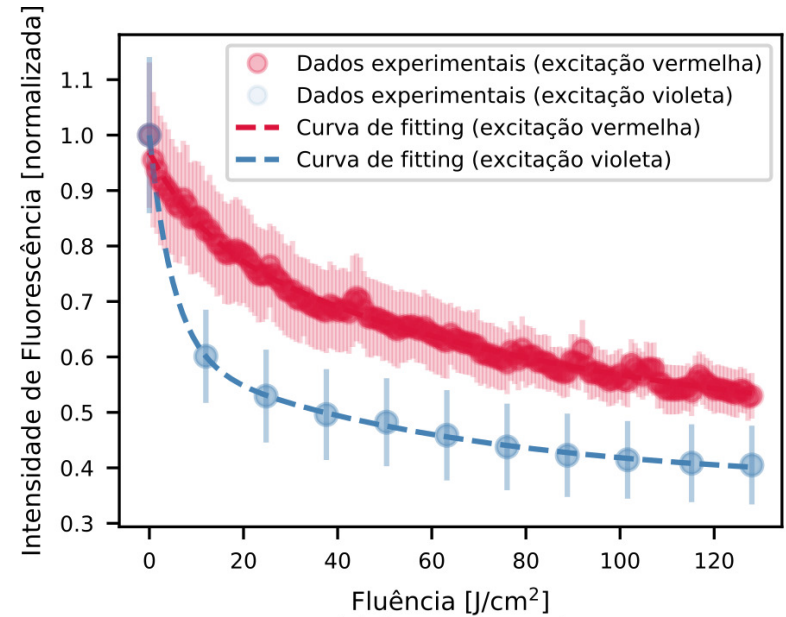

(a) Camundongo 1

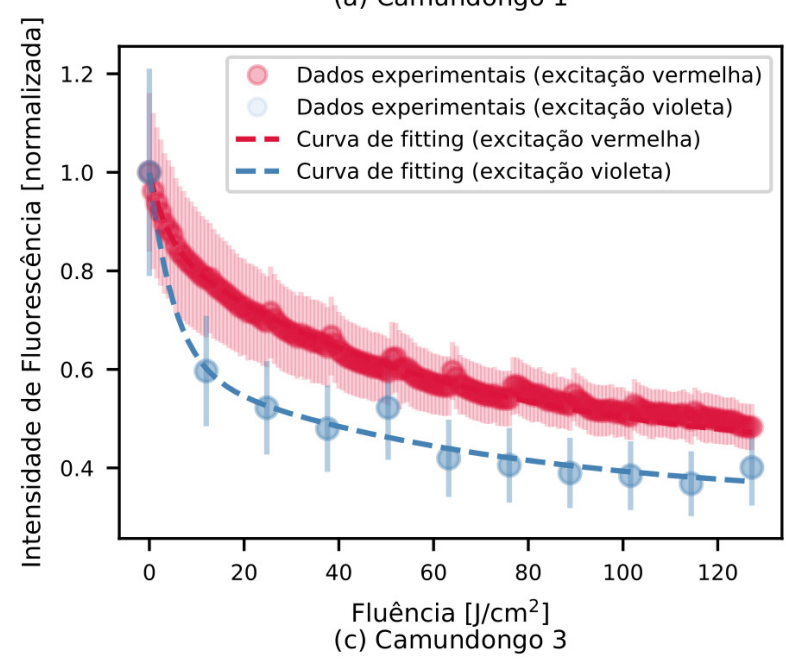

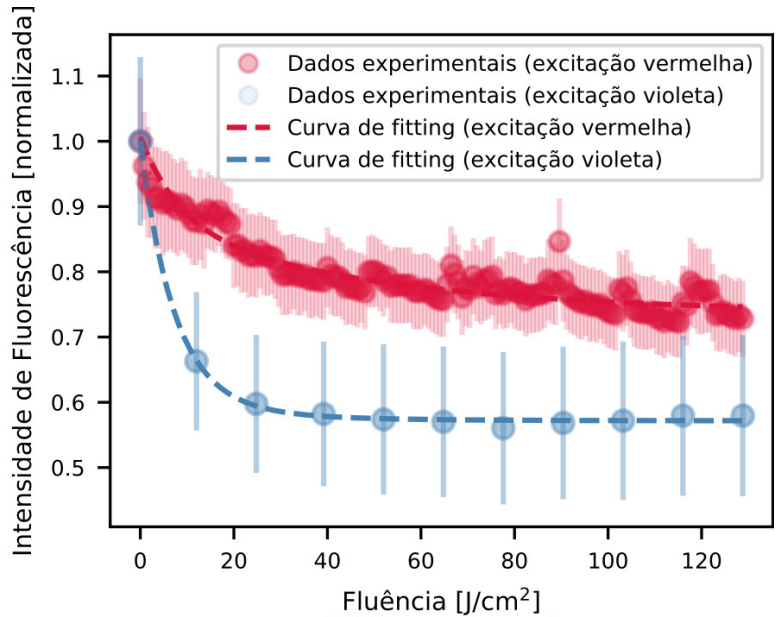

(b) Camundongo 2

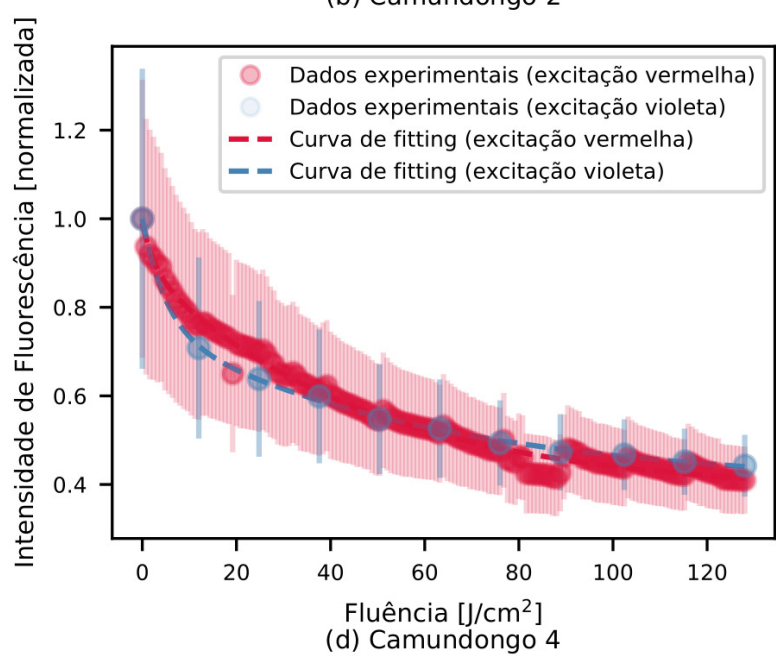

(d) Camundongo 4

Fonte: elaborada pelo autor 
Figura 38: Curvas de decaimento da intensidade de fluorescência normalizada, por fluência entregue, para uma ROI na região central da lesão, juntamente com as curvas de ajuste, calculadas pelo método dos mínimos quadrados para a Equação 5.1, adquiridas para os camundongos (a) 1, (b) 2 , (c) 3 , e (d) 4 .

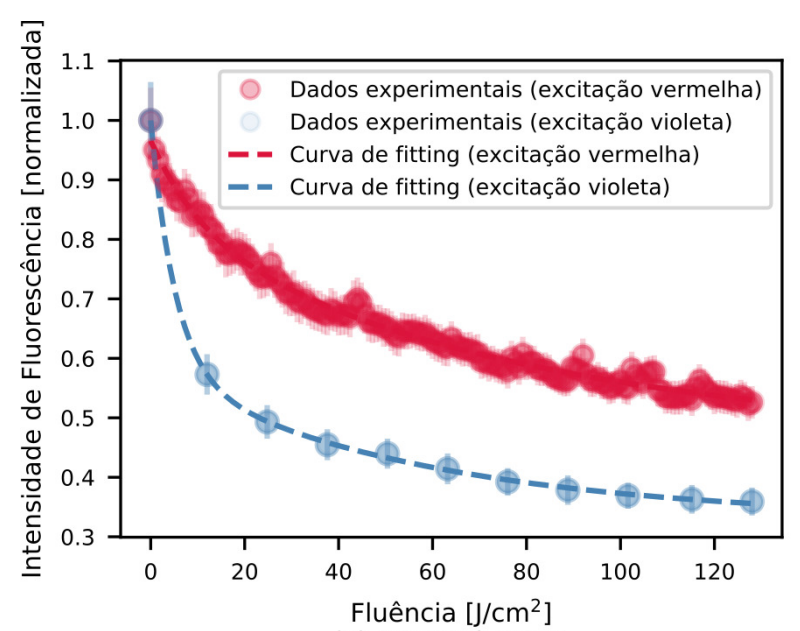

(a) Camundongo 1

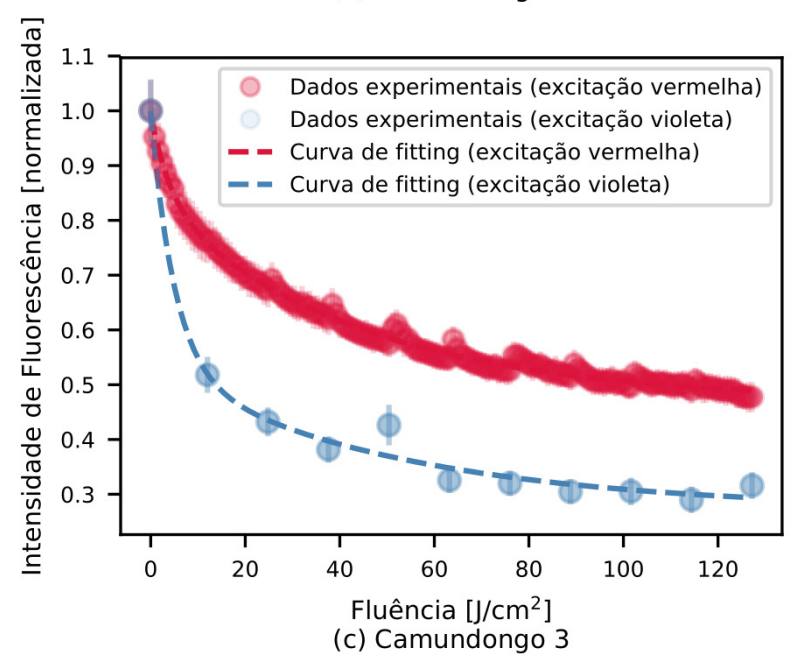

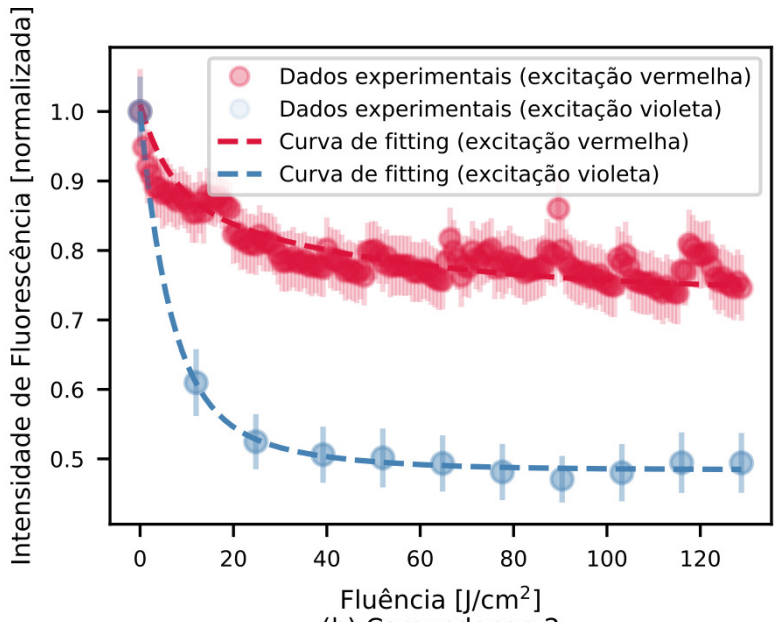

(b) Camundongo 2

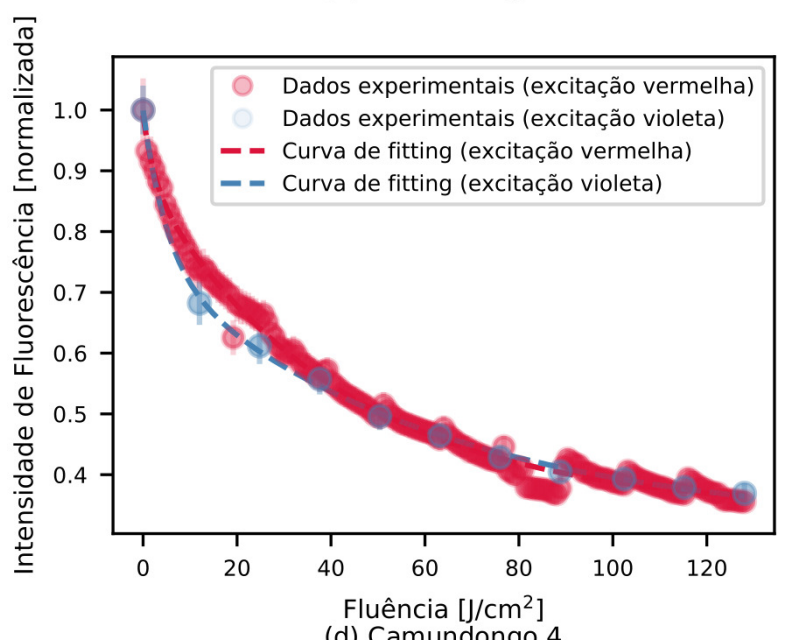

(d) Camundongo 4

Fonte: elaborada pelo autor 
Figura 39: Curvas de ajuste do decaimento da intensidade de fluorescência, calculadas pelo método dos mínimos quadrados, para os dados do experimento em modelo animal, decrescidas de seu termo $I_{b g}$, que representa a intensidade luminosa de fundo (termo constante da exponencial), para os camundongos (a) 1, (b) 2, (c) 3, e (d) 4 .

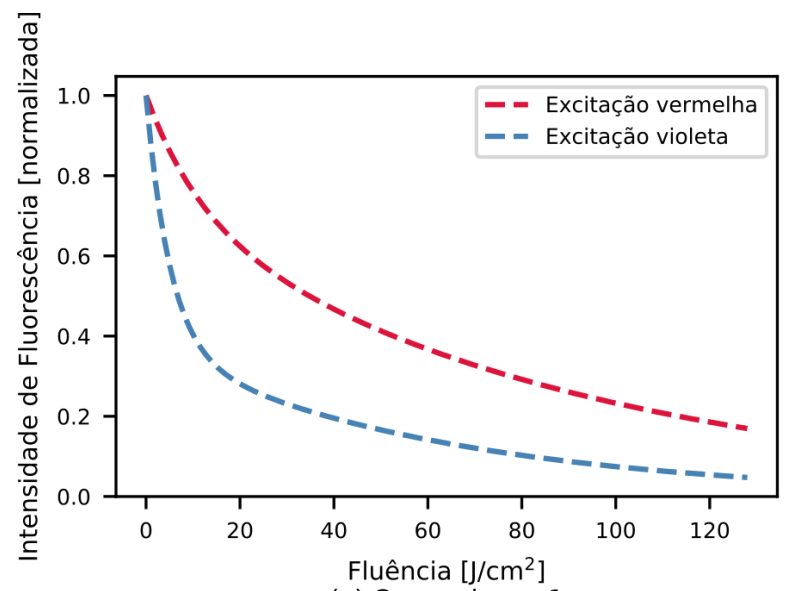

(a) Camundongo 1

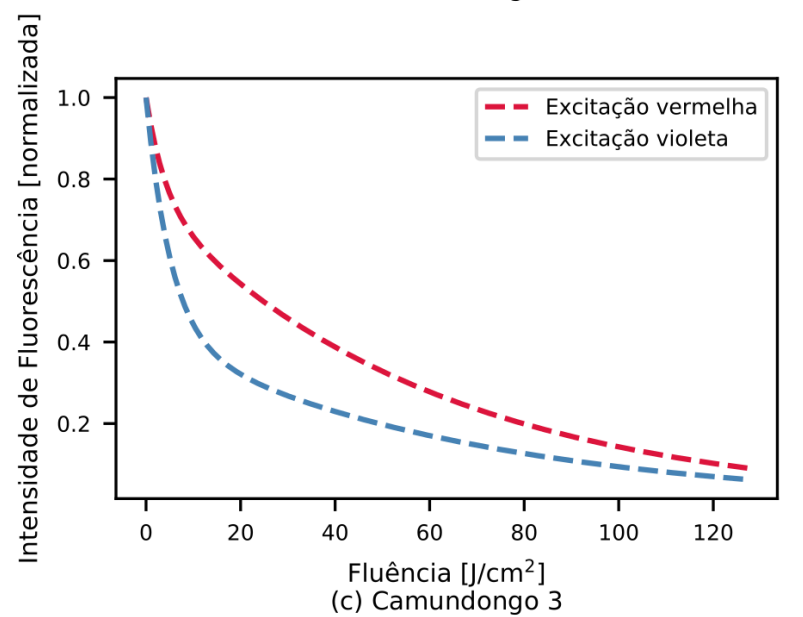

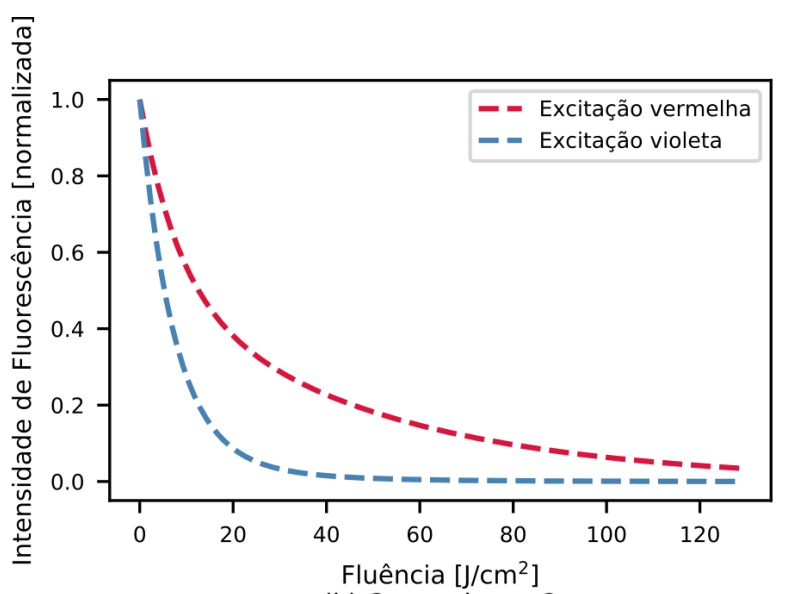

(b) Camundongo 2

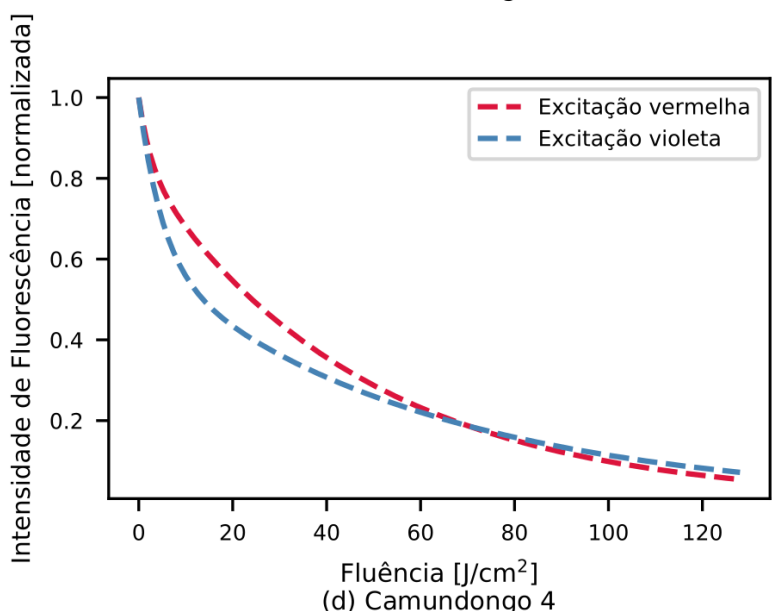

Fonte: elaborada pelo autor 
Figura 40: Sinais de tensão normalizados, obtidos da saída do circuito de fotodetecção, detectados pela placa de aquisição, durante o experimento em modelo animal, para os camundongos (a) 1, (b) 2 , (c) 3 , e (d). 4 .

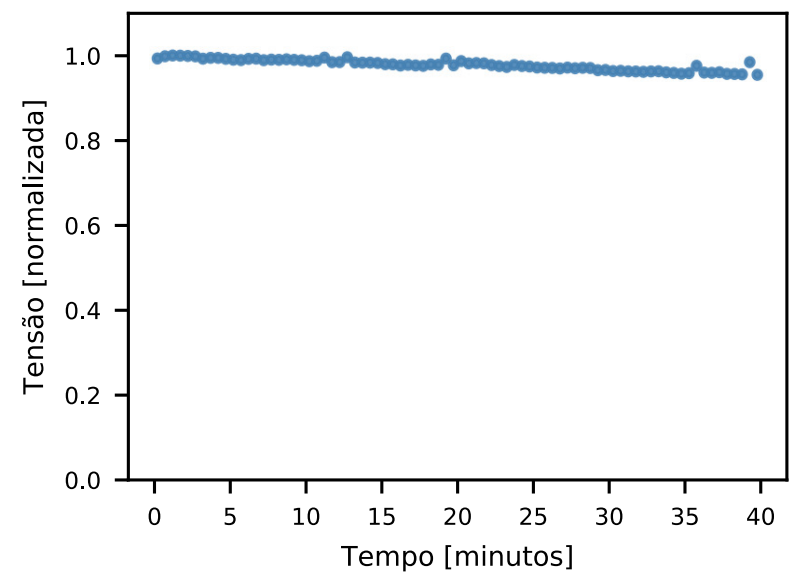

(a) Camundongo 1

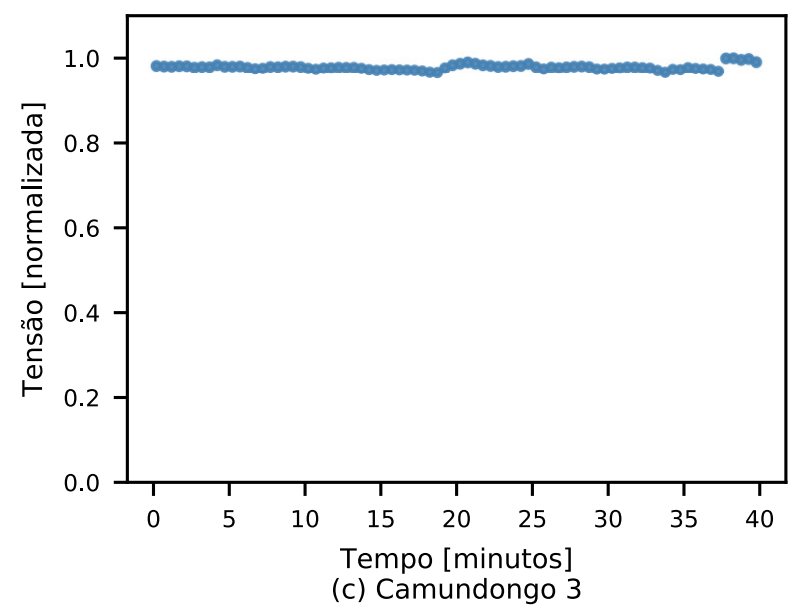

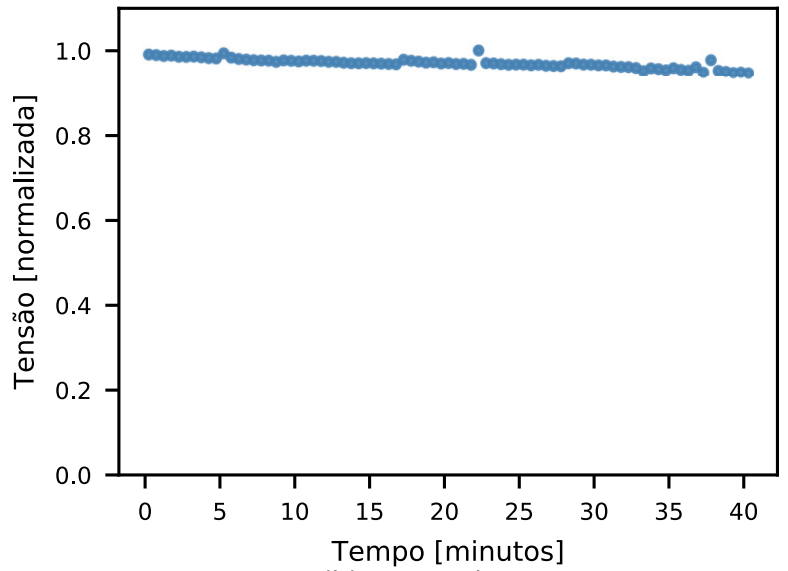

(b) Camundongo 2

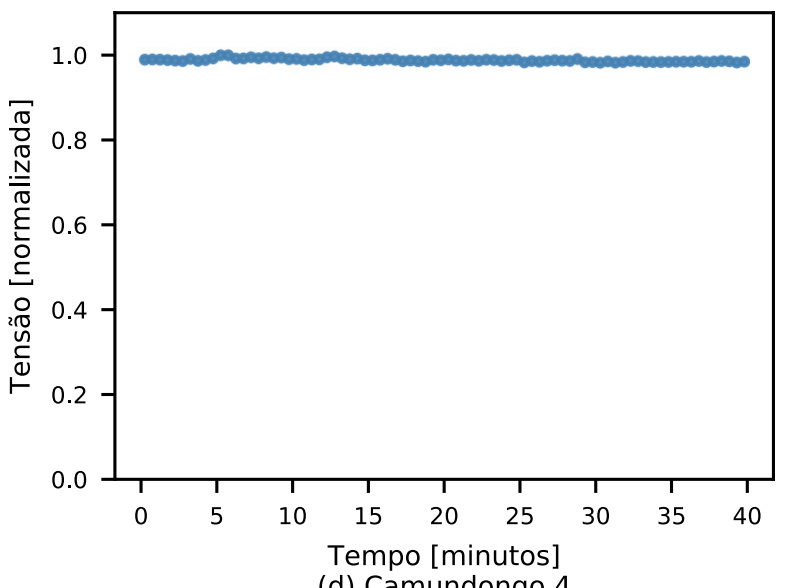

Fonte: elaborada pelo autor 



\section{DISCUSSÃO E CONSIDERAÇÕES FINAIS}

\subsection{Discussão}

\subsubsection{Caracterização da Óptica e Montagem do Sistema}

Anteriormente à montagem do equipamento, idealizou-se a óptica necessária para aquisição dos sinais de fluorescência. Nesta etapa foi possível se notar a dificuldade de se filtrar o sinal de interesse, dado sua baixa intensidade, e pequena diferença espectral com relação à fonte (baixo deslocamento de Stokes). À princípio, utilizando-se fontes de luz do tipo LED para se excitar as moléculas de PpIX, e filtros ópticos do tipo passa alta para se coletar a fluorescência, não foi possível se obter imagens de fluorescência com contraste adequado. Fez-se necessária a utilização de uma fonte de luz laser (diodo encapsulado), um filtro óptico passa baixa para filtrar a luz de excitação, e um filtro passa banda para a coleta do sinal de interesse.

Em um primeiro momento, optou-se por um filtro passa banda com um baixo valor de FWHM (filtro óptico da Proten, com 20 nm de FWHM, Figura 9(a)), buscando se filtrar somente o sinal de fluorescência. Como esse filtro não produziu imagens de fluorescência com um valor de contraste adequado, buscou-se utilizar um filtro com FWHM maior, como o FB700-40 (Thorlabs, EUA), com 40 nm de FWHM. Apesar de seu FWHM maior, esse filtro óptico permitiu a aquisição imagens de fluorescência com um alto valor de contraste.

Essa diferença na aquisição da fluorescência pelos dois filtros, provavelmente se dá por conta do corte na transmissão de comprimentos de onda menores que $680 \mathrm{~nm}$, que é significativamente mais abrupto para o filtro FB700-40 do que para o filtro com FWHM de $20 \mathrm{~nm}$ (Figura 14). Além disso, o que favoreceu a qualidade das imagens adquiridas foi a alta eficiência quântica da câmera utilizada para aquisição das imagens (DCC-1545M, Thorlabs, EUA), a qual é de $46 \%$ para a coleta de fótons com comprimento de onda de $700 \mathrm{~nm}$.

Dentre as partes mais desafiadoras na montagem do sistema, pode-se destacar: a aquisição da fluorecência NIR, excitada pelo vermelho, e o preparo dos circuitos elétricos para fornecer correntes elétricas constantes, com valores relativamente altos, para evitar picos de sobretensão no diodo laser, e para manter a temperatura do laser constante. O módulo laser, por exemplo, chega a drenar quase $5 \mathrm{~A}$ de corrente elétrica da fonte (Seção 4.2.3). Ainda, como o diodo laser é rápido o bastante para responder à picos de tensão, permitindo picos de corrente, variações abruptas de sobretensão podem danificar este dispositivo. Para resolver esse problema, adicionou-se um capacitor na base do transistor que controla a alimentação do laser, de modo a formar um filtro passa baixa. Dessa maneira, mesmo que alguma variação abrupta de tensão aconteça na base desse 
transistor, a mesma será filtrada. Os picos de tensão podem ocorrer, por exemplo, ao se ligar ou desligar o sistema da rede elétrica.

\subsubsection{Caracterização do Sistema}

Da caracterização do sistema, foi possível se observar uma alta linearidade na detecção da concentração de protoporfirina-IX em phantom, obtendo-se um coeficiente de determinação, e um valor de probabilidade de: $r^{2}=0,9997$ e $p=1,95 \times 10^{-9}$, respectivamente, para a relação entre os dados adquiridos e a curva de fitting calculada. Também pode se observar uma sensibilidade de 50, em unidades de intensidade de fluorescência normalizada, por nM de concentração de PpIX. Com relação ao limiar de detecção, foi possível se observar, com bom contraste, soluções de até 500 nM de PpIX em phantom. Esse limite de deteç̧ão também foi observado por LaRochelle et al. (2017), para a fluorescência excitada no vermelho, calculada sem se considerar a contribuição da fluorescência intrínseca da pele.

\subsubsection{Experimento em Phantom}

Para o experimento em phantom, foi possível se obter um decaimento exponencial da fluorescência, como o reportado pela literatura (SHENG et al., 2007) (Figura 27), mas com um fotobranqueamento consideravelmente mais lento. Isso provavelmente ocorreu por conta das diferenças entre o modelo animal e o phantom utilizado, já que o phantom não oferece um suprimento contínuo de oxigênio, como ocorre no modelo animal, sendo que a presença de oxigênio no meio está altamente associada a um decaimento rápido da fluorescência da PpIX (BOERE et al., 2003; SHENG et al., 2007).

\subsubsection{Modelo Animal}

Analisando-se as curvas de decaimento (figuras 31, 37, 38, e 39), e as tabelas de tempo médio de decaimento (tabelas 2, 3, e 4), é possível se notar que, com exceção do camundongo 4, todos os camundongos apresentaram um decaimento mais lento para a fluorescência excitada pelo vermelho, do que para a fluorescência excitada pelo violeta. O rápido decaimento da fluorescência excitada pelo violeta também pode ser observado nas imagens de fluorescência adquiridas ao longo do tratamento. Para as imagens excitadas pelo violeta, por exemplo, a diferença entre a fluorescência da lesão e do tecido em redor se inverte ao longo do tratamento, com a obtenção de uma região de depleção da fluorescência na área da lesão, onde a fluorescência passa a ter um valor menor do que na região de tecido saudável (figuras 30 e 36). Pode-se notar, inclusive, que a inversão da intensidade da fluorescência excitada pelo violeta ocorre antes da metade do período de iluminação, como se pode observar das figuras $28,29,32,33$, 34, e 35. 
Para o caso das imagens de fluorescência excitadas pelo vermelho, mesmo ao final do período de iluminação, pode-se observar que a intensidade da fluorescência na região interior da lesão possui valores maiores do que a intensidade de fluorescência ao redor, no tecido saudável (figuras 30 e 36). Utilizando-se essas imagens, é possível até se delinear a região da borda da lesão. Essa diferença entre as imagens de fluorescência excitadas pelo vermelho e pelo violeta já era esperada, e provavelmente ocorre devido ao maior grau de penetração da luz vermelha no tecido da pele, dados os altos valores dos coeficientes de absorção e de espalhamento para o violeta (LISTER; WRIGHT; CHAPPELL, 2012; JACQUES, 2013).

Da análise das curvas de decaimento da fluorescência, também é possível se notar que, para uma ROI na região central da lesão, a variação de intensidade de pixel é notavelmente menor do que para uma ROI englobando toda a lesão (figuras 31, 37, 38, e 39). Além do mais, a escolha de uma ROI no centro da lesão também forneceu uma maior diferença entre o decaimento do vermelho e do violeta, culminando em maiores valores da razão $\tau_{r} / \tau_{v}$, como pode ser visto nas tabelas 3 e 4 . Esse fenômeno pode ser parcialmente explicado por conta do formato elipsoidal que os tumores assumiram, já que, tendo as bordas do tumor uma menor espessura, as mesmas poderiam apresentam um volume menor de tecido com PpIX acumulada, e consequentemente menores diferenças entre a fluorescência excitada pelo vermelho e pelo violeta. Como a região central do tumor apresenta uma maior espessura, a mesma proporciona uma maior diferença entre a fluorescência excitada pelo vermelho e pelo violeta

Da análise dos dados obtidos (tabelas 3 e 4), é possível se observar uma alta variabilidade, entre os camundongos, tanto para os tempos de decaimento médio $\left(\tau_{r}\right.$ e $\left.\tau_{v}\right)$, quanto para a razão entre eles $\tau_{r} / \tau_{v}$, ou para as espessuras do tumor $(w)$ e da epiderme $(e)$. Ainda, da análise desses valores, é possível se observar uma certa tendência do aumento dos tempos de decaimento, com o aumento das espessuras do tumor e da epiderme. Entretanto, como o número de camundongos analisados é pequeno, as conclusões entre essas variáveis são limitadas.

\subsection{Considerações Finais}

Esse trabalho foi dedicado ao desenvolvimento de um equipamento capaz de aplicar e monitorar online a TFD de lesões de pele do tipo não-melanoma, via imagens de fluorescência na região do infravermelho próximo. Como a fluorescência a ser monitorada é excitada pela própria iluminação de tratamento, o sistema pode realizar o tratamento e o monitoramento da lesão, simultaneamente, eliminando-se a necessidade de interromper a iluminação de tratamento, como necessário em outros dispositivos de monitoramento descritos na literatura (FISCHER et al., 2001; LAROCHELLE et al., 2017).

Além de ser em tempo real, a fluorescência de monitoramento é excitada e emitida 
na região do vermelho-NIR, o que faz com que a mesma consiga interrogar regiões mais profundas do tecido. Desse modo, é possível se adquirir sinais de fluorescência de um volume de tecido tumoral maior, o que amplia significativamente a gama de lesões possíveis de serem monitoradas por essa técnica. Essa gama de lesões é aumentada, tanto para lesões mais espessas, quanto para lesões mais pigmentadas, tendo em conta a grande diferença entre os coeficientes de absorção e espalhamento do violeta e do vermelho, para lesões de pele não-melanoma (SALOMATINA et al., 2006).

Ademais, a utilização de uma mesma fonte de luz, tanto para o tratamento quanto para o monitoramento da lesão, contribui grandemente para a simplicidade, portabilidade, e baixo custo do sistema. Em aplicações clínicas, essas características são fundamentais, aumentando a aceitabilidade do equipamento no ambiente clínico, e facilitando sua inserção na rotina diária de tratamento (POGUE et al., 2016). De igual modo, essas qualidades também se tornam altamente desejáveis durante o processo de regulamentação e certificação do equipamento, assim como na entrada dessa tecnologia no mercado (POGUE et al., 2016).

Durante o monitoramento da terapia, o dano fotodinâmico pode ser estimado através da diminuição da intensidade de fluorescência adquirida, já que a mesma está relacionada com a concentração de espécies reativas geradas no tecido tumoral, e consequentemente com o dano fotodinâmico ocasionado (BOERE et al., 2003; SHENG et al., 2007; POGUE et al., 2016). Estando o dano fotodinâmico associado ao resultado terapêutico, prevendo-se o primeiro, é possível se estimar o último (ROBINSON et al., 1998).

A intensidade de fluorescência no período de iluminação, assim como a cinética de seu decaimento, estão relacionados com as características intrínsecas de cada lesão, assim como com a interação das mesmas com o protocolo de tratamento, como descrito na Seção 2.3 do Capítulo 2. Desse modo, o monitoramento da fluorescência irá proporcionar um melhor entendimento da terapia como um todo, possivelmente indicando quais parâmetros de protocolo, ou quais características da lesão, influenciaram mais a resposta terapêutica, tanto em cada caso específico, quanto de um modo geral. Pela fluorescência monitorada, seria possível, ainda, se indicar quais os parâmetros de protocolo que melhor atendem às necessidades de cada lesão a ser tratada. Desse modo, abre-se as portas para a possibilidade de um protocolo customizado, que possibilita a alteração de seus parâmetros de aplicação, durante o tratamento, de modo a otimizá-los para as necessidades de cada lesão.

Portanto, faz-se interessante a utilização desse sistema para o tratamento e monitoramento de lesões de pele não melanoma, o qual pode estimar o dano fotodinâmico gerado, prever o resultado terapêutico, melhorar o entendimento da terapia, e customizar o protocolo. Desse modo, torna-se possível aumentar as taxas de cura da TFD, e, em último estágio, viabilizar uma maior adesão dessa modalidade terapêutica entre os clínicos, como ferramenta padrão para o tratamento de câncer de pele do tipo não melanoma. 


\subsection{Possíveis Diretrizes Futuras}

Como possíveis diretrizes para trabalhos futuros, pretende-se utilizar o sistema em um teste clínico, a fim de validá-lo para o tratamento e monitoramento de lesões de pele humana, do tipo não-melanoma. Através do teste clínico, pode-se correlacionar as doses fotodinâmicas geradas, com as respostas das lesões ao tratamento. Com a obtenção desses dados, para um número considerável de lesões, seria possível se entender quais os parâmetros que mais influenciam a resposta das lesões, e utilizar esses dados para se prever a resposta de futuras lesões a serem tratadas.

Também pretende-se fazer melhorias no sistema, como a substituição do laptop por um computador de placa única, ou a integração de alguns cálculos no próprio software do equipamento. Por exemplo, seria interessante que o dispositivo fosse capaz de calcular, em tempo real, a intensidade de fluorescência da lesão, assim como a curva de ajuste da variação temporal da mesma. A integração desses cálculos no próprio equipamento faz-se interessante, por exemplo, para o monitoramento clínico da evolução do tratamento, e para possibilitar a aplicação de um protocolo customizado. 



\section{REFERÊNCIAS}

ACKROYD, R. et al. The history of photodetection and photodynamic therapy. Photochemistry and photobiology, BioOne, v. 74, n. 5, p. 656-669, 2001.

AGOSTINIS, P. et al. Photodynamic therapy of cancer: an update. CA: a cancer journal for clinicians, Wiley Online Library, v. 61, n. 4, p. 250-281, 2011.

AGUILAR, M. et al. A cost analysis of photodynamic therapy with methyl aminolevulinate and imiquimod compared with conventional surgery for the treatment of superficial basal cell carcinoma and bowen's disease of the lower extremities. Journal of the European Academy of Dermatology and Venereology, Wiley Online Library, v. 24, n. 12, p. 1431-1436, 2010.

AKOPOV, A. L. et al. Endobronchial photodynamic therapy under fluorescence control: Photodynamic theranostics. Photodiagnosis and Photodynamic Therapy, Elsevier, v. 19, p. 73-77, 2017.

ANDRADE, C. et al. Identification of skin lesions through aminolaevulinic acid-mediated photodynamic detection. Photodiagnosis and photodynamic therapy, Elsevier, v. 11, n. 3, p. 409-415, 2014.

ANDRADE, C. T. de et al. Study of uv-blue light propagation in a phantom to characterize a led cancer diagnosis device. In: OPTICAL SOCIETY OF AMERICA. Latin America Optics and Photonics Conference. [S.l.], 2010. p. MB10.

AULER, H.; BANZER, G. Untersuchungen über die rolle der porphyrine bei geschwulstkranken menschen und tieren. Journal of Cancer Research and Clinical Oncology, Springer, v. 53, n. 2, p. 65-68, 1942.

BAYS, R. et al. Light dosimetry for photodynamic therapy in the esophagus. Lasers in surgery and medicine, Wiley Online Library, v. 20, n. 3, p. 290-303, 1997.

BEDWELL, J. et al. Fluorescence distribution and photodynamic effect of ala-induced pp ix in the dmh rat colonic tumour model. British journal of cancer, Nature Publishing Group, v. 65, n. 6, p. 818, 1992.

BLANCO, K. C. et al. Fluorescence guided pdt for optimization of the outcome of skin cancer treatment. Frontiers in Physics, Frontiers, v. 3, p. 30, 2015.

BOERE, I. et al. Monitoring in situ dosimetry and protoporphyrin ix fluorescence photobleaching in the normal rat esophagus during 5-aminolevulinic acid photodynamic therapy. Photochemistry and photobiology, BioOne, v. 78, n. 3, p. 271-277, 2003.

BUZZÁ, H. H. et al. Overall results for a national program of photodynamic therapy for basal cell carcinoma: A multicenter clinical study to bring new techniques to social health care. Cancer Control, SAGE Publications Sage CA: Los Angeles, CA, v. 26, n. 1, p. $1073274819856885,2019$.

CELLI, J. P. et al. Imaging and photodynamic therapy: mechanisms, monitoring, and optimization. Chemical reviews, ACS Publications, v. 110, n. 5, p. 2795-2838, 2010. 
DIVARIS, D. X.; KENNEDY, J. C.; POTTIER, R. H. Phototoxic damage to sebaceous glands and hair follicles of mice after systemic administration of 5-aminolevulinic acid correlates with localized protoporphyrin ix fluorescence. The American journal of pathology, American Society for Investigative Pathology, v. 136, n. 4, p. 891, 1990.

DÖGNITZ, N. et al. Comparison of ala-and ala hexyl-ester-induced ppix depth distribution in human skin carcinoma. Journal of Photochemistry and Photobiology B: Biology, Elsevier, v. 93, n. 3, p. 140-148, 2008.

DOLMANS, D. E.; FUKUMURA, D.; JAIN, R. K. Photodynamic therapy for cancer. Nature reviews cancer, Nature Publishing Group, v. 3, n. 5, p. 380, 2003.

DOUGHERTY, T. J. et al. Photodynamic therapy. JNCI: Journal of the National Cancer Institute, Oxford University Press, v. 90, n. 12, p. 889-905, 1998.

ERICSON, M. B. et al. Bispectral fluorescence imaging combined with texture analysis and linear discrimination for correlation with histopathologic extent of basal cell carcinoma. Journal of biomedical optics, International Society for Optics and Photonics, v. 10, n. 3, p. 034009, 2005.

FIGGE, F. H. J.; WEILAND, G. S. The affinity of neoplastic embryonic and traumatized tissue for porphyrins and metalloporphyrins. Anat. Rec., v. 100, p. 659, 1948.

FISCHER, F. et al. An affordable, portable fluorescence imaging device for skin lesion detection using a dual wavelength approach for image contrast enhancement and aminolaevulinic acid-induced protoporphyrin ix. part i. design, spectral and spatial characteristics. Lasers in medical science, Springer, v. 16, n. 3, p. 199-206, 2001.

GEMMELL, N. R. et al. Singlet oxygen luminescence detection with a fiber-coupled superconducting nanowire single-photon detector. Optics express, Optical Society of America, v. 21, n. 4, p. 5005-5013, 2013.

GERALDE, M. C. et al. Pulmonary decontamination for photodynamic inactivation with extracorporeal illumination. In: INTERNATIONAL SOCIETY FOR OPTICS AND PHOTONICS. Endoscopic Microscopy IX; and Optical Techniques in Pulmonary Medicine. [S.1.], 2014. v. 8927, p. 89271B.

GRECCO, C. et al. Single led-based device to perform widefield fluorescence imaging and photodynamic therapy. In: INTERNATIONAL SOCIETY FOR OPTICS AND PHOTONICS. Biophotonics South America. [S.1.], 2015. v. 9531, p. 953121.

GREGORIE, H. B. J. et al. Hematoporphyrin-derivative fluorescence in malignant neoplasms. Annals of surgery, Lippincott, Williams, and Wilkins, v. 167, n. 6, p. 820, 1968.

GROSSWEINER, L. I. Optical dosimetry in photodynamic therapy. Lasers in surgery and medicine, Wiley Online Library, v. 6, n. 5, p. 462-466, 1986.

GROSSWEINER, L. I.; HILL, J. H.; LOBRAICO, R. V. Photodynamic therapy of head and neck squamous cell carcinoma: optical dosimetry and clinical trial. Photochemistry and photobiology, Wiley Online Library, v. 46, n. 5, p. 911-917, 1987.

HAUSMANN, W. Die sensibilisierende wirkung des hematoporphyrins. Biochem. Z., v. 30, p. 276-316, 1911. 
HEIER, S. K. et al. Photodynamic therapy for obstructing esophageal cancer: light dosimetry and randomized comparison with nd: Yag laser therapy. Gastroenterology, Elsevier, v. 109, n. 1, p. 63-72, 1995.

HENDERSON, B. W.; BUSCH, T. M.; SNYDER, J. W. Fluence rate as a modulator of pdt mechanisms. Lasers in surgery and medicine, Wiley Online Library, v. 38, n. 5, p. 489-493, 2006.

HENDERSON, B. W.; DOUGHERTY, T. J. How does photodynamic therapy work? Photochemistry and photobiology, Wiley Online Library, v. 55, n. 1, p. 145-157, 1992.

HENNIG, G.; STEPP, H.; JOHANSSON, A. Photobleaching-based method to individualize irradiation time during interstitial 5-aminolevulinic acid photodynamic therapy. Photodiagnosis and photodynamic therapy, Elsevier, v. 8, n. 3, p. 275-281, 2011.

JACQUES, S. L. Optical properties of biological tissues: a review. Physics in Medicine \& Biology, IOP Publishing, v. 58, n. 11, p. R37, 2013.

JARVI, M. T.; PATTERSON, M. S.; WILSON, B. C. Insights into photodynamic therapy dosimetry: simultaneous singlet oxygen luminescence and photosensitizer photobleaching measurements. Biophysical journal, Elsevier, v. 102, n. 3, p. 661-671, 2012.

JELÍNKOVÁ, H. Lasers for medical applications: diagnostics, therapy and surgery. [S.l.]: Elsevier, 2013.

JOHANSSON, A. et al. Protoporphyrin ix fluorescence and photobleaching during interstitial photodynamic therapy of malignant gliomas for early treatment prognosis. Lasers in surgery and medicine, Wiley Online Library, v. 45, n. 4, p. 225-234, 2013.

In vivo measurement of parameters of dosimetric importance during interstitial photodynamic therapy of thick skin tumors. Journal of Biomedical Optics, International Society for Optics and Photonics, v. 11, n. 3, p. 034029, 2006.

KANICK, S. et al. Pre-treatment protoporphyrin ix concentration in actinic keratosis lesions may be a predictive biomarker of response to aminolevulinic-acid based photodynamic therapy. Photodiagnosis and photodynamic therapy, Elsevier, v. 12, n. 4, p. 561-566, 2015.

KANICK, S. C. et al. Dual-channel red/blue fluorescence dosimetry with broadband reflectance spectroscopic correction measures protoporphyrin ix production during photodynamic therapy of actinic keratosis. Journal of biomedical optics, International Society for Optics and Photonics, v. 19, n. 7, p. 075002-075002, 2014.

KENNEDY, J. C.; POTTIER, R. H. New trends in photobiology: endogenous protoporphyrin ix, a clinically useful photosensitizer for photodynamic therapy. Journal of Photochemistry and Photobiology B: Biology, Elsevier, v. 14, n. 4, p. 275-292, 1992.

KIM, A. et al. Quantification of in vivo fluorescence decoupled from the effects of tissue optical properties using fiber-optic spectroscopy measurements. Journal of biomedical optics, International Society for Optics and Photonics, v. 15, n. 6, p. 067006, 2010. 
LAKOWICZ, J. R. Principles of Fluorescence Spectroscopy. Third edition. [S.l.]: Springer, 2006.

LAROCHELLE, E. P. et al. In vivo wide-field multispectral dosimeter for use in ala-ppix based photodynamic therapy of skin. In: INTERNATIONAL SOCIETY FOR OPTICS AND PHOTONICS. Optical Methods for Tumor Treatment and Detection: Mechanisms and Techniques in Photodynamic Therapy XXVI. [S.l.], 2017. v. 10047, p. 1004707.

LEE, S. et al. Pulsed diode laser-based monitor for singlet molecular oxygen. Journal of biomedical optics, International Society for Optics and Photonics, v. 13, n. 3, p. 034010, 2008.

LERCHE, C. M. et al. Correlation between treatment time, photobleaching, inflammation and pain after photodynamic therapy with methyl aminolevulinate on tape-stripped skin in healthy volunteers. Photochemical \& Photobiological Sciences, Royal Society of Chemistry, v. 14, n. 5, p. 875-882, 2015.

LIPSON, R. L.; BALDES, E. J. The photodynamic properties of a particular hematoporphyrin derivative. Archives of dermatology, American Medical Association, v. 82, n. 4 , p. 508-516, 1960.

LIPSON, R. L.; BALDES, E. J.; OLSEN, A. M. The use of a derivative of hematoporphyrin in tumor detection. Journal of the National Cancer Institute, Oxford University Press, v. 26, n. 1, p. 1-11, 1961.

LISTER, T.; WRIGHT, P. A.; CHAPPELL, P. H. Optical properties of human skin. Journal of biomedical optics, International Society for Optics and Photonics, v. 17, n. 9, p. 090901, 2012.

MARKWARDT, N. A. et al. $405 \mathrm{~nm}$ versus $633 \mathrm{~nm}$ for protoporphyrin ix excitation in fluorescence-guided stereotactic biopsy of brain tumors. Journal of biophotonics, Wiley Online Library, v. 9, n. 9, p. 901-912, 2016.

NIEDRE, M.; PATTERSON, M. S.; WILSON, B. C. Direct near-infrared luminescence detection of singlet oxygen generated by photodynamic therapy in cells in vitro and tissues in vivo. Photochemistry and photobiology, BioOne, v. 75, n. 4, p. 382-391, 2002.

NIEDRE, M. et al. Singlet oxygen luminescence as an in vivo photodynamic therapy dose metric: validation in normal mouse skin with topical amino-levulinic acid. British journal of cancer, Nature Publishing Group, v. 92, n. 2, p. 298, 2005.

NIEDRE, M. J. et al. In vitro tests of the validity of singlet oxygen luminescence measurements as a dose metric in photodynamic therapy. Cancer research, AACR, v. 63, n. 22, p. 7986-7994, 2003.

POGUE, B. W. et al. Revisiting photodynamic therapy dosimetry: reductionist \& surrogate approaches to facilitate clinical success. Physics in Medicine \& Biology, IOP Publishing, v. 61, n. 7, p. R57, 2016.

POLICARD, A. Etude sur les aspects offerts par des tumeurs experimentales examinees a la lumiere de wood. CR Soc Biol, v. 91, p. 1423-1424, 1924. 
POTTER, W. R.; MANG, T.; DOUGHERTY, T. The theory of photodynamic therapy dosimetry: Consequences of photo-destruction of sensitizer. Photochemistry and photobiology, Wiley Online Library, v. 46, n. 1, p. 97-101, 1987.

POWERS, S. K.; BROWN, J. T. Light dosimetry in brain tissue: an in vivo model applicable to photodynamic therapy. Lasers in surgery and medicine, Wiley Online Library, v. 6, n. 3, p. 318-322, 1986.

RADU, A. et al. Mucosal ablation with photodynamic therapy in the esophagus: optimization of light dosimetry in the sheep model. Gastrointestinal endoscopy, Elsevier, v. 57, n. 7, p. 897-905, 2003.

ROBERTS, D. W. et al. Red-light excitation of protoporphyrin ix fluorescence for subsurface tumor detection. Journal of neurosurgery, American Association of Neurological Surgeons, v. 128, n. 6, p. 1690-1697, 2018.

ROBINSON, D. J. et al. Fluorescence photobleaching of ala-induced protoporphyrin ix during photodynamic therapy of normal hairless mouse skin: the effect of light dose and irradiance and the resulting biological effect. Photochemistry and photobiology, Wiley Online Library, v. 67, n. 1, p. 140-149, 1998.

ROOZEBOOM, M. H. et al. Fractionated 5-aminolevulinic acid photodynamic therapy after partial debulking versus surgical excision for nodular basal cell carcinoma: a randomized controlled trial with at least 5-year follow-up. Journal of the American Academy of Dermatology, Elsevier, v. 69, n. 2, p. 280-287, 2013.

SALOMATINA, E. V. et al. Optical properties of normal and cancerous human skin in the visible and near-infrared spectral range. Journal of biomedical optics, International Society for Optics and Photonics, v. 11, n. 6, p. 064026, 2006.

SCHOUWINK, H. et al. Oxygen depletion during and after mthpc-mediated photodynamic therapy in rif1 and h-meso1 tumors. Radiation research, BioOne, v. 159, n. 2, p. 190-198, 2003.

SCHWARTZ, S. et al. Some relationships of porphyrins, x-rays and tumors. Univ. Minn. Med. Bull, v. 27, n. 7, 1955.

SHENG, C. et al. Photobleaching-based dosimetry predicts deposited dose in ala-ppix pdt of rodent esophagus. Photochemistry and photobiology, Wiley Online Library, v. 83, n. 3, p. 738-748, 2007.

SVANBERG, K. et al. Clinical multi-colour fluorescence imaging of malignant tumours-initial experience. Acta Radiologica, Taylor \& Francis, v. 39, n. 1, p. 2-9, 1998.

SWARTLING, J. et al. System for interstitial photodynamic therapy with online dosimetry: first clinical experiences of prostate cancer. Journal of biomedical optics, International Society for Optics and Photonics, v. 15, n. 5, p. 058003, 2010.

SZEIMIES, R. et al. A clinical study comparing methyl aminolevulinate photodynamic therapy and surgery in small superficial basal cell carcinoma $(8-20 \mathrm{~mm})$, with a 12-month follow-up. Journal of the European Academy of Dermatology and Venereology, Wiley Online Library, v. 22, n. 11, p. 1302-1311, 2008. 
THOMPSON, M. S. et al. Clinical system for interstitial photodynamic therapy with combined on-line dosimetry measurements. Applied optics, Optical Society of America, v. 44, n. 19, p. 4023-4031, 2005.

\section{TUCHIN, V. Tissue Optics, Light Scattering Methods and Instruments for}

Medical Diagnosis. Bellingham, Washington: SPIE Press, 2015.

TYRRELL, J.; CAMPBELL, S.; CURNOW, A. Protoporphyrin ix photobleaching during the light irradiation phase of standard dermatological methyl-aminolevulinate photodynamic therapy. Photodiagnosis and photodynamic therapy, Elsevier, v. 7, n. 4, p. 232-238, 2010.

VEEN, R. L. van et al. In situ light dosimetry during photodynamic therapy of barrett's esophagus with 5-aminolevulinic acid. Lasers in surgery and medicine, Wiley Online Library, v. 31, n. 5, p. 299-304, 2002.

VOLLET-FILHO, J. et al. Possibility for a full optical determination of photodynamic therapy outcome. Journal of Applied Physics, AIP, v. 105, n. 10, p. 102038, 2009.

WANG, H.-W. et al. Treatment-induced changes in tumor oxygenation predict photodynamic therapy outcome. Cancer research, AACR, v. 64, n. 20, p. 7553-7561, 2004.

WILSON, B.; MULLER, P.; YANCH, J. Instrumentation and light dosimetry for intra-operative photodynamic therapy (pdt) of malignant brain tumours. Physics in Medicine \& Biology, IOP Publishing, v. 31, n. 2, p. 125, 1986. 
Apêndices 



\section{APÊNDICE A - CIRCUITOS ELÉTRICOS E DESENHO MECÂNICO}

Este apêndice é dedicado a apresentação do diagrama esquemático dos circuitos utilizados no projeto do equipamento, e do desenho mecânico da ponta de prova utilizada. Os circuitos abordados foram:

- Circuito de alimentação geral;

- Circuito de alimentação do laser;

- Circuito de controle de temperatura;

- Circuito de fotodetecção,

os quais serão apresentados a seguir.

Na sequência dos circuitos, também se apresenta o desenho mecânico da ponta de prova do sistema, a qual detém em seu interior:

- Câmera digital (DCC-1545M, Thorlabs, EUA);

- Fibra óptica (FD1-1646, Medlight, Brasil)

- Porta filtros removível contendo:

- Filtro óptico de excitação;

- Filtro óptico de fluorescência;

- Fotodiodo;

- Duto para passagem do cabeamento do fotodiodo; 


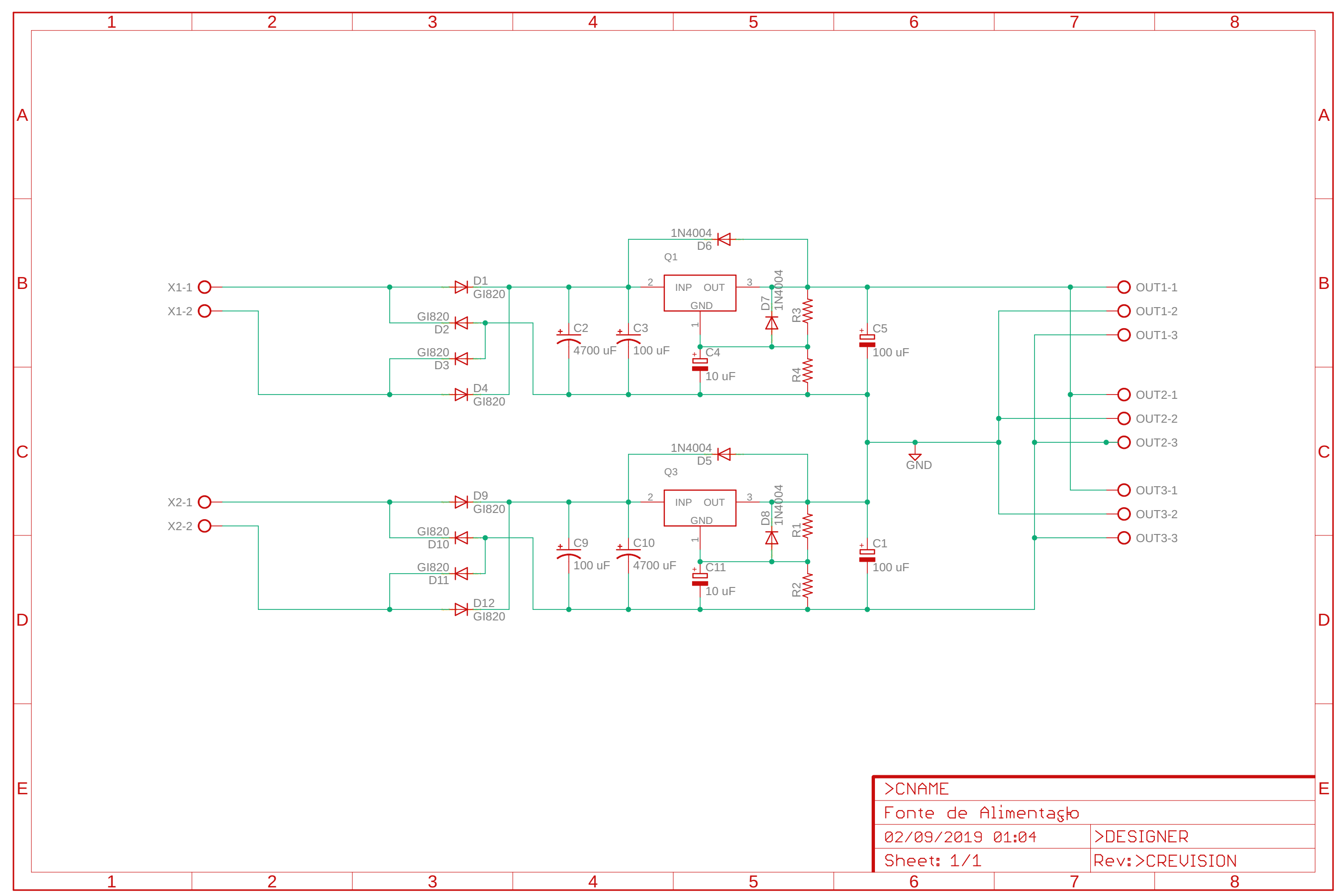




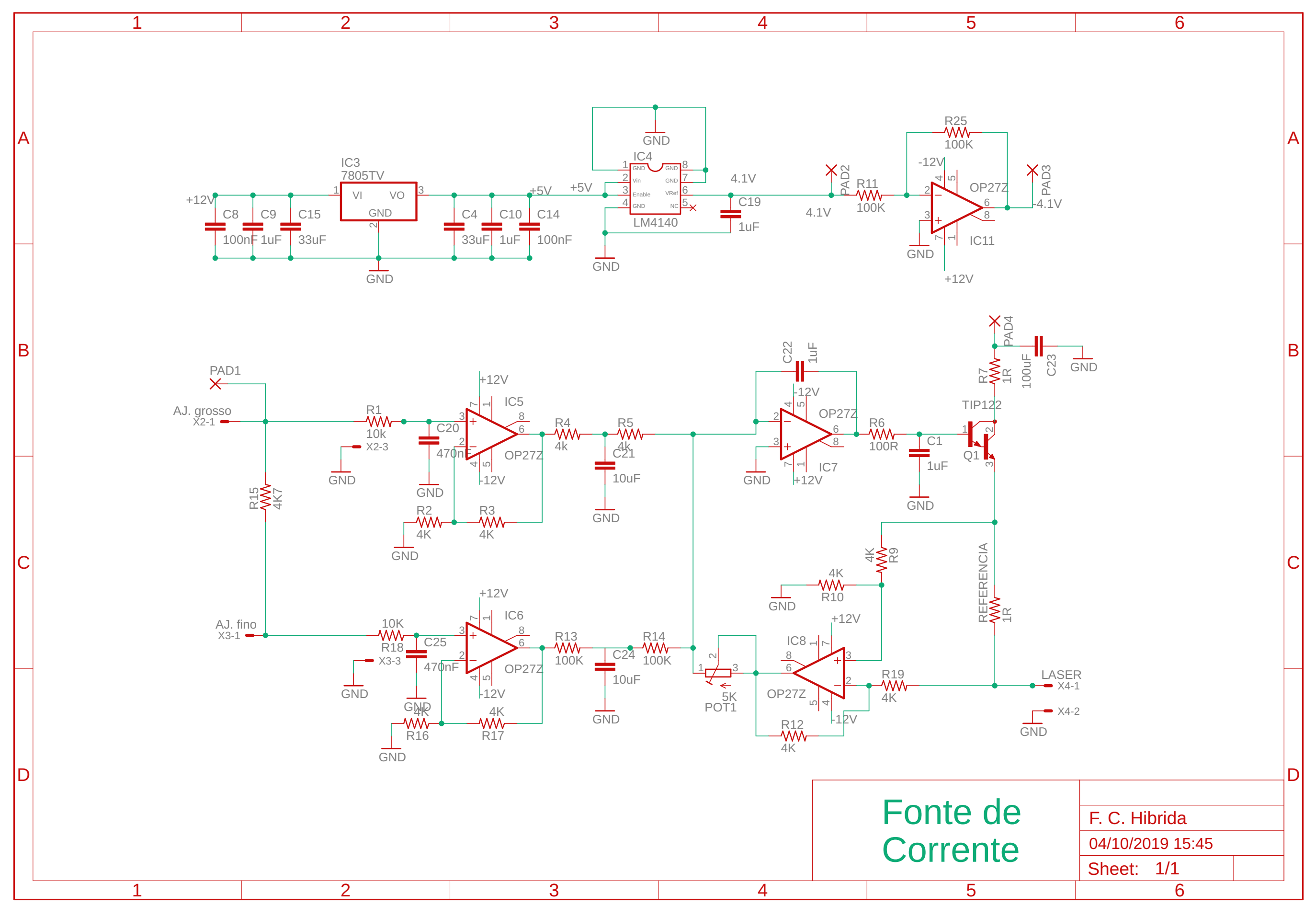




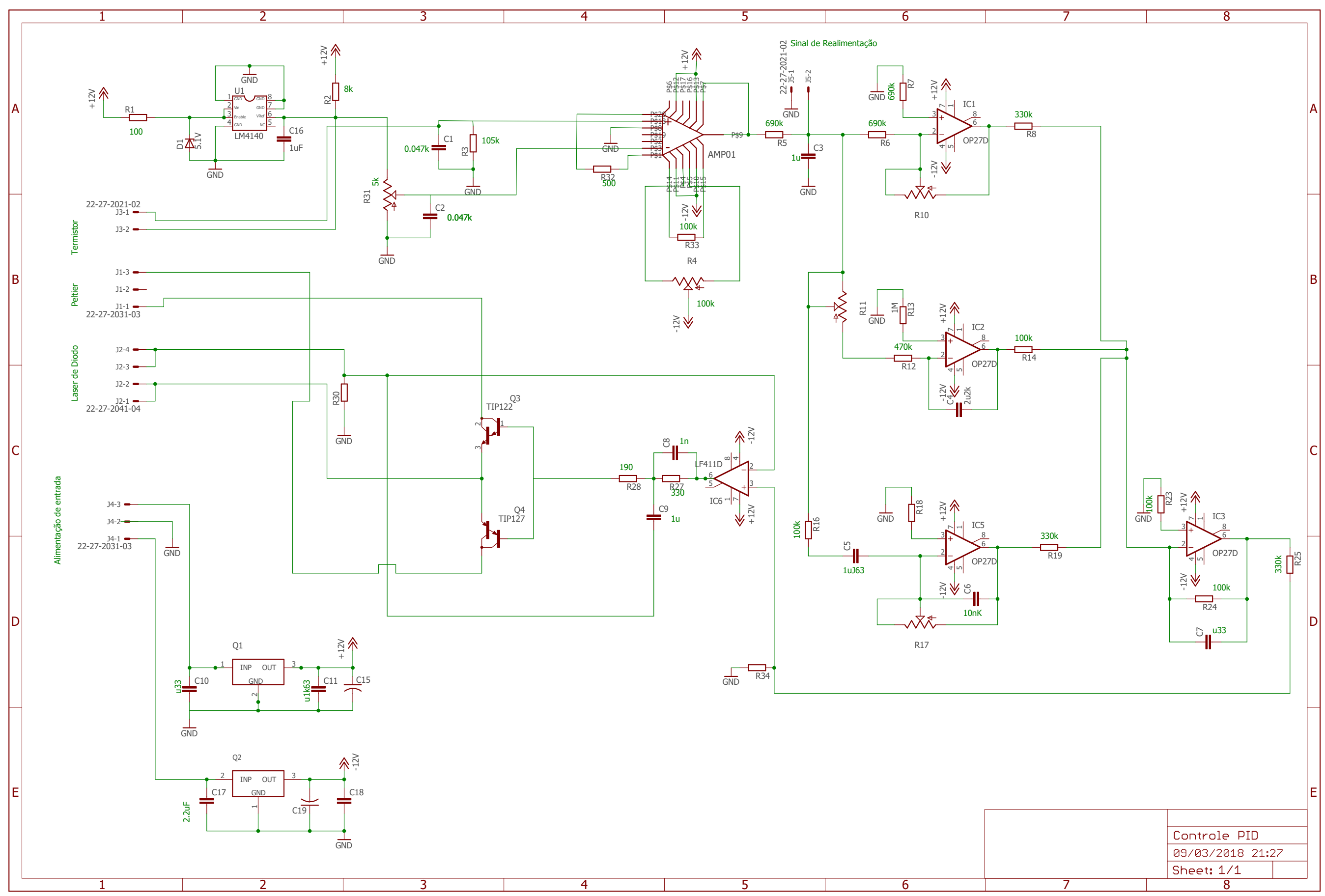




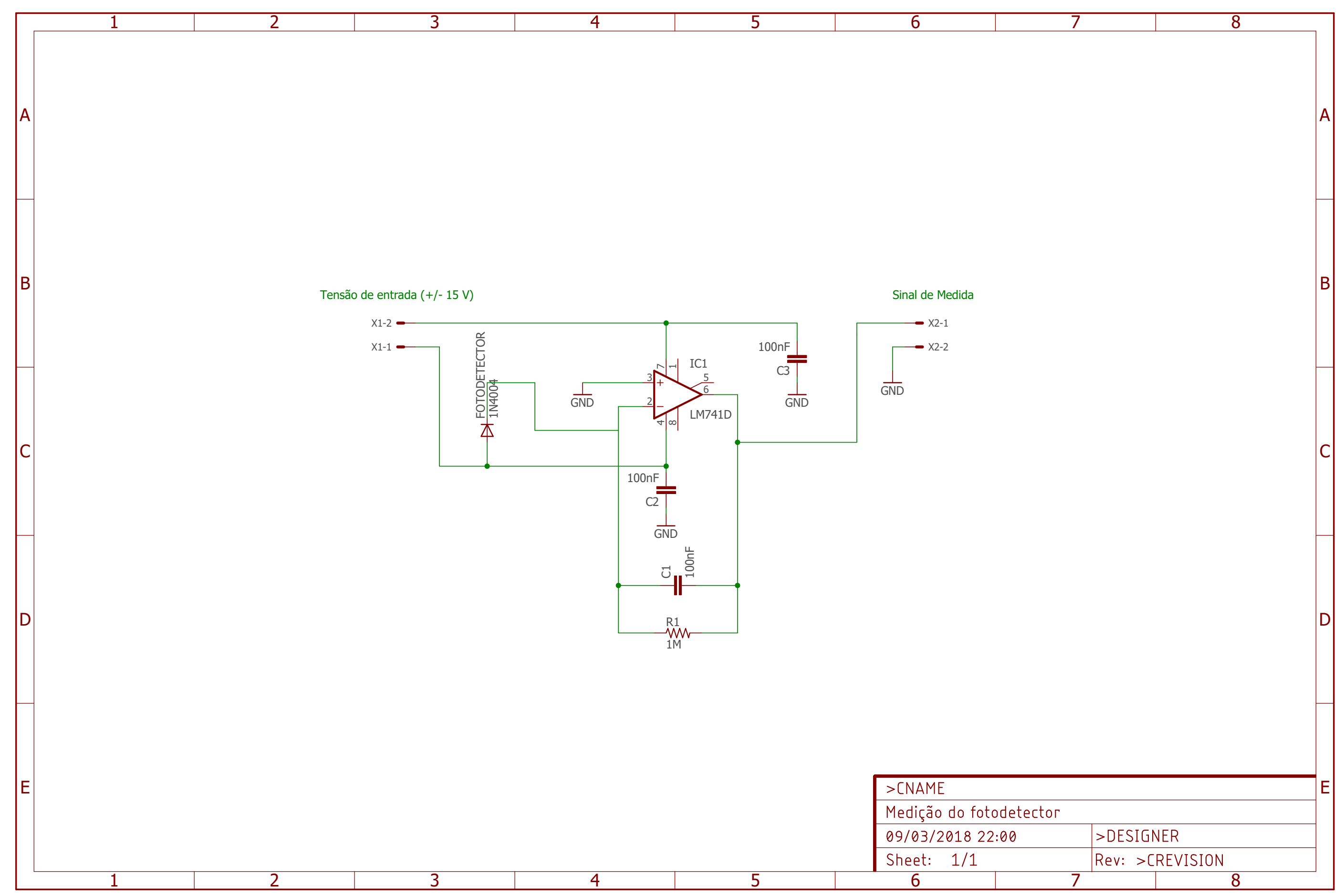




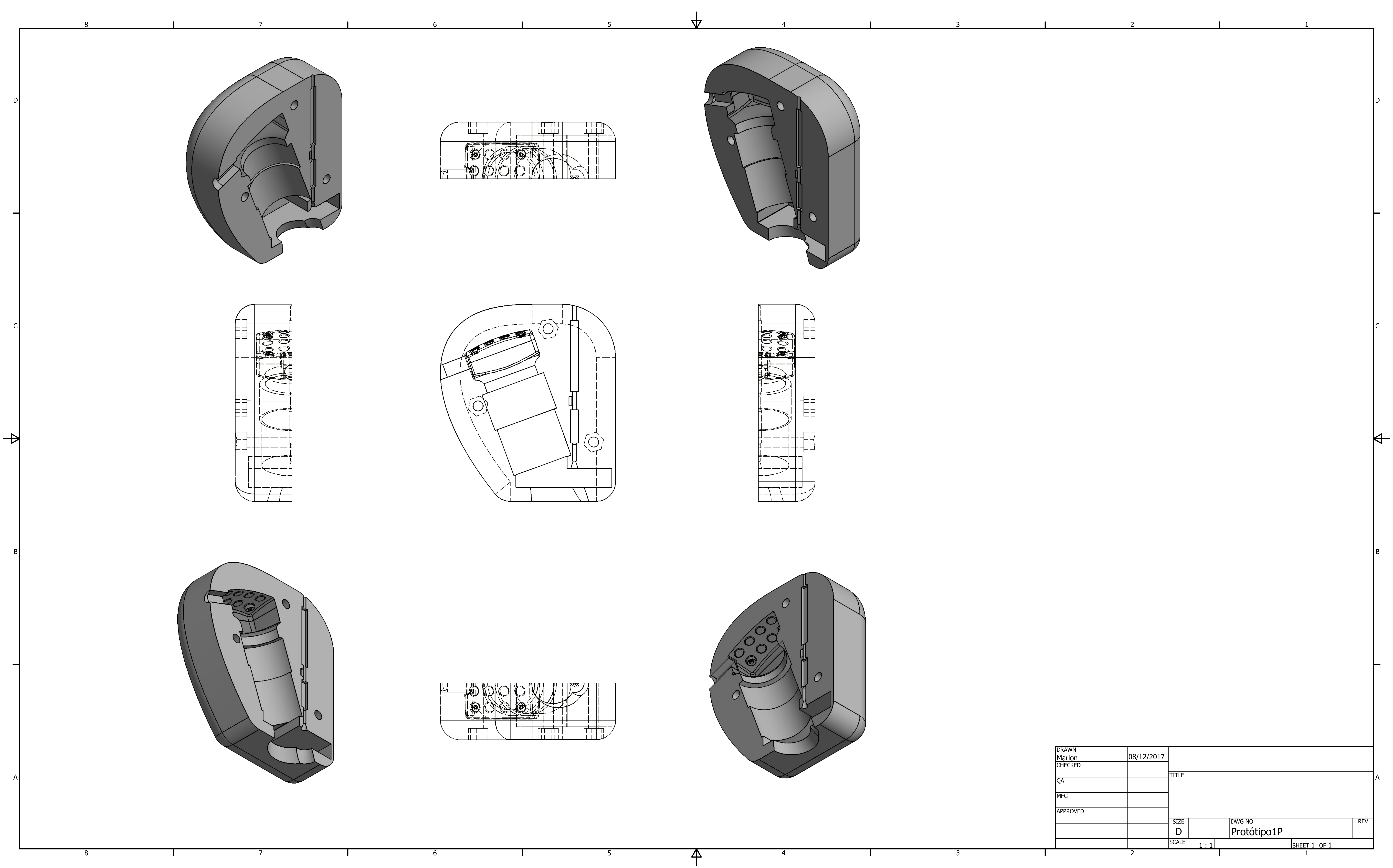

